\title{
SETUP IN THE SURFZONE
}

by

Alex Apotsos

B.S., Duke University, 1999

Submitted to the Joint Program in Civil and Environmental Engineering and Applied Ocean Science and Engineering in partial fulfillment of the requirements for the degree of

Doctor of Philosophy

at the

\section{MASSACHUSETTS INSTITUTE OF TECHNOLOGY}

and the

\section{WOODS HOLE OCEANOGRAPHIC INSTITUTION}

September 2007

(C) 2007 Massachusetts Institute of Technology/Woods Hole Oceanographic Institution All rights reserved.

Signature of Author

$$
\text { Joint Program in Civil and Environmental Engineering and }
$$
Applied Ocean Science and Engineering

Massachusetts.Institute of Technology and Wood Hole Oceanographic Institution August 2, 2007

Certified by

Britt Raubenheimer Associate Scientist Thesis Supervisor

Certified by

$$
\text { Ole Madsen }
$$

Donald and Martha Harleman Professor Thesis Reader

Accepted by

Henrik Schmidt

Chairman, Joint Committee for Applied Ocean Science \& Engineering Massachusetts Institute of Technology/Woods Hole-Oceanographic Institution

Accepted by

Daniele Veneziano

Chairman, Departmental Committee on Graduate Students 


\title{
SETUP IN THE SURFZONE
}

\author{
by \\ Alex Apotsos \\ Submitted to the Joint Program in Civil and Environmental Engineering \\ and Applied Ocean Science and Engineering \\ on August 2, 2007, in partial fulfillment of the \\ requirements for the Degree of Doctor of Philosophy in \\ Civil and Environmental Engineering
}

\begin{abstract}
Surfzone wave height transformation and wave-breaking-driven increases in the mean sea level (setup) are examined on alongshore-uniform beaches with alongshore homogeneous and inhomogeneous wave forcing. While previously derived models predict wave heights adequately (root-mean-square errors typically less than $20 \%$ ), the models can be improved by tuning a free parameter or by using a new parameterization based on the deep-water wave height. Based on a sensitivity analysis of the cross-shore momentum balance used to predict setup, a one-dimensional (1-D) model is developed that includes wave rollers and bottom stress owing to the mean offshore-directed flow. The model predicts setup accurately at three alongshore homogeneous field sites, as well as at a site where the incident wave field is alongshore non-uniform, suggesting that setup is driven primarily by the cross-shore (1-D) forcing. Furthermore, alongshore gradients of setup can be important to driving alongshore flows in the surfzone, and the 1-D setup model predicts these gradients accurately enough to simulate the observed flows.
\end{abstract}

Thesis Supervisor: Dr. Britt Raubenheimer

Title: Associate Scientist, WHOI 


\section{Acknowledgements}

My first, and heartfelt, thanks go out to my advisor, Dr. Britt Raubenheimer. I could not have asked for a better or more conscientious mentor than Britt. Though I am sure I have caused her no small amount of frustration (mastering grammar and proofreading was not in the brochure), I have been overwhelmed by the dedication, encouragement, and support she has provided. You would be hard pressed to find anyone who gives more time or effort to her students, and I feel privileged to have had the opportunity to work with her. Thanks Britt, you have set a high bar for all those I work with in the future.

I would also like to thank my committee members and coauthors, Drs. Ole Madsen, Steve Elgar, Robert Guza, Steve Lentz, Jerry Smith, and John Trowbridge. It was only through their patient guidance and encouragement that I was able to make the transition from simply repeating what I was taught to conducting independent research. I am eternally grateful for their support and collaborations. Dr. G. Ruessink is thanked for his valuable comments on the wave model analysis, and for providing the observations from The Netherlands.

This research would not have been possible without the efforts of the many dedicated professionals from the Center for Coastal Studies (Scripps Institution of Oceanography), the PVLAB (Woods Hole Oceanographic Institution), and the Field Research Facility (US Army Corps of Engineers, Duck, NC) who collected most of the field observations.

Without my fellow students in the Joint Program, specifically Greg Gerbi, Matt Mazloff, Dave Sutherland, Jim Thomson, and Ariane Verdy, I am not sure I would have kept my sanity being stuck in the North East for 5 years. They have made my time here not only survivable, but downright enjoyable.

Many thanks go to my family, who may not always understand what I do, but who always encourage me not only to do my best, but also to enjoy what I do.

A special thanks goes out to my wonderful wife. Michelle, I thank you with all my heart for being an Art Historian and not a scientist, thereby forcing me to leave my work at the office. Though she understood little of what I did, mostly by conscious choice, she was always willing to listen to my frustrations, share in my successes, and drag me outside when I needed it.

Finally, I would like to thank the National Science Foundation (OCE-0622844), the Office of Naval Research (G000783, G000782, N00014-99-10193, N00014-0210145), the MIT/WHOI Academic Programs Office, and the MIT Presidential Graduate Fellowship Program for their generous support of my research. 


\section{Table of Contents}

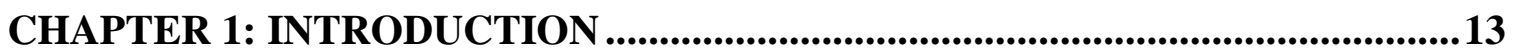

1.1 THESIS OUTLINE ..................................................................................... 14

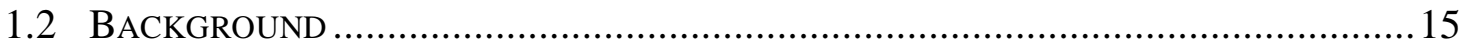

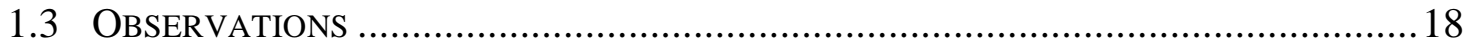

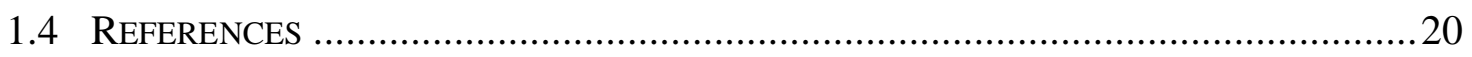

\section{CHAPTER 2: TESTING AND CALIBRATING PARAMETRIC WAVE} TRANSFORMATION MODELS ON NATURAL BEACHES....................................23

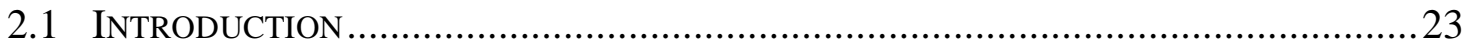

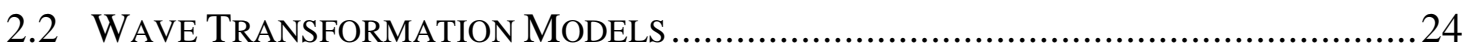

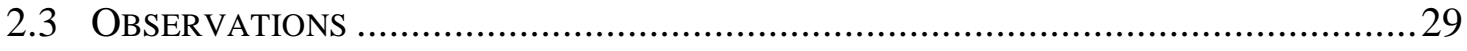

2.3.1 SandyDuck and Duck94: Duck, NC 1997 and 1994 .................................29

2.3.2 Egmond and Terschelling: The Netherlands, 1994 and $1998 \ldots \ldots \ldots \ldots \ldots \ldots \ldots \ldots . . . . . .30$

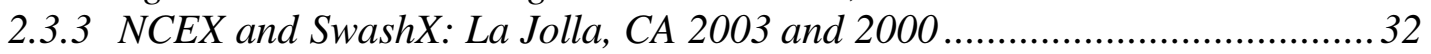

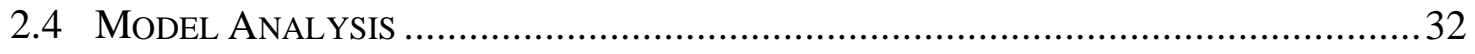

2.4.1 Model Procedure................................................................................... 32

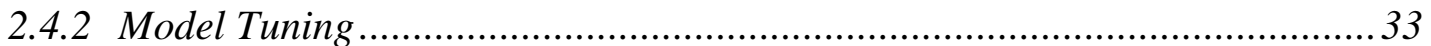

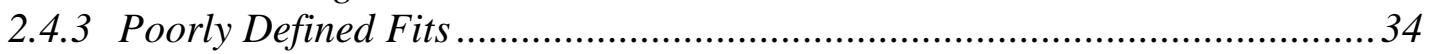

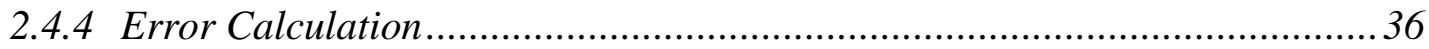

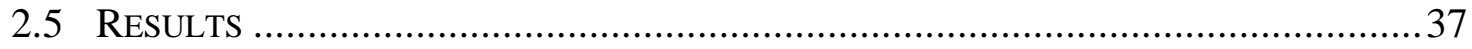

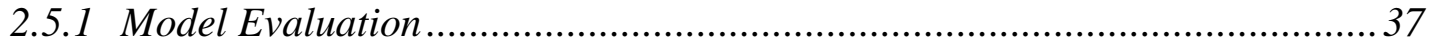

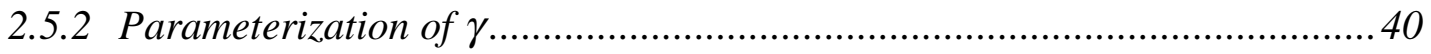

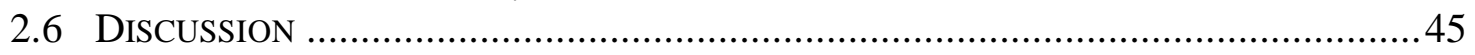

2.6.1 'Universal' Curves .....................................................................................4

2.6.2 Number of Sensors Needed for Tuning....................................................4

2.6.3 Model Accuracy as a Function of Water Depth............................................4 48

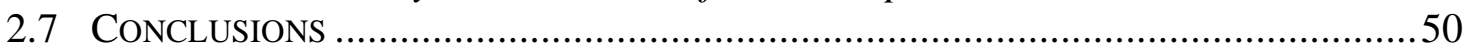

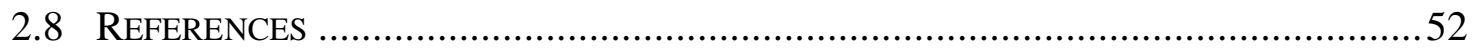

CHAPTER 3: SETUP SENSITIVITY .........................................................................55

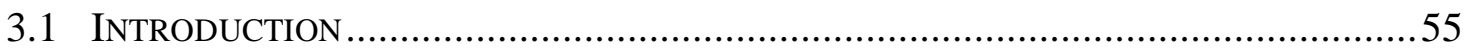

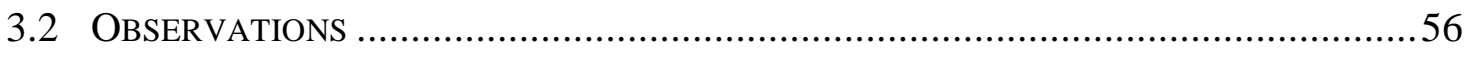

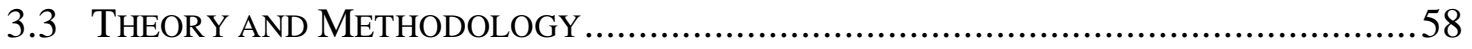




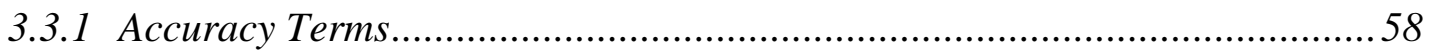

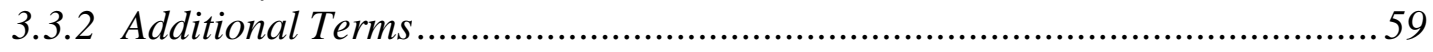

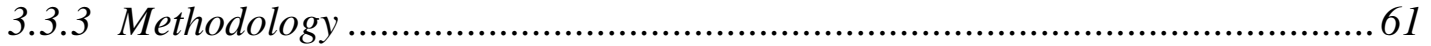

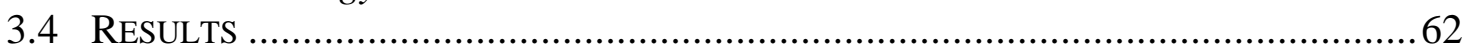

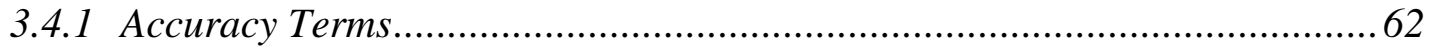

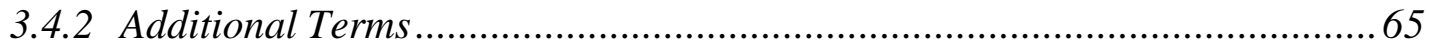

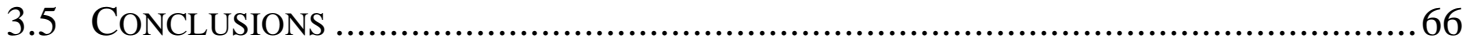

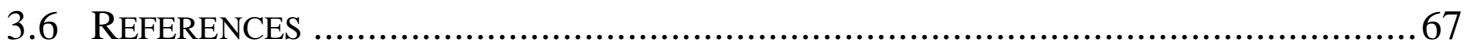

\section{CHAPTER 4: A COMPARISON OF SETUP PREDICTIONS AND

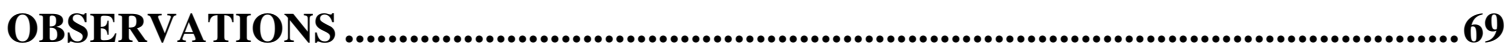

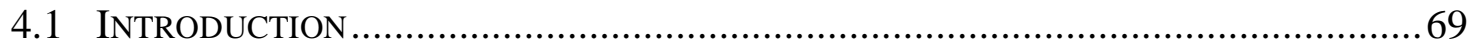

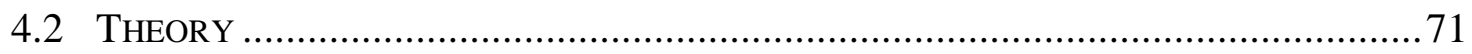

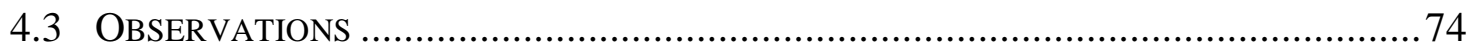

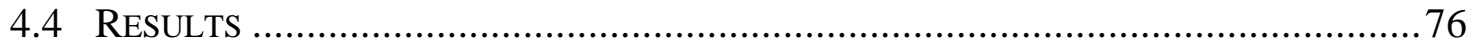

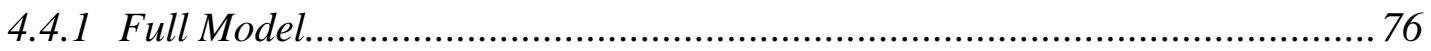

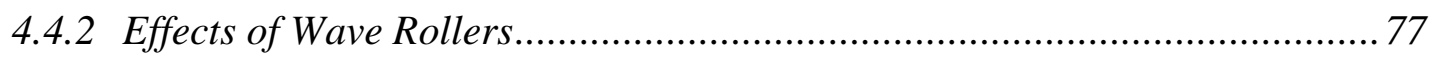

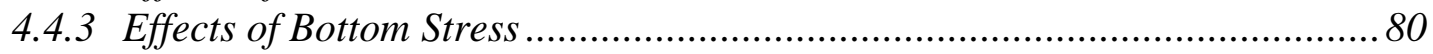

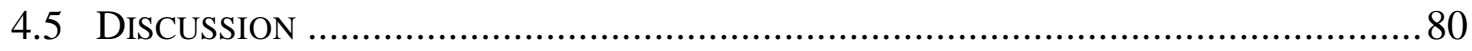

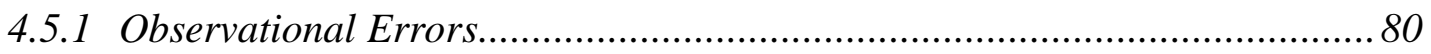

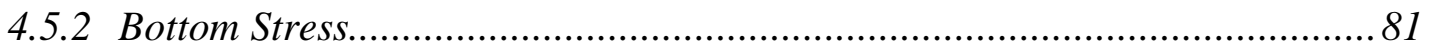

4.5.3 Effects of a Large Offshore Bar .......................................................... 92

4.5.4 Evaluation of model applicability at SwashX and NCEX......................... 93

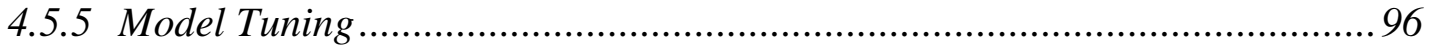

4.5.6 Modeling Setup without Observational Inputs .......................................... 99

4.5.7 Other Terms ........................................................................................ 100

4.5.8 Some Final Thoughts on the Cross-shore Momentum Balance................... 101

4.6 ConClusions ................................................................................ 103

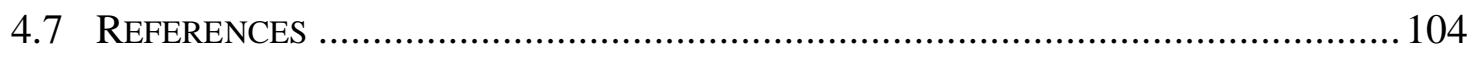

CHAPTER 5: ALONGSHORE NONUNIFORM SETUP..................................110

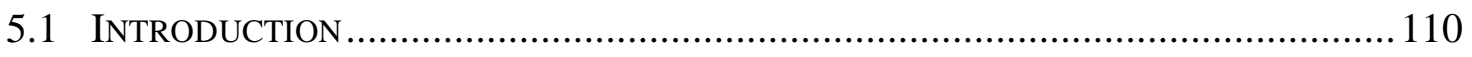

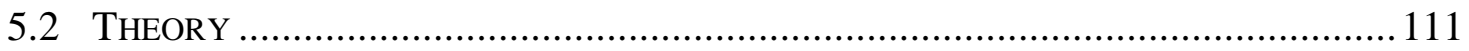

5.2.1 Cross-shore Momentum Balance ....................................................... 111

5.2.2 Alongshore Momentum Balance .......................................................... 112

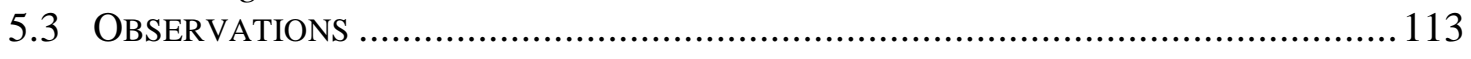

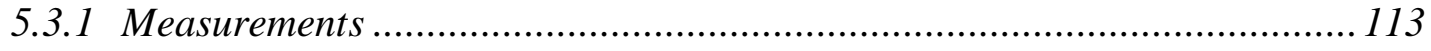

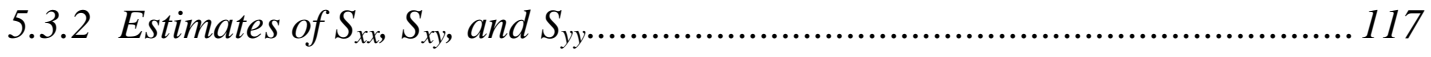




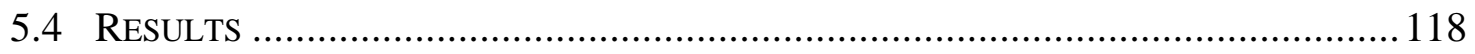

5.4.1 Cross-shore Momentum Balance ............................................................. 118

5.4.2 Alongshore Momentum Balance ..................................................... 122

5.5 DiSCUSSION .................................................................................. 128

5.5.1 Effect of Larger Wave Angles .............................................................. 128

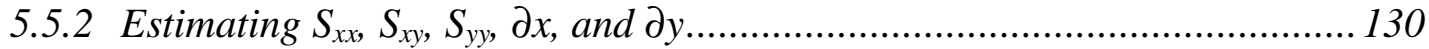

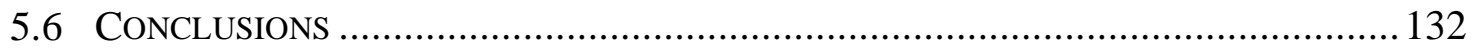

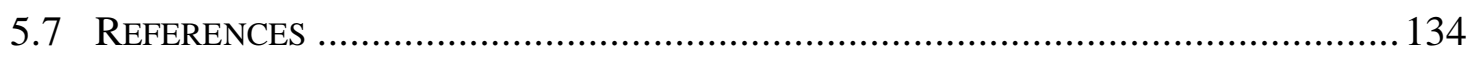

CHAPTER 6: GENERAL CONCLUSIONS............................................................138

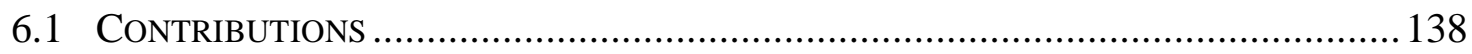

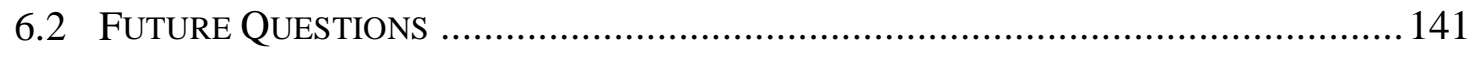

6.2.1 Determining the Free Parameter in the Wave Models............................... 141

6.2.2 Drag Coefficients .................................................................................... 142

6.2.3 Linear Theory Estimates of the Radiation Stress................................... 143

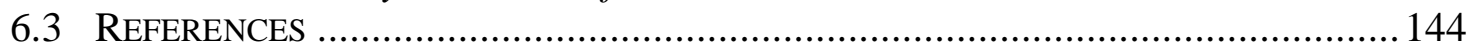




\section{List of Figures}

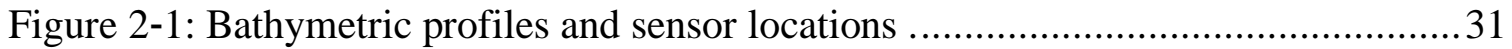

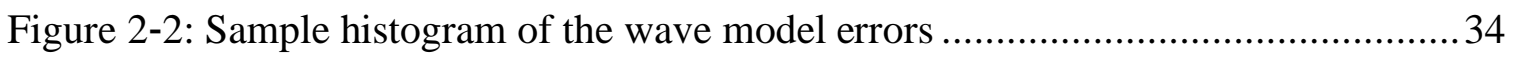

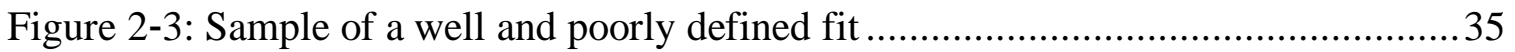

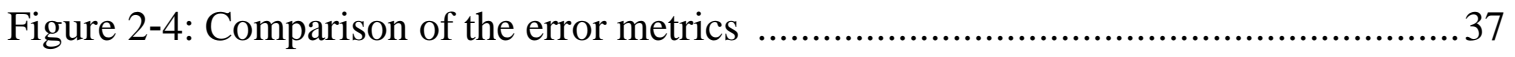

Figure 2-5: Cross-shore comparison of wave model predictions with observations .......38

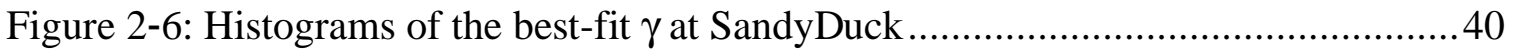

Figure 2-7: Contour plot of the number of realizations at Duck94 for a given best-fit $\gamma$

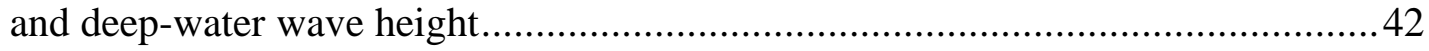

Figure 2-8: Emperical hyperbolic tangent curves for SandyDuck and Duck94 ............. 43

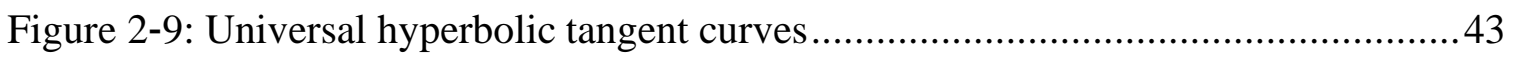

Figure 2-10: Histogram of the difference between the best-fit $\gamma$ and $\gamma$ from the universal hyperbolic tangent curves ............................................................................ 46

Figure 2-11: Number of sensors needed for model tuning .................................... 48

Figure 2-12: Depth dependence of the wave model errors .................................... 49

Figure 3-1: Bathymetric profiles and sensor locations.......................................57

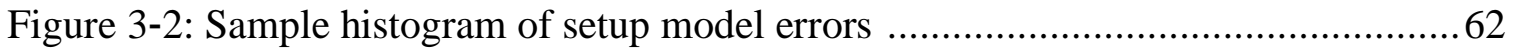

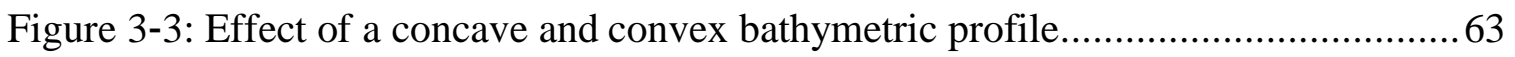

Figure 4-1: Sample cross-shore profiles of the measured bathymetry, and the predicted wave height, setup, drag coefficient, and eddy viscosity for Nov 13, $1997 \ldots \ldots \ldots \ldots . . .75$

Figure 4-2: Depth dependence of the setup model errors at SandyDuck ........................77

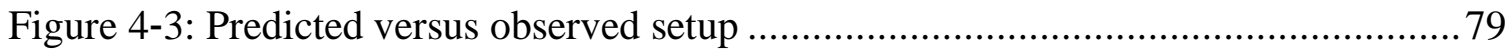

Figure 4-4: Estimating a quadratic cross-shore drag coefficient ................................ 84

Figure 4-5: Estimating a quadratic alongshore drag coefficient .................................. 86

Figure 4-6: Comparison of the undertow model with observations ............................90

Figure 4-7: Comparison of the bottom stress estimates .........................................92

Figure 4-8: Setup model simulation over a large bar ......................................... 93 
Figure 4-9: Bathymetric profiles and sensor locations for SwashX and NCEX .....

Figure 4-10: Depth dependence of model errors for SandyDuck, SwashX, and NCEX ..96

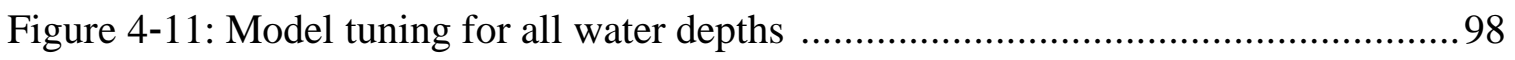

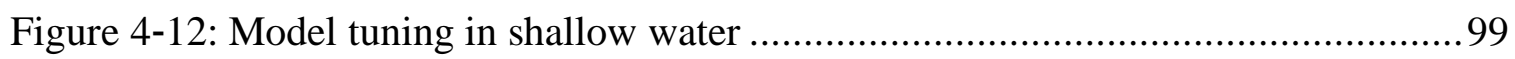

Figure 5-1: Alongshore schematic of the bathymetry and sensor locations .................. 114

Figure 5-2: Time series of the wave height and wave angle along the 2.5-m isobath .... 116

Figure 5-3: 24-hr depth averaged curves of the observed and predicted setup ............. 116

Figure 5-4: Estimates of the radiation stress tensor components................................ 118

Figure 5-5: Comparison of the cross- and along-shore wave forcings of setup ............ 120

Figure 5-6: Comparison of setup model predictions and observations ....................... 121

Figure 5-7: Comparison of the alongshore current forcings for Oct 27, 2003 .............. 123

Figure 5-8: Alongshore currents and wave forcing for Oct 27, 2003 ........................ 124

Figure 5-9: Observation-based estimates of the alongshore momentum balance for Oct

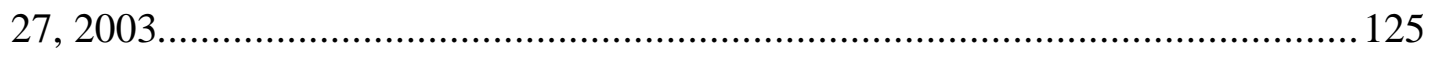

Figure 5-10: Numerical model predictions of the alongshore momentum balance ........ 127

Figure 5-11: Sensitivity analysis of the alongshore wave forcing to setup .................. 130 


\section{List of Tables}

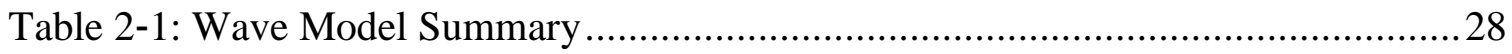

Table 2-2: 95\% exceedence (minimum), median, and 5\% exceedence (maximum) errors

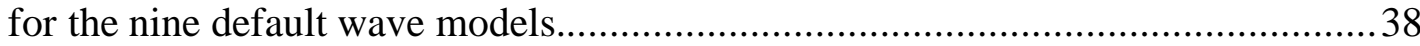

Table 2-3: 95\% exceedence, median, and 5\% exceedence errors for the six tuned wave

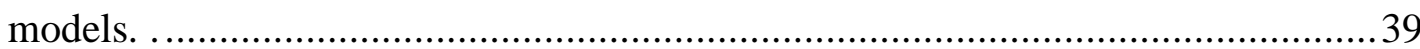

Table 2-4: The coefficients for the universal curves..................................................... 44

Table 2-5: The BSS values for the median errors using the 'universal' empirical hyperbolic tangent curves.

Table 2-6: Median errors for the six tuned models using the universal empirical $\gamma$ curves.

Table 3-1: Ranges of biases and spreads in shallow and mid-depth water for the primary and secondary Accuracy Terms. ..........................................................................63

Table 3-2: Ranges of biases and spreads in shallow and mid-depth water for the primary and secondary Additional Terms....................................................................6

Table 4-1: Squared correlation coefficients, best fit slopes, intercepts, root-mean-squared

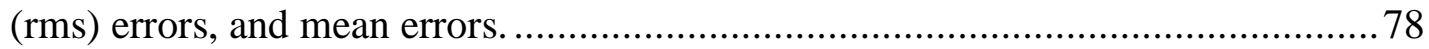




\section{Chapter 1: Introduction}

Setup is the increase in the mean sea level owing to breaking waves. Setup typically increases across the surfzone towards the shoreline where it can be a meter or more [Guza and Thornton, 1981], and thus it can be a significant design parameter for coastal structures [Nielsen, 1988], such as breakwaters and piers. Setup also is a dominant forcing mechanism for the mean offshore-directed surf zone flows (undertow) [GarcezFaria et al., 2000] that drive the offshore motion of sand during storms [Thornton et al., 1996; Gallagher et al., 1998].

The cross-shore profile of setup most often is modeled using a cross-shore momentum balance developed in the early 1960's [Longuet-Higgins and Stewart, 1962, 1964]. Although the accuracy of this model, and the processes that drive setup have been studied extensively in the laboratory, only a few field studies have been conducted owing to the difficulty of measuring the mean level of the water's surface in the surfzone accurately. Most field studies have focused on setup at the shoreline, where the signal is largest. Recently, cross-shore measurements of setup at numerous locations in the surfzone were collected on three natural beaches. Here, our ability to predict those setup observations using simple numerical models is investigated. The specific objectives of this study are to:

- test and calibrate parametric wave transformation models, which are needed to drive the setup model. 
- evaluate the sensitivity of numerical setup predictions to physical processes and observational inputs.

- develop and evaluate an extended 1-dimensional (1-D) setup model using field observations from 3 alongshore uniform field experiments.

- determine if the 1-D model can accurately predict the alongshore variations in setup on a beach where the incoming wave field at the outer edge of the surfzone is alongshore inhomogeneous.

\subsection{Thesis Outline}

Background information, including a review of previous work and a brief description of the field experiments, is presented in Chapter 1. Results from 4 different studies are presented as independent articles (i.e., separate abstracts and bibliographies) in Chapters 2 through 5:

Chapter 2, "Testing and Calibrating Parametric Wave Transformation Models On Natural Beaches," demonstrates that several default parametric wave transformation models predict the observed wave heights reasonably well, but that wave height errors can be reduced by model tuning or using a new empirical parameterization for the free parameter.

Chapter 3, "Setup Sensitivity," demonstrates that accurate measurement of the cross-shore water-depth and wave-height profiles is important for predicting setup, and that the inclusion of wave rollers and bottom stress significantly affects setup predictions in shallow water.

Chapter 4, "A Comparison of Setup Predictions and Observations," presents a new 1-D setup model that includes wave rollers and bottom stress owing to the mean offshoredirected flow, and shows that this model accurately predicts setup at 3 alongshore homogeneous field sites.

Chapter 5, "Alongshore Nonuniform Setup," shows that the newly developed 1-D model predicts setup well even on a beach with alongshore nonuniform wave forcing (i.e., setup is driven primarily by the cross-shore forcing), that alongshore gradients of 
setup are important to forcing the alongshore mean flows, and that the 1-D setup model predictions can be used to estimate these alongshore flows.

A summary of the conclusions and future motivations drawn from all 4 studies are presented in Chapter 6.

\subsection{Background}

The importance of breaking-wave-driven setup to flooding and storm damage was recognized in the early 1900's, when it was observed that storm-driven increases in sea level could be more than a meter higher along coastlines exposed to breaking waves than along protected shores. Specifically, when a hurricane struck the east coast of the United States in 1938, the maximum mean water level observed at Narragansett Pier where the waves were breaking was $1 \mathrm{~m}$ higher than that observed onshore of the calm waters off Newport [as noted by Guza and Thornton, 1981; many others]. Field observations and laboratory experiments in the 1950's and 1960's [Savage, 1957; Fairchild, 1958;

Dorrestein, 1961] further demonstrated the existence of setup onshore of breaking waves, but were not detailed enough to determine quantitative trends. More recently, studies have shown that offshore-directed flows driven by setup carry sediment offshore during storms resulting in beach erosion [Thornton et al., 1996; Gallagher et al., 1998], and alongshore gradients of setup can drive the converging alongshore flows that cause rip currents [Haller et al., 2002; Haas et al., 2003]. Thus, understanding the cross- and alongshore structure of setup is needed to improve our understanding of and ability to predict many nearshore processes.

Field and laboratory measurements have suggested that the time-averaged wave setup $\bar{\eta}$ in the surfzone depends on the local water depth $h$, the offshore wave height, and the beach slope [Guza and Thornton, 1981; King et al., 1990; Raubenheimer et al., 2001]. At the shoreline, the setup, $\bar{\eta}_{\text {shore}}$, has been parameterized as

$$
\bar{\eta}_{\text {shore }}=\kappa H_{r m s, o},
$$


where $H_{r m s, o}$ is the offshore root-mean-square wave height and $\kappa$ is a constant between 0.2 and 0.5 [Bowen et al., 1968; Hansen, 1978; Guza and Thornton, 1981; Nielsen, 1988; King et al., 1990; Hanslow et al., 1996], or as [Holman and Sallenger, 1985]

$$
\bar{\eta}_{\text {shore }} / H_{r m s, o}=\lambda \xi_{o},
$$

where $\lambda$ is a constant that was found to vary with the tidal stage and the Iribarren number $\xi_{o}=\beta_{f o r} / \sqrt{H_{r m s, o} / L_{o}}$, in which $\beta_{f o r}$ is the slope of the foreshore and $L_{o}$ is the offshore wave length. However, the scatter about (1-1) and (1-2) is often of the same order of magnitude as the observed $\bar{\eta}_{\text {shore }}$. The large scatter about (1-1) may to be owing to the presence of non-planar bathymetries, alongshore inhomogeneities, local currents, and/or wave reflection. The scatter about (1-2) could be reduced by dividing the data into low, middle, and high tidal stages, possibly owing to the effects of an offshore bar on $\bar{\eta}_{\text {shore }}$.

More recently, Raubenheimer et al. [2001] showed that $\bar{\eta}_{\text {shore }}$ is sensitive to the bathymetry of the entire surfzone. The ratio $\bar{\eta}_{\text {shore }} / H_{r m s, o}$ was correlated with a surfzone averaged beach slope $\beta_{a v}$, and was well described by the empirical relationship,

$$
\bar{\eta}_{\text {shore }} / H_{r m s, o}=0.027+0.004 \beta_{a v}^{-1} .
$$

Although the shoreline value of setup is needed to estimate probabilities of flooding, overwash, and structural requirements, accurate modeling of nearshore flows requires detailed knowledge of the cross-shore profile of $\bar{\eta}$ throughout the surfzone. Assuming alongshore-uniform waves and bathymetry and negligible wind and bottom stress, the cross-shore pressure gradient associated with $\bar{\eta}$ theoretically balances the cross-shore gradient of the time- and depth-averaged cross-shore wave momentum flux (i.e., the wave radiation stress, $S_{x x}$ ) [Longuet-Higgins and Stewart, 1962, 1964]

$$
\frac{\partial}{\partial x} S_{x x}+\rho g(\bar{\eta}+d) \frac{\partial}{\partial x} \bar{\eta}=0,
$$

where $x$ is the cross-shore coordinate (positive onshore), $d$ is the time-averaged still water depth, $\rho$ is the water density, and $g$ is the gravitational acceleration. Assuming that waves are narrow-banded in frequency and direction, and that the wave amplitude is small 
compared to the water depth, the wave radiation stress can be estimated from linear theory as

$$
S_{x x}=E_{w}\left\{\left[\cos ^{2}(\theta)+1\right] \frac{c_{g}}{c}-\frac{1}{2}\right\},
$$

where $\theta$ is the mean wave direction relative to beach normal, $c_{g}$ is the group speed, and $c$ is the phase speed. The wave energy $E_{w}$ can be estimated from linear theory as

$$
E_{w}=\frac{1}{8} \rho g H_{r m s}^{2},
$$

where $H_{r m s}$ is the root-mean-square wave height (defined as $2 \sqrt{2}$ times the standard deviation of the sea-surface elevation fluctuations). Although second-order wave theory [i.e., (1-5)] may not be expected to be valid in the surfzone [e.g., Bowen et al, 1968; Svendsen; 1984], previous field studies have suggested that local estimates are reasonably accurate [Guza and Thornton, 1980, 1981]. Furthermore, previous laboratory studies with normally incident waves (i.e., $\theta=0$ ) have shown that setup is predicted reasonably well using (1-4) and (1-5) (labeled the LHS model) on planar [Bowen et al., 1968; Battjes and Janssen, 1978; Stive and Wind, 1982], barred [Battjes and Janssen, 1978; Battjes and Stive, 1985], and other [Gourlay, 1992] bathymetries.

Using a parametric wave transformation model to estimate the cross-shore wave characteristics, Battjes and Janssen [1978] found good agreement between setup predicted with the LHS model and setup observed in the laboratory. However, the LHS model consistently predicted the transition from setdown to setup too far seaward. It was hypothesized that the turbulent front face of breaking waves, known as the wave roller, carries momentum shoreward after waves break, and thus shifts the transition from setdown to setup closer to shore [Svendsen, 1984]. Theoretical, laboratory, and field studies have shown that including a wave roller may be necessary to accurately predict the cross-shore distribution of $S_{x x}$ and thus $\bar{\eta}$ [Diegaard et al., 1991; Schäffer et al., 1993; Dally and Brown, 1995]. Recently, Tajima and Madsen [2006] showed setup observed in the laboratory is predicted well by including a wave roller in the determination of $S_{x x}$. Furthermore, it has been hypothesized that bottom and wind stresses, directionally spread wave fields, and alongshore non-uniformity also may be 
important to setup in the field.

Field measurements of setup between 2- and 4-m water depth during a storm have been predicted well with the LHS model driven by a parametric wave transformation model calibrated with the measured wave heights [Battjes and Stive, 1985]. Lentz and Raubenheimer [1999] showed that $\bar{\eta}$ measured for 2 months in approximately 2-m water depth was predicted well when wave heights were measured with a cross-shore array of pressure sensors between 8- and 2-m water depths. Furthermore, assuming a linear variation in water depth and pressure across the beach (i.e., between the sensors in 8- and 2-m water depth), setup at the $2 \mathrm{~m}$ sensor was predicted within the error of the measurements for data spanning 3.5 years. Consistent with these results, a more recent field study [Raubenheimer et al., 2001] showed that the LHS model accurately predicts $\bar{\eta}$ in water depths from 5 to $2 \mathrm{~m}$, but increasingly underpredicts $\bar{\eta}$ with decreasing depth for $h<2 \mathrm{~m}$.

Following evaluation of the parametric wave models that are used to drive the setup predictions (Chapter 2), processes that may be important to predictions of setup in shallow water are examined (Chapter 3), and an extended 1-D setup model that improves setup predictions in shallow water is developed and tested for a wide range of field conditions on 3 alongshore-uniform beaches (Chapter 4). Finally, it is shown that the extended 1-D setup model accurately predicts setup despite alongshore variations of the wave forcing, and that these predictions can be used to estimate the observed alongshore flows (Chapter 5).

\subsection{Observations}

Observations from 6 field experiments were used in this study. The field sites include two near planar (SwashX, NCEX), two single barred (Duck94, SandyDuck), and two multi-barred (Terschelling, Egmond) beaches, that are located on the west and east coasts of the US, and on the coast of The Netherlands, respectively. At all 6 field sites a single cross-shore transect was selected where the local bathymetry and wave field were assumed to be approximately alongshore uniform. At one experiment (NCEX), an along- 
and cross-shore array of pressure and velocity sensors was deployed along the 5.0-, 2.5-, and $1.0-\mathrm{m}$ isobaths over approximately $2 \mathrm{~km}$ of coast. Here, the presence of two deep, offshore canyons created an inhomogeneous offshore wave field at the southern end of the sensor array.

During all experiments, observations of the wave characteristics (height, angle, and period) were recorded across the surfzone. The bathymetry was measured regularly (between every other day and once a week), except at Terschelling where the changes in bathymetry were negligible. Mean water levels (i.e., setup) were measured at only three of the experiments (SandyDuck, SwashX, and NCEX). The other three field experiments (Duck94, Egmond, and Terschelling) were used only in the wave model analysis. The observations are described further in the sections in which they are used. 


\subsection{References}

Battjes, J.A. and J.P.F.M. Janssen, Energy loss and setup due to breaking of random waves, International Conference on Coastal Engineering, ASCE, 569-587, 1978.

Battjes, J.A. and M.J.F. Stive, Calibration and verification of a dissipation model for random breaking waves, J. Geophys. Res., 90, 9159-9167, 1985.

Bowen, A.J., D.L. Inman, and V.P. Simmons, Wave 'set-down' and set-up, J. Geophys. Res., 73, 2569-2577, 1968.

Dally, W.R. and C.A. Brown, A modeling investigation of the breaking wave roller with application to cross-shore currents, J. Geophys. Res., 100, 24873-24883, 1995.

Diegaard, R., P. Justesen, and J. Fredsoe, Modeling of undertow by a one-equation turbulence model, Coastal Eng., 15, 431-458, 1991.

Dorrestein, R., Wave set-up on a beach, Proc. 2nd Tech. Conf. Hurricanes, 230, 1961.

Fairchild, J.C., Model study of wave set-up induced by hurricane waves at Narragansett Pier, Rhode Island, Beach Erosion Board, U.S. Army Corps Engr., Washington, DC., 1958.

Gallagher, E.L., S. Elgar, and R.T. Guza, Observations of sand bar evolution on a natural beach, J. Geophys. Res., 103, 3203-3215, 1998.

Garcez-Faria, A.F., E.B. Thornton, T.C. Lippmann, and T.P. Stanton, Undertow over a barred beach, J. Geophys. Res., 105, 16999-17010, 2000.

Gourlay, M.R., Wave set-up, wave run-up, and beach water table: Interaction between surfzone hydraulics and groundwater hydraulics, Coastal Eng., 17, 93-144, 1992.

Guza, R.T. and E.B. Thornton, Local and shoaled comparisons of sea surface elevations, pressures, and velocities, J. Geophys. Res., 85, 1524-1530, 1980.

Guza, R.T. and E.B. Thornton, Wave set-up on a natural beach, J. Geophys. Res., 86, 4133-4137, 1981.

Haas, K.A., I.A. Svendsen, M.C. Haller, and Q. Zhao, Quasi-three-dimensional modeling of rip current systems, J. Geophys. Res., 108(C7), 3217, doi:10.1029/2002JC001355, 2003. 
Haller, M.C., R.A. Dalrymple, I.A. Svendsen, Experimental study of nearshore dynamics on a barred beach with rip channels, J. Geophys. Res., 107, C6, 3061 doi:10.1029/2001JC000955, 2002.

Hansen, U.A. Wave setup and design water level, J. Waterw. Port Coastal Ocean Div., 104, 227-240, 1978.

Hanslow, D.J., P. Nielsen, and K. Hibbert, Wave setup at river entrances, International Conference on Coastal Engineering, ASCE, 2244-2257, 1996.

Holman, R.A. and A.H. Sallenger, Setup and swash on a natural beach, J. Geophys. Res., 90, 945-953, 1985.

King, B.A., M.W.L. Blackley, A.P. Carr, and P.J. Hardcastle, Observations of waveinduced setup on a natural beach, J. Geophys. Res., 95, 22289-22297, 1990.

Lentz, S. and B. Raubenheimer, Field observations of wave setup, J. Geophys. Res., 104, 25867-25875, 1999.

Longuet-Higgins, M.S. and R.W. Stewart, Radiation stress and mass transport in gravity waves, with application to 'surf-beats,' J. Fluid Mech., 13, 481-504, 1962.

Longuet-Higgins, M.S. and R.W. Stewart, Radiation stresses in water waves: A physical discussion with application, Deep Sea Res., 11, 529-562, 1964.

Nielsen, P., Wave setup: A field study, J. Geophys. Res., 93, 15643-15652, 1998.

Raubenheimer, B., R.T. Guza, and S. Elgar, Field observations of wave-driven setdown and setup, J. Geophys. Res., 106, 4629-4638, 2001.

Savage, R.P., Model tests for hurricane protection project, Beach Erosion Board, U.S. Corps Engr., Washington, DC., 1957.

Schäffer, H.A., P.A. Madsen, and R. Diegaard, A Boussinesq model for waves breaking in shallow water, Coastal Eng., 20, 185-202, 1993.

Stive, M.J.F. and H.G. Wind, A study of radiation stress and set-up in the nearshore region, Coastal Eng., 6, 1-25, 1982.

Svendsen, I.A., Mass flux and undertow in the surfzone, Coastal Eng., 8, 347-365, 1984.

Tajima, Y. and O.S. Madsen, Modeling near-shore waves, surface rollers, and undertow velocity profiles, J. Waterway, Port, Coastal, and Ocean Engr., 132, 429-438, 2006 
Thornton, E.B., R.T. Humiston, and W. Birkemeier, Bar-trough generation on a natural beach, J. Geophys Res., 101, 12097-12110, 1996. 


\title{
Chapter 2: Testing and Calibrating Parametric Wave Transformation Models On Natural Beaches
}

Parts of this chapter were submitted for publication to Coastal Engineering:

Apotsos, A., B. Raubenheimer, S. Elgar, and R.T. Guza, Testing and calibrating parametric wave transformation models on natural beaches, Coastal Eng., Submitted, 2007.

\begin{abstract}
Several parametric wave transformation models are tested and calibrated with observations from 6 field experiments on barred and unbarred beaches. Using default values for a free parameter $\gamma$, all models predict the observations reasonably well (median root-mean-square wave height errors are between 10\% and 20\%) at all field sites. Model errors can be reduced by roughly $50 \%$ by tuning $\gamma$ for each data record. No tuned or default model provides the best predictions for all data records or at all experiments. Tuned $\gamma$ differs for the different models and experiments, but in all cases $\gamma$ increases as the hyperbolic tangent of the deep-water wave height, $H_{0}$. Data from 2 experiments are used to estimate empirical, universal curves for $\gamma$ based on $H_{o}$. Using the new parameterization, all models have similar accuracy, and usually show increased skill at 5 of the 6 experiments relative to using default $\gamma$.
\end{abstract}

\subsection{Introduction}

Numerical modeling increasingly is used to optimize coastal management and protection strategies. Nearshore wave transformation models used to predict currents, setup, and sediment transport range in complexity from wave-resolving, high-order solutions of the extended Boussinesq equations [Nwogu, 1993; Kennedy et al., 2000] to wave energy balances using parameterizations of breaking-wave dissipation [Battjes and Janssen, 1978; Thornton and Guza, 1983]. Here, the accuracy of the parametric models, widely used because they are easy to code and are computationally efficient, is examined. 
In all the models examined here, the breaking wave heights are assumed to follow simple probability distributions, and wave-breaking energy dissipation is parameterized using a theory for idealized bores. All of the models contain a free parameter $\gamma$ that can be tuned using wave height observations to provide more accurate predictions of the wave field at spatially dense locations, or to improve wave height forecasts for different time periods or locations.

After the models are outlined (section 2.2), the observations are described (section 2.3), and the method of model analysis is explained (section 2.4). Next, the models are evaluated using the observations, and a new parameterization for $\gamma$ is developed (section 2.5). The results are discussed (section 2.6), and the conclusions are summarized (section 2.7).

\subsection{Wave Transformation Models}

In all models, the wave field is assumed to be narrow banded in both frequency and direction, and the peak period is assumed to be constant in the cross-shore. The dissipation of wave energy caused by bottom friction is small in the surfzone [Thornton and Guza, 1983], and here all dissipation is assumed to be owing either to wave breaking $\left(\left\langle\varepsilon_{b}\right\rangle\right)$ or to the shear stress at the wave-roller interface $\left(\left\langle\varepsilon_{r}\right\rangle\right)$.

In all except one of the models considered, the cross-shore $(x)$ gradient of the cross-shore wave energy flux, $E_{w} c_{g} \cos \theta$, is assumed equal to the local mean rate of energy dissipation in a breaking wave

$$
\frac{\partial}{\partial x}\left(E_{w} c_{g} \cos \theta\right)=-\left\langle\varepsilon_{b}\right\rangle
$$

where $\theta$ is the mean wave angle relative to shore normal and $c_{g}$ is the group speed. The wave energy, $E_{w}$, is found from linear theory as $E_{w}=\frac{1}{8} \rho g H_{r m s}^{2}$, where $\rho$ is the water density, $g$ is the gravitational acceleration, and $H_{r m s}$ is the root-mean-square wave height (defined as $2 \sqrt{2}$ times the standard deviation of the sea-surface elevation fluctuations). 
The linear theory group speed is $c_{g}=c\left[\frac{1}{2}+\frac{k h}{\sinh (2 k h)}\right]$, where $c, k$, and $h=d+\bar{\eta}$ are the local wave phase speed, wave number, and water depth, respectively.

Alternatively, in one model [Lippmann et al., 1996] a wave roller is included such that

$$
\frac{\partial}{\partial x}\left(E_{r} c \cos \theta\right)+\frac{\partial}{\partial x}\left(E_{w} c_{g} \cos \theta\right)=-\left\langle\varepsilon_{r}\right\rangle
$$

where the roller energy $E_{r}$ is

$$
E_{r}=\frac{1}{8} \rho c f \frac{H_{b r}^{3}}{h \tan \sigma}
$$

in which $f$ is the peak wave frequency, $\sigma$ is the slope of the wave front, and $H_{b r}$ is the height of the wave at breaking, as described below [i.e., (2-14)]. )]. Here, $\sigma$ is held constant at $12.5^{\circ}$ (there is little variation in model accuracy for $\sigma>5^{\circ}$ or $10^{\circ}$ [Lippmann et al., 1996]). Energy balances similar to (2-2) have been used widely [e.g., Stive and De Vriend, 1994].

In most of the models (i.e., except the roller and the wave recovery models), the dissipation of energy is estimated by equating the dissipation in a single breaking wave to that in a hydraulic jump [Stoker, 1957; LeMehaute, 1962], and by incorporating a probability distribution function (p.d.f.) describing the fraction of waves that are breaking. The fraction of breaking or broken waves, $Q$, can be estimated using a Rayleigh wave height distribution truncated discontinuously at some maximum wave height $H_{m}$ [Battjes and Janssen, 1978; Battjes and Stive, 1985; and Nairn, 1990] (labeled BJ, BS, and Nairn, respectively), yielding

$$
\frac{1-Q}{-\ln Q}=\left(\frac{H_{r m s}}{H_{m}}\right)^{2}
$$

where $H_{m}$ is found by extending the Miche criterion for the maximum height of periodic waves of constant form [Miche, 1951] to 


$$
H_{m}=\frac{0.88}{k} \tanh \left(\frac{\gamma}{0.88} k h\right)
$$

The free parameter $\gamma$ is roughly equivalent to the maximum ratio of wave height to water depth, and controls the fraction of breaking waves. The dissipation is then given by

$$
\left\langle\varepsilon_{b}\right\rangle=\frac{1}{4} \rho g f B Q H_{m}^{2},
$$

where $B$ is of order 1 and controls the level of energy dissipation.

Alternatively, full (i.e., untruncated) Rayleigh distributions and empirical weighting functions can be used to describe the distribution of broken waves [Thornton and Guza, 1983; and Whitford, 1988] (labeled TG and Whit, respectively), with the corresponding energy dissipation given by

$$
\left\langle\varepsilon_{b}\right\rangle=\frac{3 \sqrt{\pi}}{16} \rho g f B^{3} \frac{H_{r m s}^{3}}{h} M\left[1-\frac{1}{\left(1+\left(H_{r m s} / \gamma h\right)^{2}\right)^{5 / 2}}\right),
$$

with (TG)

$$
M=\left(\frac{H_{r m s}}{\gamma h}\right)^{2}
$$

or (Whit)

$$
M=\left\{1+\tanh \left[8\left(\frac{H_{r m s}}{\gamma h}\right)-1\right]\right\} .
$$

For steep beaches where not all waves reach the maximum height and break, BJ can be extended using a full Rayleigh p.d.f. without the depth limitation of nearshore waves [Baldock et al., 1998; and Ruessink et al., 2003] (labeled Bald and Rues, respectively), yielding

$$
\left\langle\varepsilon_{b}\right\rangle=\frac{1}{4} \rho g f B\left\lfloor-\left(\frac{H_{b}}{H_{r m s}}\right)^{2}\right\rfloor\left(H_{b}^{2}+H_{r m s}^{2}\right),
$$

where $H_{b}$ is the local wave breaking height and can be approximated by $H_{m}$ [e.g., (2-5)] (Rues), which in the limit of shallow water (i.e., $k h \ll 1$ ) (used by Bald) is 


$$
H_{b}=\gamma h .
$$

Recently, Bald has been modified to correct for a singularity that can develop in shallow water [Janssen and Battjes, submitted] (labeled Jan), giving

$$
\left\langle\varepsilon_{b}\right\rangle=\frac{1}{4 h} B \rho g f H_{r m s}^{3}\left\lfloor\left(R^{3}+\frac{3}{2} R\right) \exp \left(-R^{2}\right)+\frac{3}{4} \sqrt{\pi}(1-\operatorname{erf}(R))\right\rfloor,
$$

where $R=H_{b} / H_{r m s}$, with $H_{b}$ determined from (2-11).

In the roller model (labeled Lipp), the work done by the roller on the surface of the wave, $\left\langle\varepsilon_{r}\right\rangle$, is

$$
\left\langle\varepsilon_{r}\right\rangle=\frac{1}{4} \rho g f \frac{H_{b r}^{3}}{h} \cos \sigma,
$$

where

$$
H_{b r}^{3}=\frac{3 \sqrt{\pi}}{4} M H_{r m s}^{3}\left[1-\frac{1}{\left(1+\left(H_{r m s} / \gamma h\right)^{2}\right)^{5 / 2}}\right),
$$

with $M$ given by (2-9). Note (2-13) and (2-14) are nearly equivalent to (2-7) if $B=1$ and $\sigma$ is small.

In the wave recovery model, the dissipation is assumed to be proportional to the difference between the local energy flux $E_{w} c_{g}$ and the energy flux of a recovered wave $E_{\text {rec }} c_{g}$ [Tajima and Madsen, 2002, 2006 as modified from Dally et al., 1985] (labeled as $\mathrm{TM})$

$$
\left\langle\varepsilon_{b}\right\rangle=\frac{K_{b}}{h} c_{g} \exp \left(-\zeta_{b}^{2}\right)\left[E_{w}\left(1+\zeta_{b}^{2}\right)-E_{r e c}\right]
$$

where $E_{\text {rec }}$ is based on the wave height to which a broken wave would recover if it were to propagate in a constant water depth and $\zeta_{b}=H_{b r e a k} / H_{r m s}$. The height of wave breaking $H_{\text {break }}$ is found from a modification of Watanabe et al.'s [1984] breaking criterion $\frac{H_{\text {break }}}{h_{\text {break }}}=\frac{\tanh k_{\text {break }} h_{\text {break }}}{k_{\text {break }} h_{\text {break }}}\left\{1.07-0.59 \exp \left(-8.6 \frac{h_{\text {break }}}{L_{o}}\right)+2.59 \tan \beta_{o} \exp \left[-15.1\left(\frac{h_{\text {break }}}{L_{o}}\right)^{1.5}\right]\right\}$, 
where the subscript break indicates the value at breaking. The empirical constant, $K_{b}$, was derived as

$$
K_{b}=\frac{5}{2} \frac{\gamma_{s}^{2} \tan \beta}{\gamma_{s}^{2}-\gamma_{r e c}^{2}},
$$

where $\beta$ is the beach slope, $\gamma_{r e c}=H_{r e c} / h$, and $\gamma_{\mathrm{s}}$ is

$$
\gamma_{s}=\gamma_{\text {rec }}+4 \tan \beta
$$

The energy in the recovered wave $E_{r e c}$ can be found from $\gamma_{r e c}=0.3$ and $E_{r e c}=\frac{1}{8} \rho g H_{r e c}^{2}$.

The wave models (i.e., Table 2-1) can be broken into three groups. The first group (TG, Whit, and Lipp) incorporates a weighting function in the determination of the dissipation. The TG, Whit, and Lipp models differ in the weighting function used [TG uses (2-8), whereas Whit and Lipp use (2-9)] and in the addition of a roller in Lipp. The second group (BJ, BS, Nairn, Bald, Rues, and Jan) estimates the dissipation following simple bore theory, but does not incorporate a weighting function. The BJ, BS, Nairn, Bald, Rues, and Jan models differ in the p.d.f. used (BJ, BS, and Nairn use a truncated Rayleigh p.d.f., whereas Bald, Rues, and Jan use a full Rayleigh p.d.f.). The last group (TM) relates the dissipation to the difference between the actual energy flux and that of a fully recovered wave in the same water depth.

Table 2-1: Wave Model Summary

\begin{tabular}{|c|c|c|c|}
\hline Wave Model & Energy Eqn. & Dissipation & $\gamma$ \\
\hline TG & $(2-1)$ & $(2-7)$ and $(2-8)$ & 0.42 or tuned \\
\hline Whit & $(2-1)$ & $(2-7)$ and $(2-9)$ & 0.34 or tuned \\
\hline Lipp & $(2-2)$ and $(2-3)$ & $(2-13)$ and $(2-14)$ & 0.32 or tuned \\
\hline BJ & $(2-1)$ & $(2-4)-(2-6)$ & Tuned \\
\hline BS & $(2-1)$ & $(2-4)-(2-6)$ & $(2-19)$ \\
\hline Nairn & $(2-1)$ & $(2-4)-(2-6)$ & $(2-20)$ \\
\hline Bald & $(2-1)$ & $(2-10)$ and $(2-11)$ & $(2-20)$ or tuned \\
\hline Rues & $(2-1)$ & $(2-5)$ and $(2-10)$ & $(2-21)$ \\
\hline Jan & $(2-1)$ & $(2-11)$ and $(2-12)$ & $(2-20)$ or tuned \\
\hline TM & $(2-1)$ & $(2-15),(2-16)$, and & $(2-18)$ \\
\hline
\end{tabular}


Although all the models but one (i.e., TM) contain two free parameters, $B$ and $\gamma$ are interdependent [Roelvink, 1993], and can be combined into a single parameter [Cacina, 1989]. Here, $B$ is held constant at 1 , and $\gamma$ is varied. Therefore, the tuned values of $\gamma$ discussed here represent model parameters that implicitly take into account variations in $B$, and are not necessarily comparable with field observations of $H_{r m s} / h$ from previous studies [Sallenger and Holman, 1985; Raubenheimer et al., 1996]. Similarly, because the model formulations differ, $\gamma$ is not expected to have the same numerical value in each model.

The default models use different formulations for $\gamma$ determined from prior laboratory and field observations. Whit, Lipp, and TG use constants of $\gamma=0.34,0.32$, and 0.42, respectively. BS, Nairn, Bald, and Jan use functions of the deep-water wave steepness, $S_{o}=H_{o} / L_{o}$, where $H_{o}$ and $L_{o}$ are the deep-water wave height and length, respectively, with $\gamma$ given by

$$
\gamma=0.5+0.4 \tanh \left(33 S_{o}\right)(\mathrm{BS})
$$

and

$$
\gamma=0.39+0.56 \tanh \left(33 S_{o}\right)(\text { Nairn, Bald, and Jan }),
$$

while Rues uses

$$
\gamma=0.76 k h+0.29
$$

Here, a more extensive data set comprised of multiple field experiments is used to evaluate and improve these formulations. See the references given above for the details of each wave model.

\subsection{Observations}

\subsubsection{SandyDuck and Duck94: Duck, NC 1997 and 1994}

Wave-induced pressures were measured at $2 \mathrm{~Hz}$ for $10752 \mathrm{~s}$ (179.2 min) starting every 3 hours using pressure gages at 21 (SandyDuck) [Elgar et al., 2001] and 13 (Duck94) [Raubenheimer et al., 1996] cross-shore locations between about 5-m water 
depth and the shoreline for 90 days during Sep to Nov 1997 (SandyDuck) and for 80 days during Aug to Oct 1994 (Duck94) on a barred beach near Duck, NC (Figures 2-1A \& B, respectively). The 3-hr-long data records were subdivided into 8.5- (SandyDuck) and 17.5- (Duck94) min-long sections to reduce tidally induced depth changes. The bathymetry was surveyed approximately every other day from about 8-m water depth to above the high tide shoreline along cross-shore transects located about $20 \mathrm{~m}$ alongshore of the instrumented transects.

Root-mean-square wave heights at the most offshore sensor $(h \approx 5 \mathrm{~m})$ ranged from 0.20 to $2.10 \mathrm{~m}$ (SandyDuck) and from 0.14 to $2.92 \mathrm{~m}$ (Duck94). Centroidal frequencies ranged from 0.08 to $0.21 \mathrm{~Hz}$ (SandyDuck) and from 0.09 to $0.24 \mathrm{~Hz}$ (Duck94). Incident wave angles ranged between $\pm 45^{\circ}$ relative to shore normal during both experiments.

\subsubsection{Egmond and Terschelling: The Netherlands, 1994 and 1998}

Wave-induced pressures were measured at $2 \mathrm{~Hz}$ for approximately $2040 \mathrm{~s}$ (34 min) starting every hour at 7 cross-shore locations on a double-barred beach between about 15- and 1-m water depths for 40 days during Oct and Nov 1998 near Egmond, The Netherlands [Ruessink et al., 2001], and at 6 cross-shore locations on a triple-barred beach between 9- and 2-m water depths for 34 days during April and May 1994 near Terschelling, The Netherlands [Ruessink et al., 2003; Ruessink et al., 1998] (Figure 2-1C $\& \mathrm{D}$, respectively). The data were processed in 34-min-long records. The bathymetry was surveyed approximately every other day at Egmond. At Terschelling the bathymetry was surveyed only once, but morphological changes during the experiment were negligible [Ruessink, personal communication].

The wave models were initialized with offshore wave conditions in 15- (Egmond) and 9- (Terschelling) $\mathrm{m}$ water depths. Root-mean-square wave heights ranged from 0.19 to $3.93 \mathrm{~m}$ (Egmond) and from 0.12 to $1.84 \mathrm{~m}$ (Terschelling). Centroidal frequencies ranged from 0.08 to $0.26 \mathrm{~Hz}$ (Egmond) and from 0.08 to $0.33 \mathrm{~Hz}$ (Terschelling). Incident wave angles ranged between $\pm 45^{\circ}$ at both experiments. 


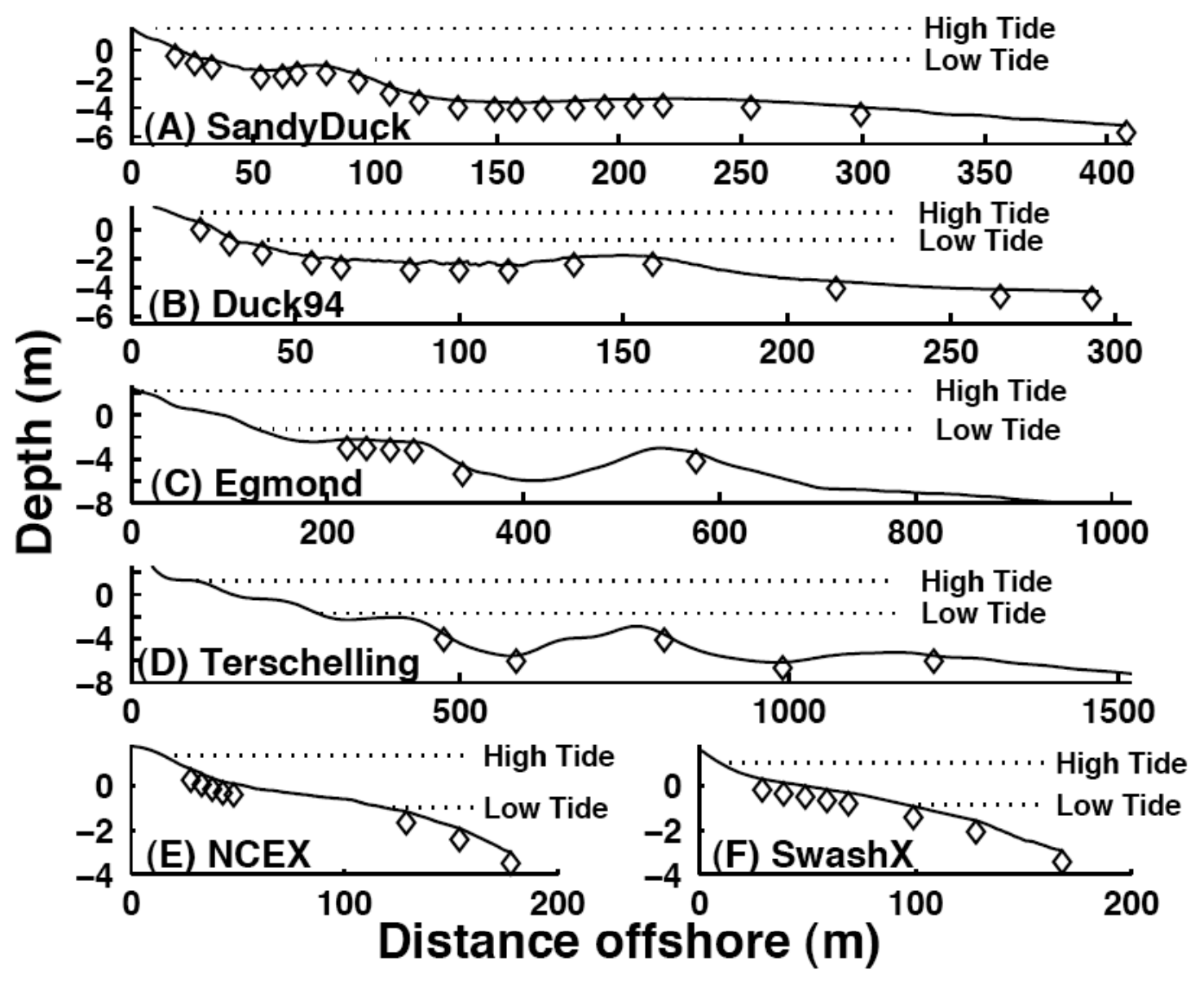

Figure 2-1: Water depth (relative to mean sea level) (solid curves), pressure sensor locations (diamonds), and tidal levels (dotted lines) versus distance offshore for (A) SandyDuck, (B) Duck94, (C) Egmond, (D) Terschelling, (E) NCEX, and (F) SwashX. The most offshore sensors for Egmond (15 m depth) and Terschelling (9 m depth) are not shown. 


\subsubsection{NCEX and SwashX: La Jolla, CA 2003 and 2000}

Wave-induced pressures were measured at $16 \mathrm{~Hz}$ for $3072 \mathrm{~s} \mathrm{(51.2} \mathrm{min)} \mathrm{starting}$ every hour using buried pressure gages at 8 cross-shore locations between about $3.5-\mathrm{m}$ water depth and the shoreline for 23 days during Oct and Nov 2003 (NCEX) [Thomson et al., 2006] and for 14 days during Sep and Oct 2000 (SwashX) [Raubenheimer, 2002] on near planar beaches near La Jolla, CA (Figures 2-1E \& F, respectively). The 1-hr-long data records were subdivided into 8.5-min-long sections. The bathymetry was surveyed between about 5-m water depth and the shoreline roughly $5 \mathrm{~m}$ alongshore from the instrumented transects approximately every other day.

Root-mean-square wave heights at the most offshore sensor $(h \approx 3.5 \mathrm{~m})$ ranged from 0.21 to $1.00 \mathrm{~m}$ (NCEX) and from 0.19 to $1.05 \mathrm{~m}$ (SwashX). Centroidal frequencies ranged from 0.07 to $0.17 \mathrm{~Hz}$ (NCEX) and from 0.09 to $0.20 \mathrm{~Hz}$ (SwashX). Incident wave angles were within $5^{\circ}$ of shore normal during both experiments.

\subsection{Model Analysis}

\subsubsection{Model Procedure}

All models were initialized with the rms wave height, centroidal frequency, mean wave angle, and still water depth observed at the most offshore sensor. The wave period was assumed constant for all depths, and the wave angle was interpolated in the crossshore using Snell's Law. The local water depth was estimated from the measured bathymetric profile, the tidal elevation relative to mean sea level at the offshore sensor, and the setup, $\bar{\eta}$, predicted as [Longuet-Higgins and Stewart, $1962 \&$ 1964]

$$
\frac{\partial}{\partial x} S_{x x}+\rho g(\bar{\eta}+d) \frac{\partial}{\partial x} \bar{\eta}=0
$$

where $d$ is the still water level and the wave radiation stress $S_{x x}$ is

$$
S_{x x}=E_{w}\left\{\left[\cos ^{2}(\theta)+1\right] \frac{c_{g}}{c}-\frac{1}{2}\right\} .
$$


A $1^{\text {st }}$-order forward-step technique was used to determine the onshore variation of the wave heights. Wave heights were not estimated in depths less than $0.30 \mathrm{~m}$ where small errors in the measured bathymetry can lead to significant errors in the modeled wave heights. The nonlinear models, Lipp, BJ, Nairn, and BS, were solved iteratively at each step. Unless noted otherwise, all models were run for all data records in all experiments (see section 2.4.3).

\subsubsection{Model Tuning}

For each data record in each experiment, $\gamma$ in TG, Whit, Lipp, Bald, BJ, and Jan was fit to the observations. The best-fit $\gamma$ was found by varying $\gamma$ from 0.10 to 1.00 with a step size of 0.005 , and by minimizing the weighted root-mean-square (rms) percent error

$$
\text { Weighted rms Percent Error }=\sqrt{\sum_{n}\left[\left(\left(o b s_{n}-\text { pred }_{n}\right) / o b s_{n}\right)^{2} * w_{e i g h t}\right]} * 100 \% \text {, }
$$

where the weighting function, weight ${ }_{n}$, is

$$
\text { weight }_{n}=\frac{\text { dist }_{n-1}+\text { dist }_{n+1}}{\text { dist }_{\text {tot }}}
$$

and dist $_{n-1}$ and dist $_{n+1}$ are the distances from the $n^{\text {th }}$ sensor to the neighboring offshore and onshore sensors, and dist tot is the sum of all distances such that the sum of the weights is 1. All interior distances are counted twice, and for the most shoreward sensor $d_{i s t_{n+1}}$ is assumed equal to $d i s t_{n-1}$. The model was initialized with the most offshore wave height, and this value was not used in model tuning and the most offshore distance was counted only once. The $95 \%$ exceedence, the median, and the $5 \%$ exceedence errors for each model at each experiment were estimated as the smallest rms error that was larger than that calculated for 5\%, 50\%, and 95\% of the records (e.g., Figure 2-2).

Percent errors were used [e.g., (2-24)] to give extra weight to the smaller wave heights near the shoreline. The distance weighting [e.g., (2-25)] was used to give roughly equal weight across the instrumented transects, which prevents the errors from being biased toward one section of the profile when the sensors are not distributed evenly in the 
cross-shore (e.g., NCEX). However, the conclusions are not changed if unweighted or absolute error metrics are used (see section 2.4.4).

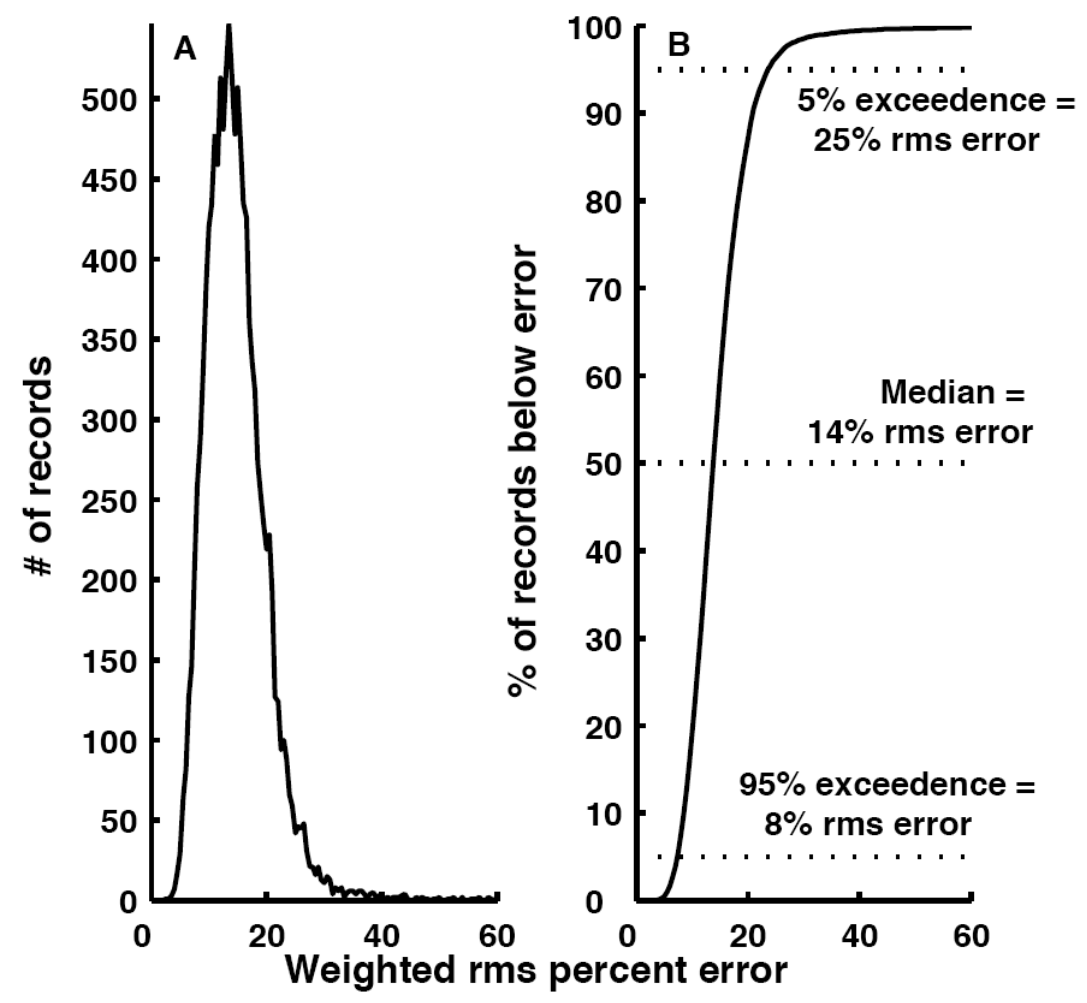

Figure 2-2: (A) Number of records (e.g., histogram) and (B) cumulative sum of the number of records (as a percent of the total number of records) versus the weighted rms percent errors for the default Whit model for the SandyDuck experiment.

\subsubsection{Poorly Defined Fits}

To tune the models, the rms error must have a well-defined minimum at some $\gamma$ (e.g., Figure 2-3A). However, when only one wave height observation is located within the surfzone the minimum in the rms error curve often becomes broad (e.g., Figure 2-3B), resulting in a poorly defined best-fit $\gamma$. In this case, small errors in the measured bathymetry or wave heights can change the estimated value of $\gamma$ significantly. 


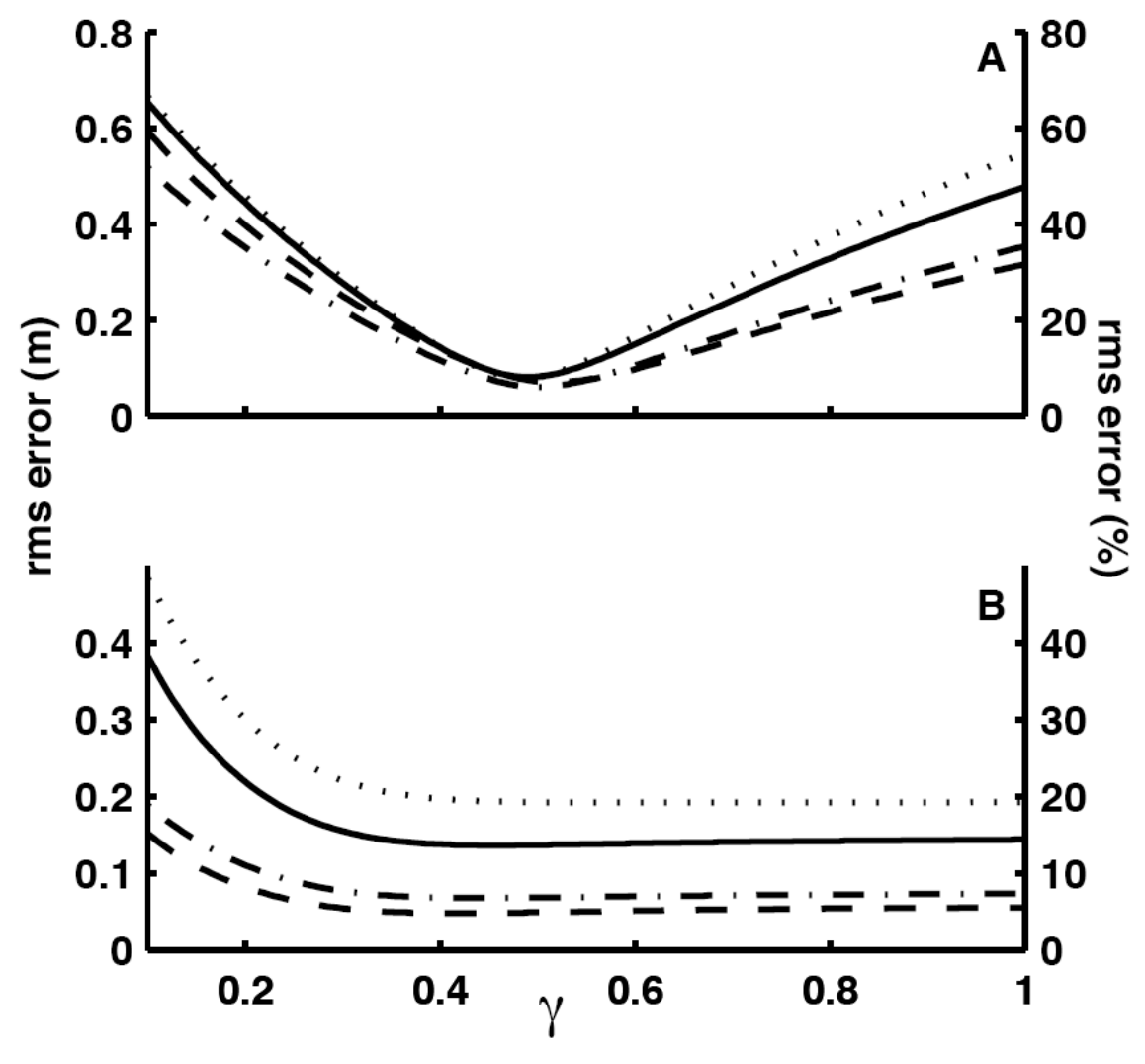

Figure 2-3: Root-mean-square (rms) errors versus $\gamma$ for a data record from Duck94 with (A) a well defined best-fit $\gamma$ and (B) a poorly defined best-fit $\gamma$. The four curves correspond to the four error metrics: weighted rms percent error (solid curves, right axes), percent error (dotted curves, right axes), weighted rms absolute error (dashed curves, left axes), and absolute error (dashed-dotted curves, left axes).

At SandyDuck, $\gamma$ always was well defined. However, at Duck94, instruments often were sparsely spaced both over the sandbar and on the steep foreshore, where there was a shore break (and narrow surfzone) during periods of high tides and small waves. Thus, there are a significant number of data records for which only one sensor was located in the surfzone. To avoid using poorly fit $\gamma$ 's in determining the universal curves, Duck94 data records with broad minima in the rms error curve were excluded. Visual examination of the results (not shown) indicates a reasonably clear delineation between the regimes of well and poorly defined fits. 
All data records from Egmond and Terschelling were used. The data records with small $H_{o}$ were retained to ensure that the models did not dissipate too much energy over the relatively long distance between the location of model initialization and the outer edge of the surfzone.

At NCEX and SwashX, $\gamma$ becomes poorly defined at low tides when the five shallowest sensors were above mean sea level. Therefore, data records from these experiments were included in the analysis only when at least one of the nearshore sensors was submerged.

\subsubsection{Error Calculation}

The sensitivity of the results to the error metric is evaluated by calculating the root-mean-square (rms) error in four ways: percent (a) weighted [i.e., (2-24)] and (b) unweighted error, and absolute (c) weighted and (d) unweighted error, given as

$$
\begin{aligned}
& \text { Unweighted Percent Error }=\sqrt{\text { mean } \left.\left[\left(\text { obs }_{n}-\text { pred }_{n}\right) / o b s_{n}\right)^{2}\right]} * 100 \% \text {, } \\
& \text { Weighted Absolute Error }=\sqrt{\sum_{n}\left[\left(\text { obs }_{n}-\text { pred }_{n}\right)^{2} * \text { weight }_{n}\right]} \text {, }
\end{aligned}
$$

and

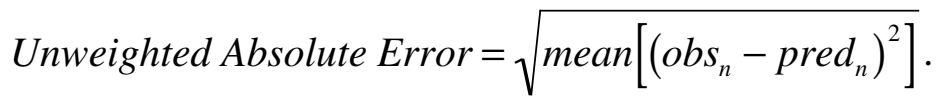

Model errors and best-fit $\gamma$ are similar for all error metrics. For example, the mean best-fit $\gamma$ values for the TG and Bald models for SandyDuck (Figure 2-4A \& B) are similar for all four error metrics. Although $\gamma$ varies slightly for individual data records, the histograms of best-fit $\gamma$ are not significantly different for any of the error metrics (Figure 2-4C \& D). Similar results were found for the other models, and at Duck94.

Using a percent error metric [i.e., (2-24)], which gives more weight to the smaller wave heights in shallower water, minimizes the mean and rms errors in shallow water at the expense of larger errors in deeper water. However, the difference in errors between 
error metrics is significantly smaller than the difference in errors between tuned and default models.
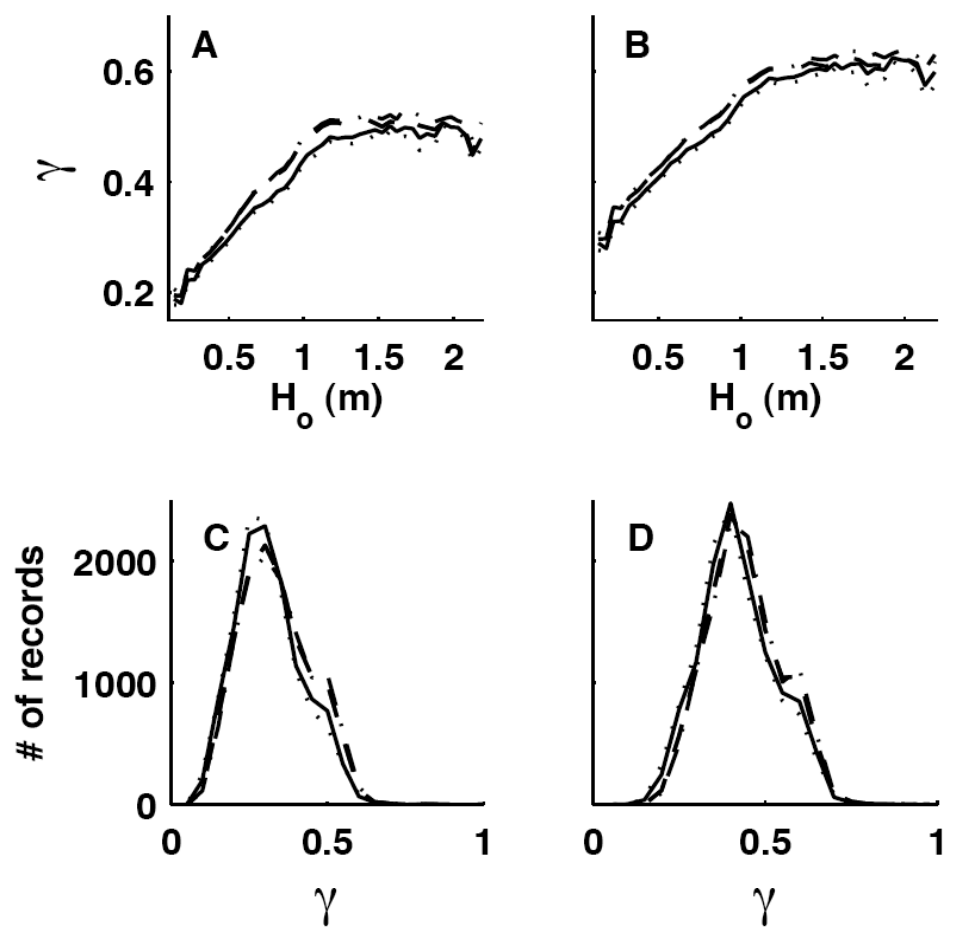

Figure 2-4: The mean best-fit $\gamma\left( \pm 0.1 \mathrm{~m}\right.$ bins in $\left.H_{o}\right)$ versus deep-water wave height $H_{o}$ at SandyDuck for (A) TG and (B) Bald models for the four different error metrics (solid curve is eqn (2-24), dotted curve is eqn (2-26), dashed curve is eqn (2-27), and dasheddotted curve is eqn (2-28) and (C \& D) the corresponding number of records (i.e., histograms) versus best-fit values of $\gamma$ at SandyDuck.

\subsection{Results}

\subsubsection{Model Evaluation}

\subsubsection{Default Models}

Using default values for $\gamma$, the eight models (e.g., TG, Whit, Lipp, BS, Nairn, Bald, Rues, and Jan in Table 2-1) show reasonable agreement with the observations (e.g., Table 2-2 and Figure 2-5). However, the predicted cross-shore profile of wave heights can differ significantly for different models for a single data record (e.g., Figure 2-5), and the prediction errors for any one model can change significantly between different data 
records from one experiment (e.g., note the range between the $95 \%$ and $5 \%$ exceedence errors in Table 2-2). No single default model predicts the observations best for all data records (not shown), or for all experiments (for example, Bald has the lowest median error of any model at NCEX, but the third highest at Egmond and Terschelling). If an unweighted percent error is used [e.g., (2-26)], the max, median, and min errors in Table 2-2 are approximately 10-20\% larger.

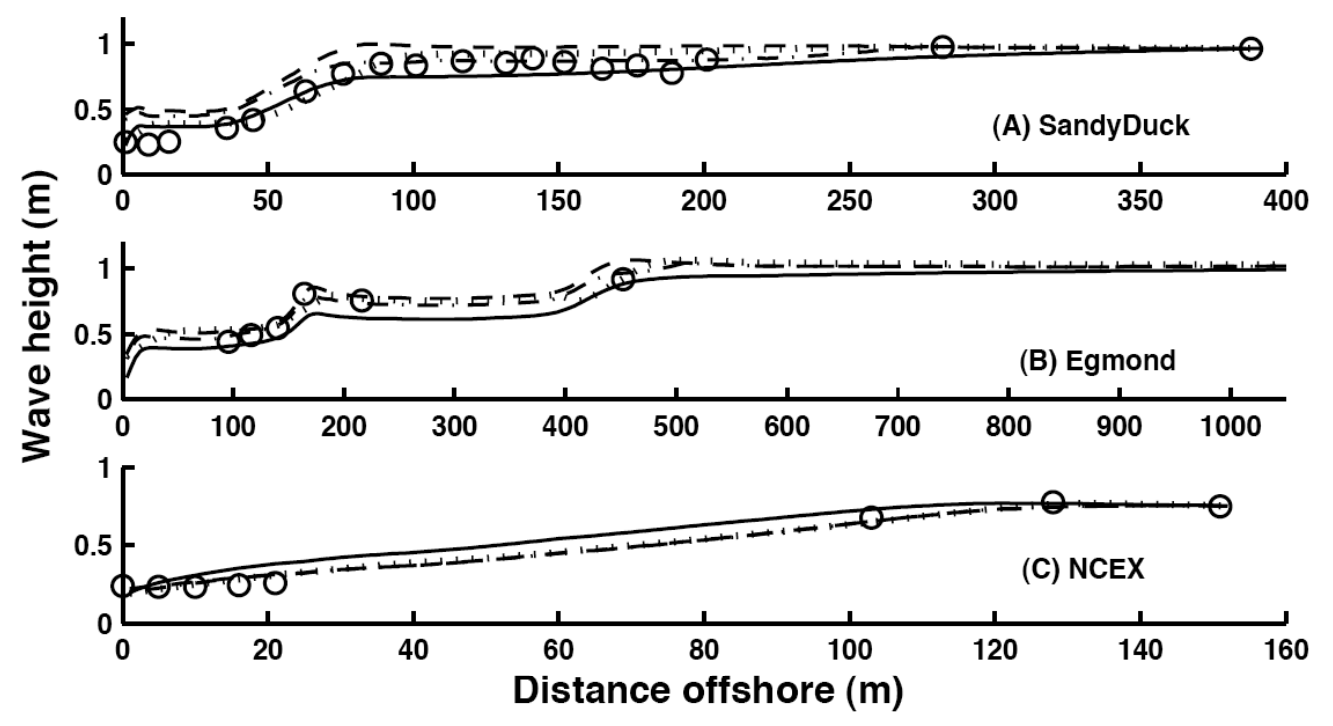

Figure 2-5: Observed (circles) and predicted [TG (solid curves), Bald (dashed curves), Nairn (dashed-dotted curves), and Lipp (dotted curves) models] wave heights versus distance offshore for (A) SandyDuck Sep 27 19:51, (B) Egmond Nov 4 15:00, and (C) NCEX Nov 10 08:34 (local standard time).

\subsubsection{Tuned Models}

Tuning the models improves model-data accuracy (e.g., errors are smaller in Table 2-3 than in Table 2-2). The tuned BJ, BS, and Nairn models are identical, and only $\mathrm{BJ}$ is given in subsequent figures and tables. The TM model is not included in this section because it does not contain an easily tunable parameter. The percent error reduction owing to model tuning is estimated from the Brier Skill Score (BSS) [Murphy and Epstein, 1989; Ruessink et al., 2003]

Table 2-2: 95\% exceedence (minimum), median, and $5 \%$ exceedence (maximum) errors for the nine default wave models for all six experiments. 


\begin{tabular}{|c|c|c|c|c|c|c|c|c|c|c|}
\hline & & TG & Whit & Lipp & Bald & Rues & Nairn & BS & Jan & TM \\
\hline \multirow{3}{*}{ SandyDuck } & Min & $7.5 \%$ & $7.5 \%$ & $7.3 \%$ & $6.7 \%$ & $7.2 \%$ & $6.5 \%$ & $7.5 \%$ & $7.7 \%$ & $7.8 \%$ \\
\cline { 2 - 11 } & Median & $14.4 \%$ & $13.6 \%$ & $13.8 \%$ & $13.7 \%$ & $15.0 \%$ & $12.3 \%$ & $15.5 \%$ & $18.0 \%$ & $16.4 \%$ \\
\cline { 2 - 11 } & Max & $25.7 \%$ & $24.5 \%$ & $25.9 \%$ & $32.6 \%$ & $28.3 \%$ & $26.1 \%$ & $30.2 \%$ & $36.9 \%$ & $29.5 \%$ \\
\hline \multirow{3}{*}{ Duck94 } & Min & $6.3 \%$ & $9.0 \%$ & $7.9 \%$ & $5.1 \%$ & $4.8 \%$ & $4.7 \%$ & $4.5 \%$ & $5.2 \%$ & $6.2 \%$ \\
\cline { 2 - 11 } & Median & $13.7 \%$ & $15.3 \%$ & $13.4 \%$ & $10.4 \%$ & $10.7 \%$ & $9.2 \%$ & $8.8 \%$ & $11.1 \%$ & $11.1 \%$ \\
\hline \multirow{3}{*}{ SwashX } & Max & $22.0 \%$ & $24.8 \%$ & $23.4 \%$ & $23.2 \%$ & $19.2 \%$ & $18.2 \%$ & $18.6 \%$ & $26.5 \%$ & $21.3 \%$ \\
\hline \multirow{3}{*}{ NCEX } & Median & $5.6 \%$ & $4.4 \%$ & $3.4 \%$ & $3.5 \%$ & $3.2 \%$ & $3.2 \%$ & $5.0 \%$ & $5.6 \%$ & $3.8 \%$ \\
\cline { 2 - 11 } & Max & $23.4 \%$ & $33.9 \%$ & $26.1 \%$ & $20.6 \%$ & $22.7 \%$ & $20.5 \%$ & $20.5 \%$ & $23.4 \%$ & $22.8 \%$ \\
\hline \multirow{3}{*}{ Egmond } & Min & $7.1 \%$ & $5.2 \%$ & $3.4 \%$ & $1.5 \%$ & $3.3 \%$ & $1.9 \%$ & $6.5 \%$ & $6.9 \%$ & $6.0 \%$ \\
\cline { 2 - 11 } & Median & $16.0 \%$ & $12.0 \%$ & $10.3 \%$ & $7.1 \%$ & $10.9 \%$ & $7.7 \%$ & $14.8 \%$ & $16.1 \%$ & $14.4 \%$ \\
\cline { 2 - 11 } & Max & $43.0 \%$ & $27.9 \%$ & $26.7 \%$ & $21.2 \%$ & $25.4 \%$ & $21.5 \%$ & $37.6 \%$ & $40.5 \%$ & $29.6 \%$ \\
\cline { 2 - 10 } & Median & $4.7 \%$ & $4.0 \%$ & $3.8 \%$ & $4.7 \%$ & $2.4 \%$ & $3.2 \%$ & $3.3 \%$ & $6.8 \%$ & $2.8 \%$ \\
\cline { 2 - 10 } & Max & $45.3 \%$ & $48.2 \%$ & $19.2 \%$ & $19.0 \%$ & $17.0 \%$ & $15.5 \%$ & $16.5 \%$ & $22.8 \%$ & $21.0 \%$ \\
\hline \multirow{3}{*}{ Terschelling } & Min & $5.7 \%$ & $6.1 \%$ & $5.7 \%$ & $5.6 \%$ & $6.0 \%$ & $5.7 \%$ & $5.4 \%$ & $6.3 \%$ & $6.7 \%$ \\
\cline { 2 - 10 } & Median & $16.0 \%$ & $17.3 \%$ & $16.5 \%$ & $17.4 \%$ & $18.8 \%$ & $15.6 \%$ & $17.2 \%$ & $19.7 \%$ & $20.1 \%$ \\
\cline { 2 - 10 } & Max & $33.0 \%$ & $40.9 \%$ & $44.0 \%$ & $43.5 \%$ & $39.7 \%$ & $38.0 \%$ & $38.8 \%$ & $41.6 \%$ & $42.8 \%$ \\
\hline
\end{tabular}

Table 2-3: $95 \%$ exceedence, median, and 5\% exceedence errors for the six tuned wave models for all six experiments. Results for BJ, BS, and Nairn are identical, and are listed as BJ.

\begin{tabular}{|c|c|c|c|c|c|c|c|}
\hline & & TG & Whit & Lipp & Bald & BJ & Jan \\
\hline \multirow{3}{*}{ SandyDuck } & Min & $5.0 \%$ & $5.3 \%$ & $5.1 \%$ & $5.0 \%$ & $4.9 \%$ & $5.1 \%$ \\
\cline { 2 - 8 } & Median & $8.6 \%$ & $9.4 \%$ & $9.0 \%$ & $8.7 \%$ & $8.6 \%$ & $8.9 \%$ \\
\cline { 2 - 8 } & Max & $15.6 \%$ & $17.2 \%$ & $16.9 \%$ & $17.1 \%$ & $15.8 \%$ & $18.4 \%$ \\
\hline \multirow{3}{*}{ Duck94 } & Min & $3.6 \%$ & $6.3 \%$ & $4.8 \%$ & $3.2 \%$ & $3.5 \%$ & $3.3 \%$ \\
\cline { 2 - 8 } & Median & $7.5 \%$ & $11.1 \%$ & $9.3 \%$ & $6.0 \%$ & $6.6 \%$ & $6.1 \%$ \\
\cline { 2 - 8 } SwashX & Max & $14.8 \%$ & $17.5 \%$ & $15.4 \%$ & $12.9 \%$ & $13.4 \%$ & $13.1 \%$ \\
\hline \multirow{3}{*}{ NCEX } & Min & $0.8 \%$ & $1.4 \%$ & $0.8 \%$ & $1.0 \%$ & $0.6 \%$ & $1.5 \%$ \\
\cline { 2 - 8 } & Median & $8.5 \%$ & $12.1 \%$ & $11.1 \%$ & $8.8 \%$ & $8.7 \%$ & $7.2 \%$ \\
\cline { 2 - 8 } & Max & $17.6 \%$ & $21.2 \%$ & $18.0 \%$ & $16.5 \%$ & $15.4 \%$ & $13.9 \%$ \\
\cline { 2 - 8 } & Median & $0.5 \%$ & $2.3 \%$ & $1.1 \%$ & $0.4 \%$ & $0.5 \%$ & $0.4 \%$ \\
\cline { 2 - 8 } & Max & $11.6 \%$ & $16.1 \%$ & $5.0 \%$ & $3.1 \%$ & $3.6 \%$ & $4.0 \%$ \\
\hline \multirow{3}{*}{ Terschelling } & Min & $1.2 \%$ & $1.4 \%$ & $1.4 \%$ & $1.1 \%$ & $1.1 \%$ & $1.1 \%$ \\
\cline { 2 - 8 } & Median & $4.6 \%$ & $5.8 \%$ & $5.5 \%$ & $5.4 \%$ & $5.0 \%$ & $5.1 \%$ \\
\cline { 2 - 8 } & Max & $11.6 \%$ & $15.2 \%$ & $14.5 \%$ & $12.9 \%$ & $12.5 \%$ & $11.4 \%$ \\
\cline { 2 - 8 } & Min & $2.9 \%$ & $4.2 \%$ & $3.5 \%$ & $3.5 \%$ & $3.4 \%$ & $3.6 \%$ \\
\cline { 2 - 8 } & Max & $17.8 \%$ & $11.6 \%$ & $10.1 \%$ & $10.3 \%$ & $7.9 \%$ & $9.5 \%$ \\
\hline \multirow{3}{*}{} & & & $23.2 \%$ & $20.6 \%$ & $17.8 \%$ & $16.2 \%$ & $17.3 \%$ \\
\hline
\end{tabular}




$$
B S S=\left[1-\frac{\operatorname{Error}\left(\gamma_{\text {tuned }}\right)}{\operatorname{Error}\left(\gamma_{\text {untuned }}\right)}\right] * 100 \%
$$

Tuning reduces the median errors by 25-50\% (SandyDuck), 27-45\% (Duck94), 67\%-77\% (Egmond), 32\%-52\% (Terschelling), 41-75\% (NCEX), and 22-37\% (SwashX) relative to the errors estimated from the default models. Similar reductions are found for the $95 \%$ and $5 \%$ exceedence errors (not shown). No single tuned model predicts the observations best for all data records or at all experiments.

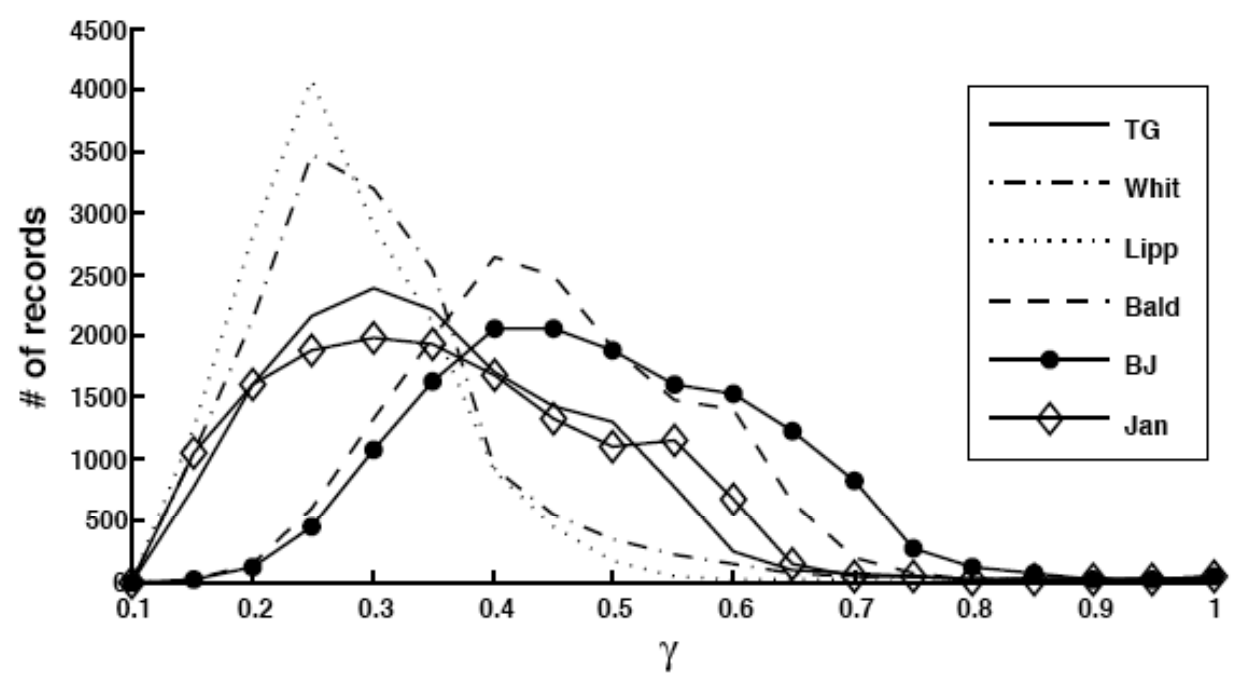

Figure 2-6: Number of records (histograms) versus the best-fit $\gamma$ for the TG (solid curve), Whit (dashed-dotted curve), Lipp (dotted curve), Bald (dashed curve), BJ (solid curve with circles), and Jan (solid curve with diamonds) models for SandyDuck. Histograms of the best-fit $\gamma$ at the other experiments are similar.

\subsubsection{Parameterization of $\gamma$}

\subsubsection{Best-fit $\gamma$}

Each model shows a large spread in the best-fit $\gamma$ for each experiment (e.g., Figure 2-6). For SandyDuck, the spreads in best-fit $\gamma$ between the $95 \%$ and $5 \%$ exceedence values are 0.38, 0.35, 0.27, 0.38, 0.43, and 0.43 for the TG, Whit, Lipp, Bald, BJ, and Jan models, respectively. In addition, the weighting functions [i.e., (2-8) and (2-9)] used by TG, Whit, 
and Lipp and the new dissipation formulation (2-12) used in Jan result in best-fit $\gamma$ 's that are smaller than those found for BJ and Bald. Therefore, the empirical relationships developed using BJ or Bald [i.e., (2-19)-(2-21)] are not appropriate for use with TG, Whit, Lipp, or Jan. The mean best-fit $\gamma$ in each model also varies between the six field experiments, from 0.30 to 0.51 (TG), 0.21 to 0.37 (Whit), 0.20 to 0.37 (Lipp), 0.37 to 0.61 (Bald), 0.41 to 0.66 (BJ), and 0.26 to 0.56 (Jan), suggesting that $\gamma$ likely changes with the wave conditions and details of the bathymetry.

\subsubsection{Correlation with $\mathrm{S}_{0}$ and $\mathrm{H}_{0}$}

The two Duck experiments (i.e., SandyDuck and Duck94), which had a large number of sensors distributed relatively evenly across the surfzone, are used to develop a universal empirical relationship between $\gamma$ and the incident wave field. This relationship is then tested at the other four experiments.

Previous studies [Battjes and Stive, 1985; Nairn, 1990] showed that $\gamma$ depends on the deep-water wave steepness, $S_{o}=H_{o} / L_{o}$. At all experiments, the deep-water wave height $H_{o}$ was estimated by unshoaling the observations from the deepest sensor assuming conservation of wave energy flux. Here, the correlations between the best-fit $\gamma$ and $H_{o}$ at SandyDuck and Duck94 (average correlations of the unbinned data are 0.67 and 0.66 , respectively) are about $50 \%$ larger than those between best-fit $\gamma$ and $S_{o}$.

For all models, $\gamma$ increases almost linearly with increasing $H_{o}$ for small waves, then becomes nearly constant for large $H_{o}$ (e.g., Figure 2-7). This relationship is described well by a hyperbolic tangent curve

$$
\gamma=a+b\left[\tanh \left(c H_{o}\right)\right]
$$

where $a, b$, and $c$ are determined (using a least squares fit) for each model and experiment. Correlations between the binned values of best-fit $\gamma$ and (2-30) usually are greater than 0.9 (e.g., Figure 2-8). Best-fit $\gamma$ 's also are correlated with the inverse Iribarren number, $\frac{1}{\xi}=\frac{\sqrt{S_{o}}}{\beta_{a v}}$, where $\beta_{a v}$ is the surfzone averaged beach slope [Raubenheimer et al., 2001]. However, on beaches with large or multiple bars (e.g., 
Egmond and Terschelling), $\beta_{a v}$ is poorly defined owing to its dependence on the definition of the offshore boundary of the surfzone. Furthermore, if the offshore boundary of the surfzone is estimated from the predicted wave energy dissipation, the location will depend on $\gamma$.

The empirical curves for $\gamma$ based on $H_{o}$ differ slightly for all models at the two experiments (Figure 2-8, compare the grey dashed curve with the solid black curve in each panel). Universal, experiment-averaged curves for $\gamma$ are obtained for each model (Table 2-4 and Figure 2-9) by averaging the curves from the two Duck experiments.

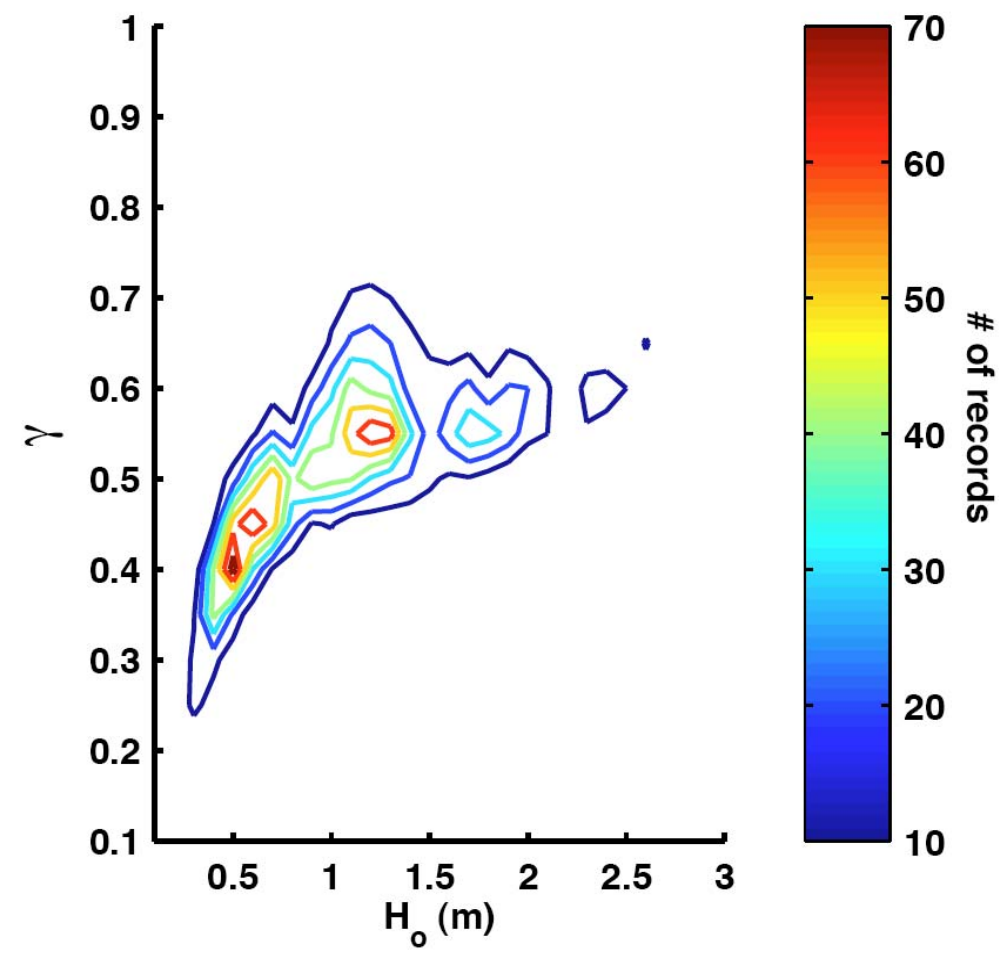

Figure 2-7: The number of data records (contours) as a function of the best-fit $\gamma$ and the deep-water wave height $\boldsymbol{H}_{\mathrm{o}}$ for the TG model at Duck94. Red contours are the largest number of data records and dark blue contours are the smallest number of data records (color scale is on the right hand side). The pattern observed between the best-fit $\gamma$ and $H_{o}$ is similar for the other models and experiments. 

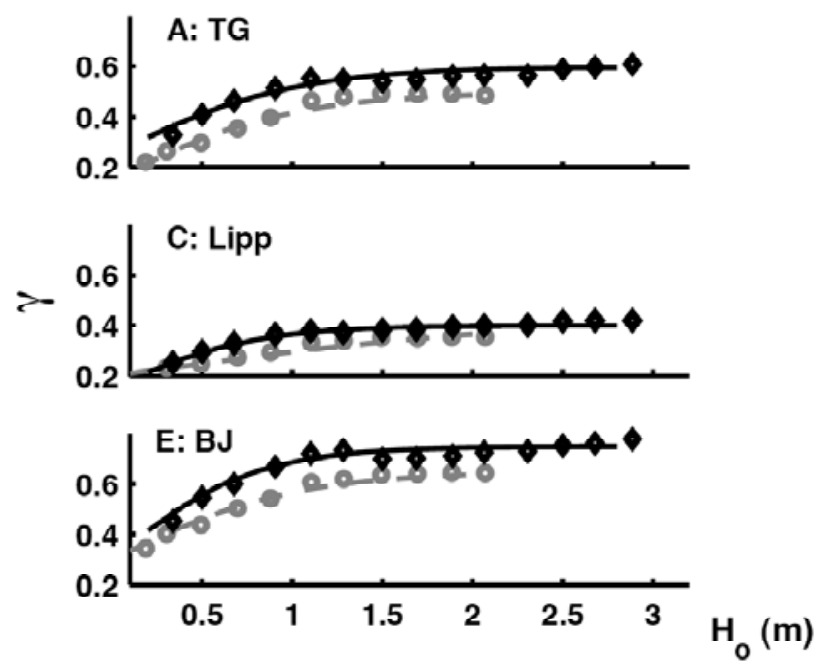

B: Whit
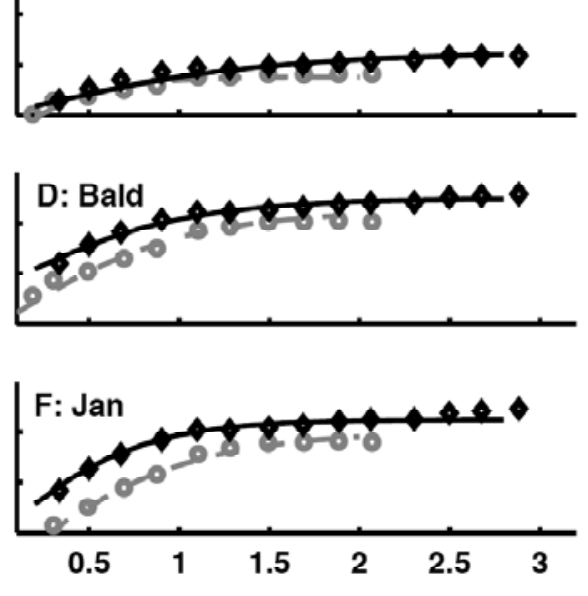

Figure 2-8: Empirical hyperbolic tangent curves fit to data from SandyDuck (grey dashed curve) and Duck94 (black solid curve) for the (A) TG, (B) Whit, (C) Lipp, (D) Bald, (E) BJ, and (F) Jan models. The diamonds (Duck94) and circles (SandyDuck) are the mean values of the best-fit $\gamma$ in bins of $H_{o} \pm 0.10 \mathrm{~m}$. Standard deviations about the means ranged between 0.01 and 0.10 in $\gamma$ and were larger for small $H_{o}$. Average correlations for the two experiments between the unbinned data and the universal curves were 0.77 (TG), 0.60 (Whit), 0.67 (Lipp), 0.81 (Bald), 0.73 (BJ), and 0.85 (Jan).

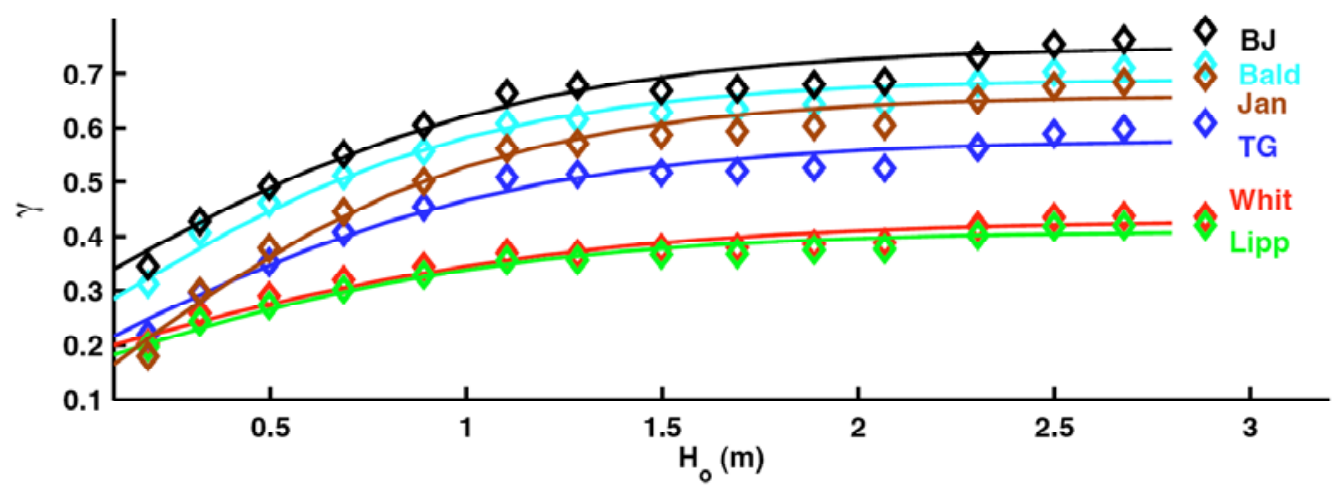

Figure 2-9: Universal empirical curves averaged over the two Duck experiments for the TG (blue), Whit (red), Lipp (green), Bald (cyan), BJ (black), and Jan (brown) models. These curves are based on averaging the curves shown in Figure 2-8, rather than on fits to the raw data because the two experiments had different numbers of data points. The diamonds are the mean values of the best-fit $\gamma$ in bins of $H_{o} \pm 0.10 \mathrm{~m}$ taken as the average of the mean values (i.e., Figure 2-8, diamonds and circles) from Duck94 and SandyDuck. 
Table 2-4: The coefficients for the universal curves.

\begin{tabular}{|c|c|c|c|}
\hline Model & $a$ & $b$ & $c$ \\
\hline TG & 0.18 & 0.40 & 0.9 \\
\hline Whit & 0.18 & 0.25 & 0.8 \\
\hline Lipp & 0.16 & 0.25 & 0.9 \\
\hline Bald & 0.24 & 0.45 & 1.0 \\
\hline BJ & 0.30 & 0.45 & 0.9 \\
\hline Jan & 0.11 & 0.55 & 1.0 \\
\hline
\end{tabular}

\subsubsection{Application of the $\gamma$ Curves}

Application of the universal curves for each model at SandyDuck and Duck94 reduces the prediction errors by 7 to $36 \%$ (mean $=18 \%$ ) and 7 to $28 \%$ (mean $=17 \%$ ), respectively, relative to the default models. To examine the applicability of the new parameterization of $\gamma$ to other sites, the universal curves are applied at the other four experiments.

\subsection{Comparison with Egmond and Terschelling}

Using the universal curves instead of default $\gamma$ improves the results for five (TG, Whit, Bald, BJ, and Jan) of the wave models at Egmond and for all six of the wave models at Terschelling (Table 2-5, see Table 2-6 for median errors). Although the wave models were initialized far offshore of the surfzone at these two experiments, including bottom stress estimates [e.g., Thornton and Guza, 1983] in the models has little effect on either the predicted wave heights or the best-fity. For unknown reasons, at Egmond the skill of the Lipp model decreased using the universal curve relative to using the default $\gamma$.

Similar to previous results [Ruessink, personal communication], use of $\gamma=0.42$ in the TG model for large deep-water waves $\left(H_{o}>1.5 \mathrm{~m}\right)$ causes too much dissipation in the outer surfzone, and thus the predicted waves are smaller than the observed waves. For data records at Egmond when $H_{o}>1.5 \mathrm{~m}$, using $\gamma$ determined from the universal curves with five of the wave models (i.e., excluding the Lipp model) reduces median errors by 
$35 \%$ relative to using default values for $\gamma$, with the largest improvement (60\%) for the TG model and a slight reduction in accuracy (-3\%) for the BJ model. Thus, use of the default value of $\gamma=0.42$ in the TG model may result in significant underprediction of surfzone wave heights when $H_{o}$ is large.

Table 2-5: The BSS values for the median errors using the 'universal' empirical hyperbolic tangent curves at the four experiments not used in calibration. Here the tuned BJ model is compared with default Nairn as (2-20) was obtained using a bit more data than (2-19).

\begin{tabular}{|c|c|c|c|c|c|c|}
\hline & TG & Whit & Lipp & Bald & BJ & Jan \\
\hline Egmond & $27.3 \%$ & $5.0 \%$ & $-19.5 \%$ & $17.7 \%$ & $3.4 \%$ & $24.8 \%$ \\
\hline Terschelling & $16.4 \%$ & $6.0 \%$ & $6.1 \%$ & $8.7 \%$ & $2.7 \%$ & $17.5 \%$ \\
\hline NCEX & $48.0 \%$ & $1.0 \%$ & $2.0 \%$ & $22.4 \%$ & $1.0 \%$ & $52.5 \%$ \\
\hline SwashX & $-7.1 \%$ & $-48.7 \%$ & $-48.5 \%$ & $-38.5 \%$ & $-8.0 \%$ & $12.5 \%$ \\
\hline
\end{tabular}

\subsection{Comparison with SwashX and NCEX}

Using the universal curves reduces model errors relative to default $\gamma$ for all six of the wave models at NCEX, but for unknown reasons only one (Jan) of the wave models at SwashX (Table 2-4).

\subsection{Discussion}

\subsection{1 'Universal' Curves}

Compared with default $\gamma$, using the universal curves reduces prediction errors most for TG, Bald, and Jan (e.g., highest BSS values in Table 2-5) and least for Whit, Lipp, and BJ. For the models using a constant default $\gamma$ (i.e., TG, Whit, and Lipp), TG may show more improvement owing to its wider range of best-fit $\gamma$ (Figure 2-6, compare the solid curve with the dotted and dashed-dotted curves, and Figure 2-8A-C, compare the maximum value of $\gamma$ reached for each of the curves). For the models using a variable default $\gamma$ (i.e., Bald, BJ, and Jan), BJ may show the smallest improvement because the default values [i.e., (2-19) and (2-20)] were determined using BJ, and therefore do not take into account changes in $\gamma$ owing to the modifications of the dissipation in Bald and Jan. 
The universal curves for $\gamma$ typically overestimate the best-fit values for SandyDuck, Egmond, Terschelling, and NCEX, and underestimate the values for SwashX and Duck94 (e.g., Figure 2-10). The larger spread at Egmond and Terschelling (Figure 2-10, cyan and yellow curves) likely occurs because the lack of sensors in shallow water decreases best-fit $\gamma$ for small $H_{o}$. The spread in $\gamma$ owing to using the universal curves rather than the best-fit values is roughly similar for the other five models (not shown).

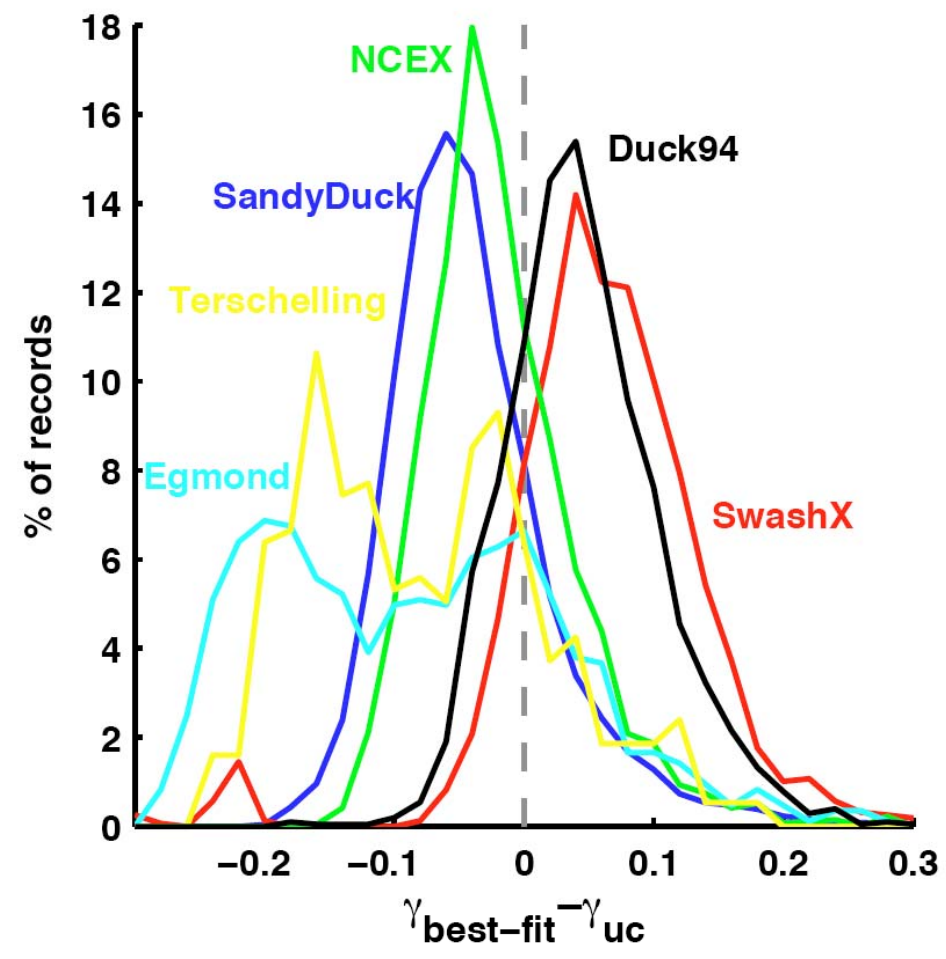

Figure 2-10: Percent of data records for the TG model versus the difference between the best-fit $\gamma\left(\gamma_{\text {best-fit }}\right)$ and the $\gamma$ based on the universal curves $\left(\gamma_{u c}\right.$, e.g., Figure 7$)$ for SandyDuck (blue curve), Duck94 (black curve), SwashX (red curve), NCEX (green curve), Egmond (cyan curve), and Terschelling (yellow curve). The vertical grey dashed line represents perfect agreement, and values less (greater) than 0 occur when the universal curve over- (under-) estimates the best-fit $\gamma$.

Including the NCEX data in developing the universal curves does not change the curves significantly. Inclusion of the data from Egmond and Terschelling reduces the 
values of $\gamma$ estimated for small $H_{o}$ (see above), but does not change significantly the values estimated for $H_{o}>1.5 \mathrm{~m}$.

Using the universal curves [e.g. the 3 free parameters $(a, b, c)$ given in Table 2-4] all the models have similar accuracy (Table 2-6).

Table 2-6: Median errors for the six tuned models using the universal empirical $\gamma$ curves.

\begin{tabular}{|c|c|c|c|c|c|c|}
\hline & TG & Whit & Lipp & Bald & BJ & Jan \\
\hline SandyDuck & $11 \%$ & $12 \%$ & $11 \%$ & $11 \%$ & $11 \%$ & $12 \%$ \\
\hline Duck94 & $10 \%$ & $13 \%$ & $11 \%$ & $9 \%$ & $9 \%$ & $9 \%$ \\
\hline NCEX & $8 \%$ & $12 \%$ & $10 \%$ & $6 \%$ & $8 \%$ & $8 \%$ \\
\hline SwashX & $14 \%$ & $23 \%$ & $21 \%$ & $17 \%$ & $14 \%$ & $10 \%$ \\
\hline Egmond & $12 \%$ & $17 \%$ & $23 \%$ & $16 \%$ & $15 \%$ & $17 \%$ \\
\hline Terschelling & $13 \%$ & $16 \%$ & $16 \%$ & $16 \%$ & $15 \%$ & $16 \%$ \\
\hline
\end{tabular}

\subsubsection{Number of Sensors Needed for Tuning}

The usefulness of model tuning depends on the number and locations of the observations used. Here, the rms error between the observed wave heights and the TG model predictions at all sensor locations increases when fewer than 4 locations are used in tuning the model (Figure 2-11A). However, the accuracy of the model tuned with data from only two locations is higher than for a constant default $\gamma$ of 0.42 (Figure 2-11A, see the data point at 0 tuning locations).

To optimize predictions of the cross-shore distribution of wave heights, data are needed from at least two sensors spanning the surfzone, which changes in width and location with changing wave conditions and tidal levels. At SandyDuck, three sensors are needed close to the shore to ensure that at least two sensors are located in the surfzone during all tidal stages for small waves, and at least one (or ideally two) sensors are needed in deeper water to span the width of the wider surfzone during large waves (not shown). The scatter in best-fit $\gamma$ increases relative to that calculated using all sensors (i.e., Figure 2-6) for small waves when only two tuning locations are located near the shoreline 
(Figure 2-11B, compare the dashed with the solid curve), and for most wave heights when only one offshore tuning location is used (Figure 2-11B, compare the dashed-dotted with the solid curve). Similar results are found using the Bald model.
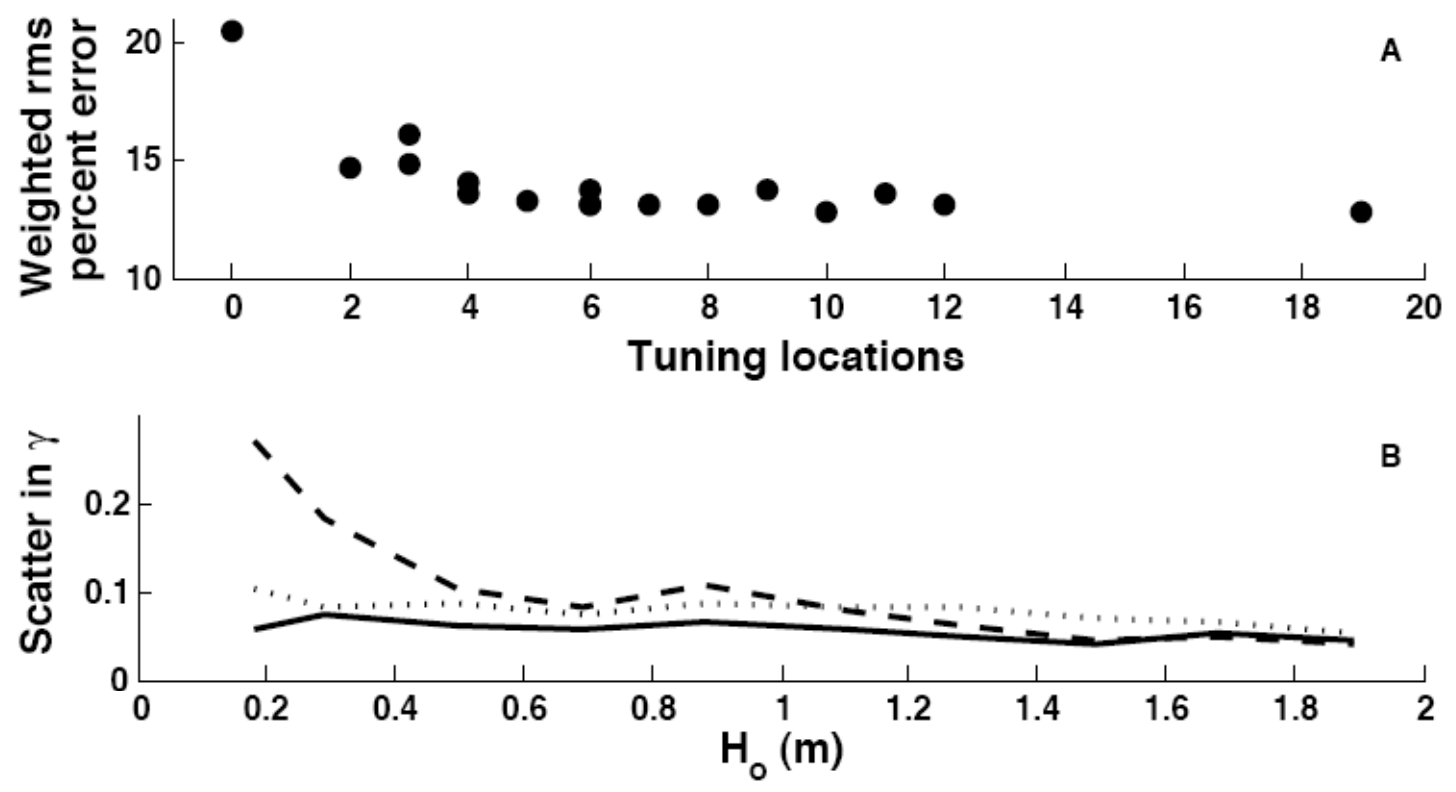

Figure 2-11: (A) Weighted rms percent error versus the number of tuning locations used with the TG model at SandyDuck, and (B) the scatter (defined as one standard deviation of the best-fit $\gamma$ ) of the best-fit $\gamma$ versus the deep-water wave height $H_{o}$ when the TG model is tuned using data from all sensors (solid curve), 2 offshore sensors and 2 shallow sensors (dashed curve), and 3 shallow sensors, but only 1 offshore sensor (dashed-dotted curve). Tuning locations used in (A) were chosen to span the surfzone for most conditions. For 3, 4, and 6 tuning locations, two different sets of locations were tested (i.e., 2 symbols in the vertical at tuning locations $=3,4$, and 6 in A).

\subsubsection{Model Accuracy as a Function of Water Depth}

Model accuracy decreases with decreasing water depth, partially owing to the accumulation of errors with increasing distance from the location of model initialization. However, the model predictions show similar deviations from the observations at all experiments even though the bathymetries and offshore initialization depths are different.

The mean and rms errors using the default and universal $\gamma$ 's with the TG model are small for $h>2 \mathrm{~m}$ (Figure 2-12), with rms errors increasing with decreasing depth for 
$h<2$ m (Figure 2-12B, D, F, and H). Except at NCEX (Figure 2-12G), using the universal curves results in slight overprediction of the observed wave heights for roughly $h>1 \mathrm{~m}$ (Figure 2-12A, C, and E), and underprediction of the wave heights for $h<1 \mathrm{~m}$. Differences between the patterns of under- and overprediction at each experiment are at least partly related to the value of $\gamma$ used. For example, using $\gamma=0.32$ instead of $\gamma=0.42$ in the TG model at NCEX, which has a smaller best-fit $\gamma$ than SwashX (not shown), results in similar mean and $\mathrm{rms}$ errors in $h=1 \mathrm{~m}$ for both experiments. Furthermore, the pattern of over- and underprediction across the surfzone may be caused by cross-shore variations in the observed ratio of wave height to water depth $\left(\gamma_{o b s}\right)$. For example, the underprediction of wave heights in shallow water may be related to the shoreward increase in $\gamma_{o b s}$ [Raubenheimer et al., 1996].
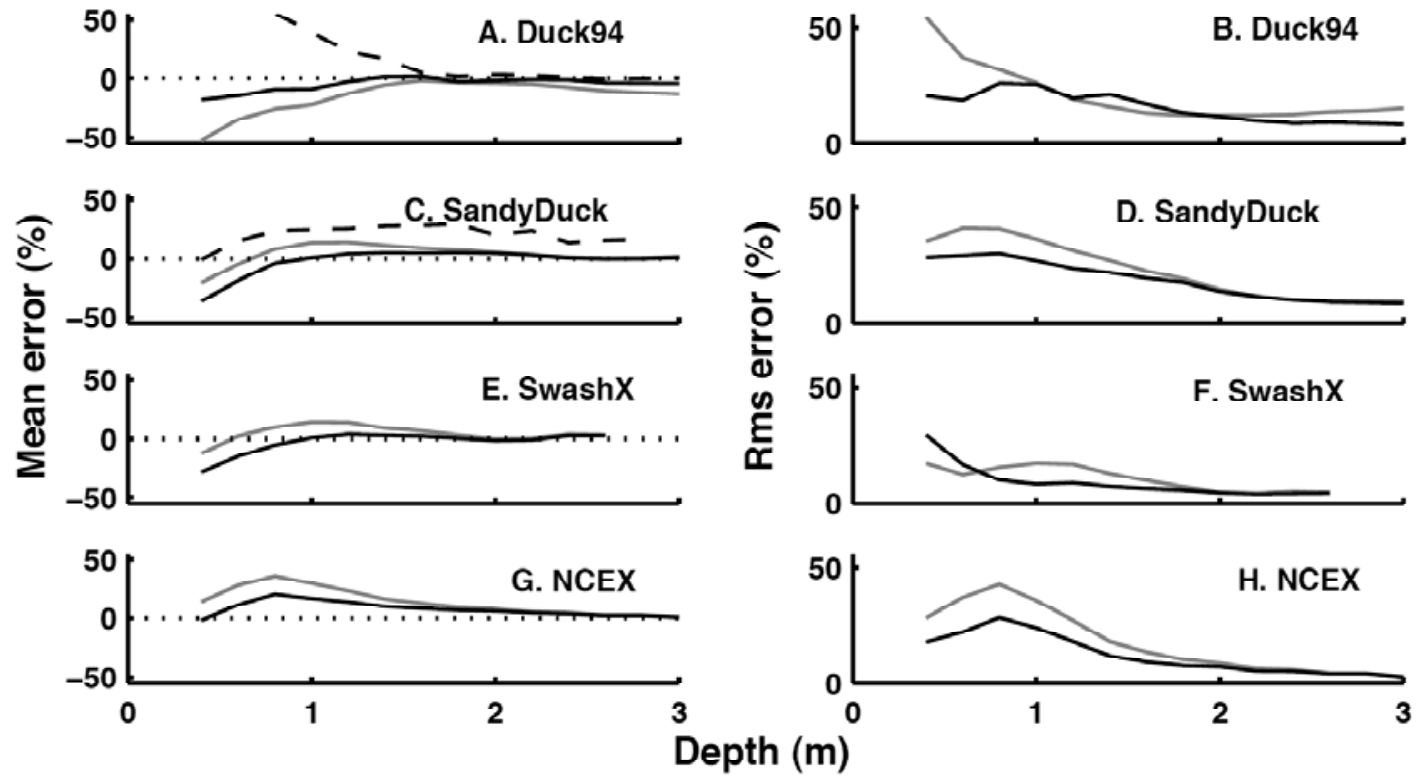

Figure 2-12: Mean (A, C, E, \& G) and rms (B, D, F, \& H) prediction errors for the TG model with $\gamma=0.42$ (default, grey curves) and $\gamma$ from the universal curve (black curves) versus water depth for Duck94 (A \& B), SandyDuck (C \& D), SwashX (E \& F), and NCEX (G \& H). Positive (negative) mean errors correspond to overprediction (underprediction). Mean errors for Duck94 and SandyDuck (A and C, respectively) were calculated for locations shoreward (dashed black curves) and seaward (solid black curves) of the sandbar trough. 
At Duck94 and SandyDuck mean errors at a given water depth are larger on the shoreward edge of the bar trough than at more offshore locations (Figure 2-12, the solid black curves have smaller mean errors than the dashed black curves for all water depths in $\mathrm{A}$ and $\mathrm{C}$ ). Thus, although the pattern of over- and underprediction (Figure 2-12A, C, E, and $\mathrm{G}$, black curves) is similar at different experiments, it is sensitive to cross-shore location on barred bathymetries. Previous studies on multi-barred bathymetries [Ruessink et al., 2003] found a similar increase in overprediction of wave heights in bar troughs.

Using universal $\gamma$ decreases both the mean and rms errors in almost all water depths (Figure 2-12, compare black with grey curves). Although using best-fit $\gamma$ further decreases the errors, no tuned, universal, or default model has the smallest mean or rms errors in all water depths for all experiments (not shown). Egmond and Terschelling were not used in this analysis because sensors rarely were located in $h<2 \mathrm{~m}$.

\subsection{Conclusions}

Several parametric models for the transformation of wave heights across the surfzone were tested and calibrated with observations collected along cross-shore transects at six experiments on barred and unbarred beaches. Models using default values for the free parameter $\gamma$ predict the cross-shore distribution of the observed wave heights with median rms errors between $10 \%$ and $20 \%$. Tuning the free parameter in each model reduces the errors by approximately 50\%, resulting in median errors between $3 \%$ and $12 \%$. Root-mean-square errors for all models are small in water depths $h>2 \mathrm{~m}$, and increase with decreasing depth for $h<2 \mathrm{~m}$. To tune the models accurately, data must span the surfzone, which may require at least three to five sensors depending on tidal and wave height ranges. No tuned or default model provides the best predictions for all data records or at all experiments.

Best-fit $\gamma$ are correlated with the deep-water wave height, $H_{o}$. Relative to using the default values of $\gamma$, estimating $\gamma$ using universal curves based on $H_{o}$ from two experiments at Duck, NC usually reduces errors for all models at five of the six 
experiments. On average errors are reduced by $4 \%$ to $30 \%$, resulting in median errors around $8 \%$ to $15 \%$. 


\subsection{References}

Baldock, T.E., P. Holmes, S. Bunker, and P. Van Weert, Cross-shore hydrodynamics within an unsaturated surf zone, Coastal Eng., 34, 173-196, 1998.

Battjes, J.A. and J.P.F.M. Janssen, Energy loss and setup due to breaking of random waves, International Conference on Coastal Engineering, ASCE, 569-587, 1978.

Battjes, J.A. and M.J.F. Stive, Calibration and verification of a dissipation model for random breaking waves, J. Geophys. Res., 90, 9159-9167, 1985.

Cacina, N., Test and evaluation of surf forecasting model, M.Sc. Thesis, Naval Postgraduate School, Monterey, CA, 41 pp., 1989.

Dally, W.R., R.G. Dean, and R.A. Dalrymple, Wave height variation across beaches of arbitrary profile, J. Geophys. Res., 90, 11917-11927, 1985.

Elgar, S., R.T. Guza, W.C. O'Reilly, B. Raubenheimer, and T.H.C. Herbers, Wave energy and direction observed near a pier, ASCE J. Waterway, Port, Coastal, and Ocean Engineering, 127, 2-6, 2001.

Janssen, T.T. and J.A. Battjes, A note on wave energy dissipation over steep beaches, Coastal Eng., Submitted, 2007.

Kennedy, A.B., Q. Chen, J.T. Kirby, and R.A. Dalrymple, Boussinesq modeling of wave transformation, breaking and runup. I: One dimension. ASCE J. Waterway, Port, Coastal, and Ocean Engineering, 126, 39-47, 2000.

LeMehaute, B., On non-saturated breakers and the wave run-up, International Conference on Coastal Engineering, ASCE, 77-92, 1962.

Lippmann, T.C., A.H. Brookins, and E.B. Thornton, Wave energy transformation on natural profiles, Coastal Eng., 27, 1-20, 1996.

Longuet-Higgins, M.S. and R.W. Stewart, Radiation stress and mass transport in gravity waves, with application to 'surf-beats,' J. Fluid Mech., 13, 481-504, 1962.

Longuet-Higgins, M.S. and R.W. Stewart, Radiation stresses in water waves: A physical discussion with applications, Deep Sea Res., 11, 529-562, 1964.

Miche, M., Le Pouvoir Reflechissant des Ouvrages Maritimes Exposes a l'Action de la Houle Annals des Ponts et Chaussess, 121e Annee, 285-319, 1951. (Translated by 
Lincoln and Chevron, University of California, Berkeley, Wave Research Laboratory, Series 3, Issue 363, June 1954.)

Murphy, A.H. and E.S. Epstein, Skill scores and correlation coefficients in model verification, Mon. Weather Rev., 117, 572-581, 1989.

Nairn, R.B., Prediction of cross-shore sediment transport and beach profile evolution, Ph.D thesis, Imperial College, London, 391 pp., 1990.

Nwogu, O., Alternative form of Boussinesq equations for nearshore wave propagation, ASCE J. Waterway, Port, Coastal, and Ocean Engineering, 119, 618-638, 1993.

Raubenheimer, B., R.T. Guza, and S. Elgar, Wave transformation across the inner surf zone, J. Geophys. Res., 101, 25589-25597, 1996.

Raubenheimer, B., R.T. Guza, and S. Elgar, Field observations of wave-driven setdown and setup, J. Geophys. Res., 106, 4629-4638, 2001.

Raubenheimer, B., Observations and predictions of fluid velocities in the surf and swash zones, J. Geophys. Res., 107, 3190, doi:10.1029/2001JC001264, 2002.

Roelvink, J.A., Dissipation in random wave groups incident on a beach, Coastal Eng., 19, 127-150, 1993.

Ruessink, B.G., K.T. Houwman, and P. Hoekstra, The systematic contribution of transporting mechanisms to the cross-shore sediment transport in water depths 3 to $9 \mathrm{~m}$, Mar. Geol., 152, 295-324, 1998.

Ruessink, B.G., J.R. Miles, F. Feddersen, R.T. Guza, and S. Elgar, Modeling the alongshore current on barred beaches, J. Geophys. Res., 106, 22451-22463, 2001.

Ruessink, B.G., D.J.R. Walstra, and H.N. Southgate, Calibration and verification of a parametric wave model on barred beaches, Coastal Eng., 48, 139-149, 2003.

Sallenger, A.H. and R.A. Holman, Wave energy saturation on a natural beach of variable slope, J. Geophys. Res., 90, 11939-11944, 1985.

Stive, M.J.F. and H.J. De Vriend, Shear stress and mean flow in shoaling and breaking waves, International Conference on Coastal Engineering, ASCE, 594-608, 1994.

Stoker, J.J., Water Waves, Interscience, New York, 1957.

Tajima, Y. and O.S. Madsen, Shoaling, breaking and broken wave characteristics, International Conference on Coastal Engineering, ASCE, 222-234, 2002. 
Tajima, Y. and O.S. Madsen, Modeling near-shore waves, surface rollers, and undertow velocity profiles, ASCE J. Waterway, Port, Coastal, and Ocean Engineering, 132, 429438, 2006.

Thomson, J., S. Elgar, T.H.C. Herbers, B. Raubenheimer, and R.T. Guza, Tidal modulation of infragravity waves via nonlinear energy losses in the surfzone, Geophysical Research Letters, 33, L05601, doi:10.1029/2005GL025514, 2006.

Thornton, E.B. and R.T. Guza, Transformation of wave height distribution, J. Geophys. Res., 88, 5925-5938, 1983.

Whitford, D.J., Wind and wave forcing of longshore currents across a barred beach, Ph.D Thesis, Naval Postgraduate School, Monterey, CA, 205 pp., 1988.

Watanabe, A., T. Hara, and K. Horikawa, Study on breaking condition for compound wave trains, Coast Eng. Japan, 27, 71-82, 1984. 


\title{
Chapter 3: Setup Sensitivity
}

Parts of this chapter were reprinted with permission from:

Apotsos, A., B. Raubenheimer, S. Elgar, R.T. Guza, and J. Smith, A Note on Setup Sensitivity

and Prediction Accuracy, Proc. of the 30th International Conference on Coastal Engineering, ASCE, 946-

958, 2006.

Copyright 2007, World Scientific Publishing Co. Pte. Ltd.

http://www.worldscibooks.com/engineering/6439.html

\begin{abstract}
The sensitivity of numerical model predictions of the cross-shore profile of wavedriven setup, the increase in the mean sea level associated with breaking waves, to the accuracy of the observational inputs and to different physical processes is explored using data from three field experiments. Accurate measurement of the cross-shore water-depth and wave-height profiles is important when predicting setup. Using different parametric wave models to estimate the cross-shore distribution of wave heights and energy used to drive the setup model can result in up to $90 \%$ changes in the predicted setup. Including bottom stress and wave rollers affects significantly setup predictions in water depths less than $1 \mathrm{~m}$.
\end{abstract}

\subsection{Introduction}

Assuming alongshore uniform waves and bathymetry and negligible wind and bottom stress, the cross-shore pressure gradient associated with the time-averaged wave setup, $\bar{\eta}$, theoretically balances the cross-shore gradient of the time- and depth-averaged cross-shore wave momentum flux (i.e., the wave radiation stress, $S_{x x}$ ) [Longuet-Higgins and Stewart, 1962, 1964]

$$
\frac{\partial}{\partial x} S_{x x}+\rho g(\bar{\eta}+d) \frac{\partial}{\partial x} \bar{\eta}=0
$$

where $x$ is the cross-shore coordinate (positive onshore), $d$ is the time-averaged still water depth, $\rho$ is the water density, and $g$ is the gravitational acceleration. The wave radiation stress can be estimated as 


$$
S_{x x}=E_{w}\left\{\left[\cos ^{2}(\theta)+1\right] \frac{c_{g}}{c}-\frac{1}{2}\right\},
$$

where $\theta$ is the mean wave direction relative to beach normal, $c_{g}$ is the group speed, and $c$ is the phase speed. The wave energy, $E_{w}$, can be estimated from linear theory as

$$
E_{w}=\frac{1}{8} \rho g H_{r m s}^{2}
$$

where $H_{r m s}$ is the root-mean-square wave height (defined as $2 \sqrt{2}$ times the standard deviation of the sea-surface elevation fluctuations).

The accuracy of the data used to drive models based on (3-1), (3-2), and (3-3) may be important when predicting setup. Here, the sensitivity of setup predictions to errors in the offshore wave height, angle, and period, the local bathymetry, tidal fluctuations, the wave theory used to estimate $E_{w}$, and the technique used to estimate the cross-shore distribution of wave heights is examined. Within this chapter, these terms, which concern the accuracy of the model inputs, are referred to as "Accuracy" terms.

The model based on (3-1) and (3-2) is a simplification of the cross-shore momentum balance. Here, the effects of wind stress, wave rollers, bottom stress, convective acceleration of the cross-shore current, directional spread of the incident waves, alongshore variations in the wave radiation stress, wave nonlinearities, infragravity wave reflection from the beach, wave skewness, and the Coriolis force on the cross-shore, surfzone setup profile are examined. Within this chapter, these terms, which represent additional physical processes not included in the simple model, are referred to as "Additional" terms.

The observations and methodology are described first (Sections 3-2 and 3-3), followed by the sensitivity analyses (Section 3-4) and conclusions (Section 3-5).

\subsection{Observations}

Wave-induced pressures and mean water levels were measured for 90 days during Sep to Nov 1997 (SandyDuck) on a barred beach near Duck, NC, and for 14 days during Sep and Oct 2000 (SwashX) and 23 days during Oct and Nov 2003 (NCEX) on near planar beaches near La Jolla, CA. The 3-hr-long (SandyDuck) and 1-hr-long (SwashX 
and NCEX) data records were subdivided into 8.5-min-long sections for processing to ensure stationarity in the presence of tidally induced depth changes. Wave heights were measured at 11 (SandyDuck) and 8 (SwashX and NCEX) cross-shore locations (Figure 31A circles and 3-1B \& C diamonds, respectively). Mean water levels (i.e., setup) were measured at 13 (SandyDuck) and 8 (SwashX and NCEX) cross-shore locations (Figure 31A-C diamonds, respectively).

Offshore root-mean-square wave heights ranged from 0.20 to $2.10 \mathrm{~m}$ (SandyDuck), 0.19 to $1.05 \mathrm{~m}$ (SwashX), and 0.20 to $1.00 \mathrm{~m}$ (NCEX). Setup ranged from -0.06 to 0.48 m (SandyDuck), -0.01 to $0.18 \mathrm{~m}$ (SwashX), and -0.01 to $0.21 \mathrm{~m}$ (NCEX). Wave angles during SandyDuck ranged between $\pm 45^{\circ}$ with respect to beach normal, whereas waves were near-normally incident (ranging from about $\pm 5^{\circ}$ ) during both SwashX and NCEX. Centroidal wave frequencies ranged from 0.09 to $0.24 \mathrm{~Hz}$ (SandyDuck), 0.09 to $0.20 \mathrm{~Hz}$ (SwashX), and 0.08 to $0.21 \mathrm{~Hz}$ (NCEX).

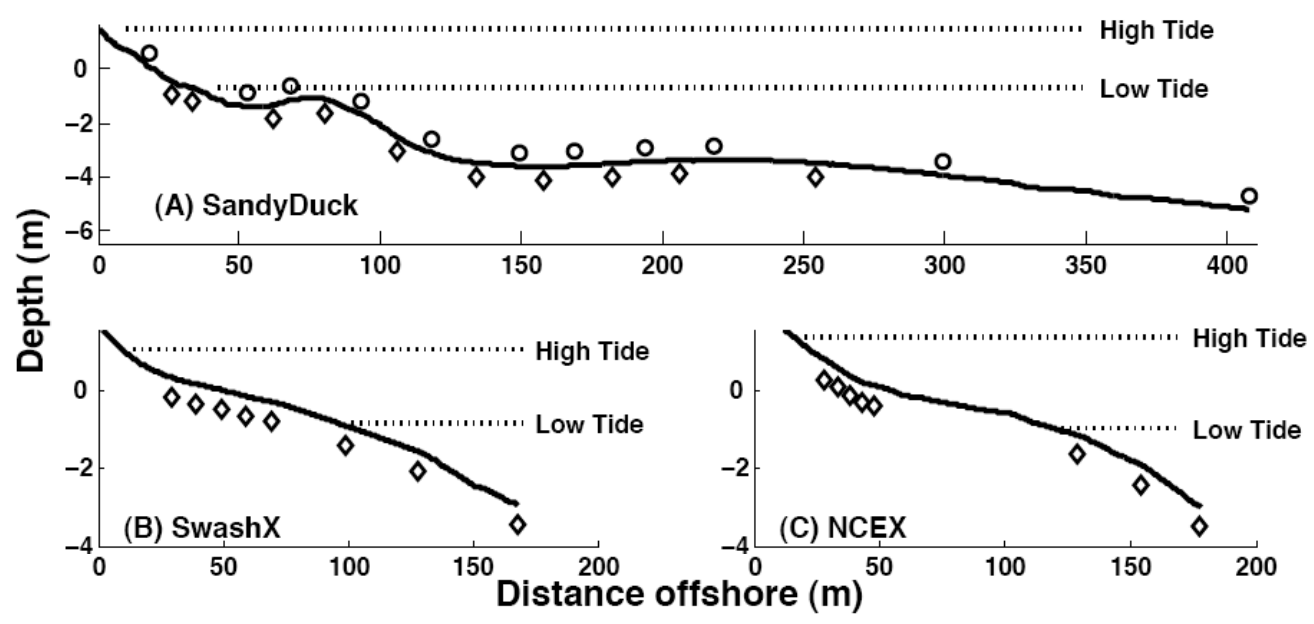

Figure 3-1: Observed bathymetry (solid curves), unburied pressure gages (circles), and buried pressure gages (diamonds) versus distance offshore for SandyDuck (A), SwashX (B), and NCEX (C).

Cross-shore bathymetric profiles were measured relative to mean sea level (MSL) approximately every other day using an amphibious vehicle (SandyDuck) or a sonar and GPS mounted on a waverunner (SwashX and NCEX). The time-varying still water levels 
are obtained by adding the mean water level above MSL owing to tidal fluctuations measured at the most offshore setup sensor to the surveyed bathymetric profiles. The tidal ranges relative to MSL were -0.67 to $1.50 \mathrm{~m}$ (SandyDuck), -0.87 to $1.04 \mathrm{~m}$ (SwashX), and -0.96 to $1.40 \mathrm{~m}(\mathrm{NCEX})$.

\subsection{Theory and Methodology}

The sensitivity of setup predictions to the Accuracy and Additional terms is examined with respect to predictions of a model based on (3-1), (3-2), and (3-3) and driven with the measured offshore wave conditions and the tidally adjusted bathymetric profiles. In this "base" model, the cross-shore distribution of $H_{r m s}$ is estimated with the parametric wave model developed by Thornton and Guza [1983] using fixed constants of $B=1$ and $\gamma=0.42$. Snell's Law is used to refract the input offshore wave angle into shallow water for all models. Each Accuracy or Additional term is varied or added to the base model one at a time.

\subsubsection{Accuracy Terms}

The sensitivity of setup predictions based on (3-1), (3-2), and (3-3) to errors in the offshore wave conditions is estimated by varying the input offshore wave height by $\pm 20 \%$, angle by $\pm 10^{\circ}$, and period by $\pm 2 \mathrm{~s}$, as well as by using constant offshore wave angles $\left(0\right.$ to $\left.45^{\circ}\right)$, the experiment-averaged wave angle, and the experiment-averaged wave period for all data records. The sensitivity of the predictions to errors in the bathymetric profile is examined by comparing predictions based on the bathymetry measured nearest in time to the data record with predictions based on a single, randomly selected profile measured during an experiment and to an artificially planar profile. At all three experiments, five different profiles are selected and used for all data records to estimate the effects on setup predictions of morphological change during the experiment. To obtain planar profiles, a constant linear slope is fit from the shoreline to the most offshore measured depth (SwashX and NCEX) or to the local depth maximum in the most offshore bar trough (SandyDuck, e.g., $x=140 \mathrm{~m}$ in Figure 3-1A). Additionally, the sensitivity to the depth profile is examined by comparing predictions based on the tidally 
adjusted profiles with predictions for tidal levels $\pm 0.20 \mathrm{~m}$, for a tidal level of zero, and for a linear model in which the contribution of setup to the water depth is ignored [e.g., (3-1) is linearized by assuming that $\bar{\eta}<<d$.

The sensitivity to errors in the cross-shore distribution of $H_{r m s}$ is examined by comparing setup predictions based on the cross-shore distribution of wave heights estimated with a wave model [Thornton and Guza, 1983] with predictions based on fitting a cubic spline to the measured cross-shore distribution of wave heights, and with predictions based on 7 different parametric wave models [Battjes and Janssen, 1978; Battjes and Stive, 1985; Whitford, 1988; Nairn, 1990; Lippmann et al., 1996; Baldock et al., 1998; Ruessink et al., 2003]. The effect of using linear theory to determine $E_{w}$ [i.e., (3-3)] is examined by estimating $E_{w}$ from a weakly nonlinear cnodial theory.

\subsubsection{Additional Terms}

The momentum balance equation (3-1) can be extended to include bottom stress $\tau_{B}$, wind stress $\tau_{w}$, the effects of the Coriolis force, the convective acceleration of the time and depth-averaged cross-shore current $U_{r}$, and alongshore gradients of the alongshore radiation stress $S_{x y}$ such that

$$
\frac{\partial}{\partial x} S_{x x}+\rho g(\bar{\eta}+d) \frac{\partial}{\partial x} \bar{\eta}+\tau_{B}-\tau_{w}+f v \rho(\bar{\eta}+d)-\frac{\partial \rho U_{r}^{2}(\bar{\eta}+d)}{\partial x}+\frac{\partial S_{x y}}{\partial y}=0 .
$$

Bottom stress is estimated following Apotsos et al. [2007] (see Chapter 4). Wind stress is found as

$$
\tau_{w}=\rho_{a} C_{10}\left|V_{w}\right| V_{w},
$$

where $\rho_{\mathrm{a}}$ is the density of air, $V_{w}$ is the wind speed in $\mathrm{m} / \mathrm{s}$ measured approximately $10 \mathrm{~m}$ above the water surface, and $\mathrm{C}_{10}$ is given by $[\mathrm{Wu}, 1980]$

$$
C_{10}=\left(0.8+0.065 V_{w}\right) 10^{-3} \text {. }
$$

While (3-6) is not dimensionally consistent, it is a useful parameterization based on observations. The Coriolis term is found from the latitude dependant Coriolis parameter, 
$f$, and the time- and depth-averaged alongshore current estimated from measurements, $v$. The time- and depth-averaged cross-shore current, $U_{r}$, is estimated as

$$
U_{r}=\frac{M_{w}}{\rho d}
$$

where the mass flux of the wave $M_{w}=E_{w} / c$. The alongshore radiation stress is estimated as

$$
S_{x y}=E_{w} \cos (\theta) \frac{c_{g}}{c} \sin (\theta) .
$$

To estimate the alongshore gradient of the radiation stress, the wave model [Thornton and Guza, 1983] and Snell's Law were used to calculate $E_{w}$ and $\theta$ along crossshore profiles measured roughly $\pm 20 \mathrm{~m}$ alongshore of the instrument transect.

The wave radiation stress equation (3-2) can be extended to account for a wave skewness parameter $C_{s}$, the directional spread of the incoming waves $\sigma_{\theta}$ [Feddersen, 2004], and wave roller energy $E_{r}$ such that

$$
\left.S_{x x}=\left\lfloor E_{w}\left\{\left[\cos ^{2}(\theta)+1\right] \frac{c_{g}}{c}-\frac{1}{2}+C_{s}\right\}+2 E_{r}\left(\cos ^{2} \theta\right)\right\rfloor 1-\frac{2}{3} \sigma_{\theta}^{2}\right) .
$$

The wave skewness parameter is given by [Johnson and Kobayashi, 1998]

$$
C_{s}=\frac{\sigma}{d} s-\left(\frac{\sigma}{d}\right)^{2}
$$

where $\sigma$ is the standard deviation of the sea surface elevation and $s$ is the wave skewness. The directional spread of the incoming waves is estimated both using Snell's Law to refract the observed offshore directionally spread waves into shallow water, and by fitting a cubic spline to the observed cross-shore distribution of directional spreads, which may increase in the surfzone [Hendersen et al., 2006]. The wave roller energy is estimated using four different formulations for $E_{r}$ [Lippmann et al., 1996; Ruessink et al., 2001; Tajima and Madsen, 2003; Smith, unpublished].

Using the linear theory approximation of equipartition of energy [e.g., (3-3)] may underestimate the wave energy $E_{w}$ by as much as $50 \%$ in 0.30 m water depth [Raubenheimer et al., 2004]. Consequently, wave nonlinearities in shallow water are 
examined by multiplying $E_{w}$ calculated with (3-3) by a factor that increases linearly from 1.0 (in $1.30 \mathrm{~m}$ water depth) to 1.5 (in $0.30 \mathrm{~m}$ water depth).

The effect of infragravity wave reflection is examined by assuming that [LonguetHiggins and Stewart, 1964]

$$
\bar{\eta}_{r}=\int_{f}\left[2 A^{2}(f) k(f) \operatorname{coth} 2 k(f) h \cos 2 k(f) x\right],
$$

where $A^{2}(f)$ is determined from the spectral amplitude of the reflected wave estimated from observations and $k(f)$, the frequency dependent wave number, is estimated from the linear dispersion relation. It is assumed that $\bar{\eta}_{r}$ can be linearly superimposed on $\bar{\eta}$.

\subsubsection{Methodology}

Setup in deep water $(h=\bar{\eta}+d>1.0 \mathrm{~m})$ can be smaller than the measurement error, and the shoreline setup $(h=0.1 \mathrm{~m})$ is sensitive to small changes in the local bathymetry. Thus, the focus here is on setup in shallow $(0.1$ to $0.5 \mathrm{~m})$ and mid-depth $(0.5$ to $1.0 \mathrm{~m})$ water.

The models were run for all data records, and each term was evaluated using four separate indicators: biases, $50 \%$ spreads, best fit linear slopes, and squared correlation coefficients $\left(r^{2}\right)$. Biases and spreads are found from a histogram of the percent differences between the base and modified models for all data records at each experiment (Figure 32). The bias is defined as the median of the percent differences (e.g., $50 \%$ of the records have a smaller (or larger) percent difference). The 50\% spread is defined as the difference between the values for which $25 \%$ and $75 \%$ of the records have smaller differences. Best-fit linear slopes and squared correlations are calculated between the predictions for each term and the predictions of the base model. Slopes less than 1 and negative biases signify underprediction. 


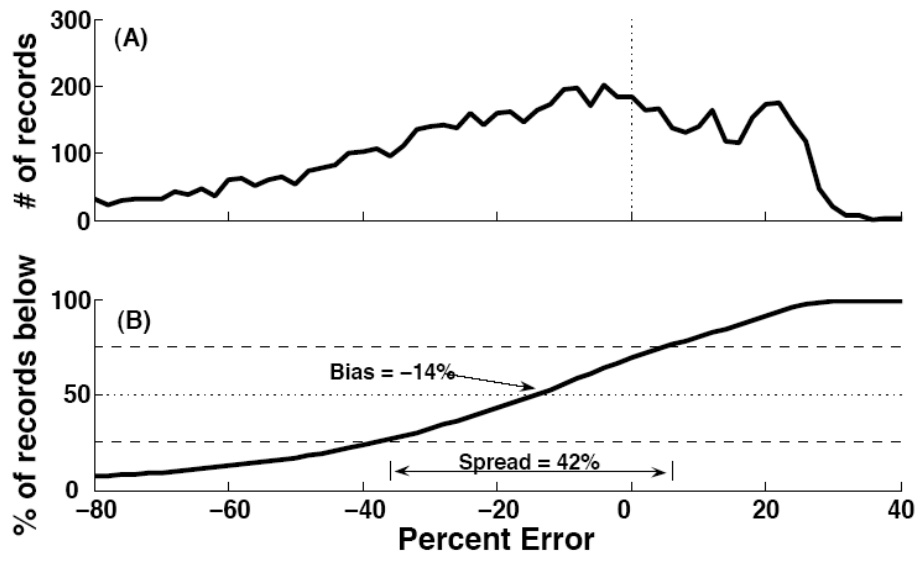

Figure 3-2: (A) Histogram of the differences between the base model and the model modified by adding a roller following Ruessink et al., [2001], and (B) the cumulative sum of the histogram with the bias (dotted line) and the limits of the spread (dashed lines). The dotted line in $(A)$ indicates a bias of 0 .

\subsection{Results}

\subsubsection{Accuracy Terms}

\subsubsection{Summary}

For the ranges of parameters considered here, variations in the wave height and water depth have the largest effect on the setup predictions, whereas variations in the offshore wave period and angle, and the theory used to estimate $E_{w}$ are of secondary importance (Table 3-1). Inclusion of $\bar{\eta}$ in the calculation of the local water depth has a negligible effect on the setup predictions.

\subsubsection{Primary Terms}

Percent changes in the offshore wave height result in roughly equal percent changes in shallow water setup (i.e., a $20 \%$ increase in $H_{r m s, o}$ results in approximately a $20 \%$ increase in shallow water setup) at all three experiments (Table 3-1). The change in setup owing to increasing or decreasing the offshore wave height typically occurs in $h>1$ $\mathrm{m}$, thus larger percent changes in setup occur in mid (and deep) water depths because the absolute setup decreases (e.g., the denominator decreases). Using different parametric 
wave models or a cubic spline of the observed wave heights results in biases as large as $30 \%$, and spreads up to $90 \%$ for both shallow and mid-depth water (Table 3-1).

Table 3-1: Ranges of biases and spreads in shallow and mid-depth water for the primary and secondary Accuracy Terms.

\begin{tabular}{|c|c|c|c|c|}
\hline \multirow{2}{*}{ Accuracy Term } & \multicolumn{2}{|c|}{ Shallow $(0.1$ to $0.5 \mathrm{~m})$} & \multicolumn{2}{c|}{ Mid-depth $(0.5$ to $1.0 \mathrm{~m})$} \\
\cline { 2 - 5 } & Bias & Spread & Bias & Spread \\
\hline Offshore Wave Height $\pm 20 \%$ & $-20 \%$ to $26 \%$ & 6 to $12 \%$ & $-48 \%$ to $50 \%$ & $34 \%$ to $50 \%$ \\
\hline Wave Model & $-12 \%$ to $36 \%$ & $8 \%$ to $90 \%$ & $-18 \%$ to $26 \%$ & $4 \%$ to $92 \%$ \\
\hline Linear Profile & $-64 \%$ to $-12 \%$ & $40 \%$ to $54 \%$ & $-68 \%$ to $-46 \%$ & $64 \%$ to $86 \%$ \\
\hline Single Profile & -38 to $0 \%$ & $10 \%$ to $64 \%$ & $-38 \%$ to $18 \%$ & $28 \%$ to $94 \%$ \\
\hline Tide $\pm 0.2 \mathrm{~m}$ & -34 to $44 \%$ & 6 to $50 \%$ & $-44 \%$ to $54 \%$ & $22 \%$ to $72 \%$ \\
\hline No Tidal Fluctuations & $-34 \%$ to $-18 \%$ & $60 \%$ to $72 \%$ & $-14 \%$ to $44 \%$ & $72 \%$ to $120 \%$ \\
\hline Offshore Wave Angle $=45^{\circ}$ & $-30 \%$ to $-24 \%$ & $6 \%$ to $8 \%$ & $-34 \%$ to $42 \%$ & $8 \%$ to $20 \%$ \\
\hline Offshore Peak Period $\pm 2 \mathrm{~s}$ & $-14 \%$ to $8 \%$ & $2 \%$ to $12 \%$ & $-16 \%$ to $8 \%$ & $6 \%$ to $18 \%$ \\
\hline Cnodial Theory & $-24 \%$ to $-20 \%$ & $10 \%$ to $22 \%$ & $0 \%$ to $2 \%$ & $30 \%$ to $46 \%$ \\
\hline
\end{tabular}

Changes in the local water depth can affect setup predictions significantly. On average, using a linear profile reduces the predicted setup in shallow (mid-depth) water by $64 \%(54 \%), 24 \%(46 \%)$, and 12\% (68\%) at SandyDuck, SwashX, and NCEX, respectively (Table 3-1). However, limiting the data records from NCEX to high tides during which the surfzone bathymetry is concave results in a positive bias in shallow and mid-depth setup (Figure 3-3), suggesting the negative biases calculated using all data records are owing to the surfzone beach profiles being typically convex (e.g., Figure 31A-C).

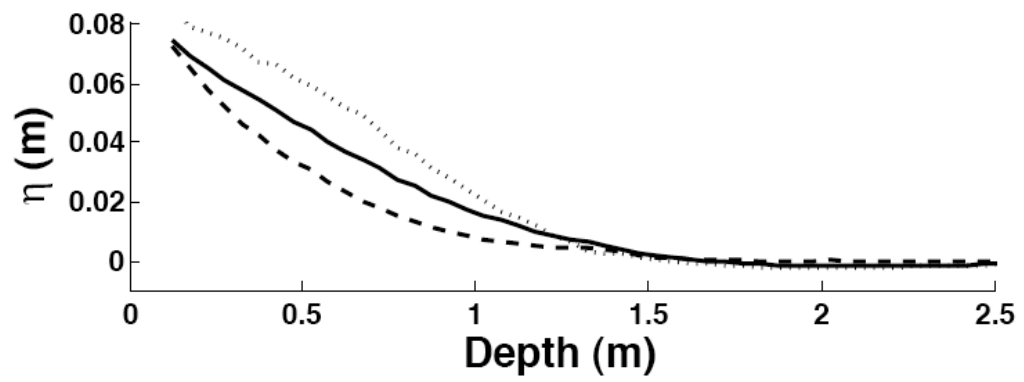

Figure 3-3: Average predicted setup at NCEX for all data records and the most recent bathymetry (solid curve), and the average setup predicted approximating the profile as planar for data records when the measured surfzone beach profile was concave (dotted curve) or convex (dashed curve) vs. water depth. 
Using a single bathymetric profile for the duration of the experiment can result in a positive, negative, or near zero bias depending on the profile used. At all three experiments, the calculated spread for predictions based on a single profile can be large (Table 3-1), indicating that the accuracy of setup predictions depends partially on the accuracy of the cross-shore depth profile. Thus, accurate and possibly repeated measurement of the beach profile is important for predicting setup, especially during times of significant morphological change.

For the ranges considered here, model predictions are most sensitive (largest spreads and smallest $r^{2}$ values, Table 3-1) to accurate estimates of the tidal fluctuations. Varying the tidal level by $\pm 0.2 \mathrm{~m}$ causes approximately a $\pm 40 \%$ bias in the predicted setup in both shallow and mid-depth water (Table 3-1). As the tide increases (decreases), the predicted setup decreases (increases) at a given cross-shore location because the water depth is larger (smaller). Neglecting the tidal fluctuations results in negative bias (-34 to $18 \%$ ) in shallow water for all three experiments, possibly owing to the positively skewed tidal ranges.

\subsubsection{Secondary Terms}

Using an experiment-averaged offshore wave angle or period, varying the measured offshore wave angle by $\pm 10^{\circ}$, or using an offshore wave angle $<20^{\circ}$ for all data records results in less than a $5 \%$ bias and small spreads $(<15 \%)$ at all three experiments. However, using an offshore wave angle $>25^{\circ}$ for all data records causes increasingly negative biases up to about $-30 \%$ for $\theta=45^{\circ}$ (Table $3-1$ ).

Varying the wave period by $\pm 2 \mathrm{~s}$ results in small biases $(<16 \%)$ and small spreads $(<$ 20\%) (Table 3-1). As the period increases (decreases) the predicted setup increases (decreases) owing partly to changes in the cross-shore distribution of $E_{w}$ estimated from the wave models and partly to changes in the calculation of $c$ and $c_{g}$ in (3-2).

Using cnodial theory instead of linear theory to estimate $E_{w}$ in (3-2) results in a maximum bias of $-24 \%$ in shallow water (Table 3-1), and has a larger effect for larger waves. However, it is unclear if a nonlinear wave theory should be used in conjunction 
with (3-2), which is based on linear theory, or if a relationship between linear and nonlinear waves should be developed [e.g., Tajima and Madsen, 2003].

\subsubsection{Negligible Terms}

The bias owing to neglecting the contribution of $\bar{\eta}$ to the water depth is less than $6 \%$, and is reduced to almost $0 \%$ by using $\bar{\eta}$ calculated at the previous cross-shore step. However, it is likely that for waves larger than those observed during these three experiments (i.e., for $H_{r m s, o}>2 \mathrm{~m}$ ), $\bar{\eta}$ will become more important to the local water depth for $h<1 \mathrm{~m}$.

\subsubsection{Additional Terms}

\subsubsection{Summary}

Including bottom stress and wave rollers in the model significantly affects setup predictions, whereas infragravity wave reflection and wave nonlinearities may be of secondary importance (Table 3-2). The effects of the Coriolis force, wind stress, convective acceleration of the cross-shore current, wave directional spread, alongshore variations in the wave radiation stress, and wave skewness are negligible for the three experiments considered.

Table 3-2: Ranges of biases and spreads in shallow and mid-depth water for the primary and secondary Additional Terms.

\begin{tabular}{|c|c|c|c|c|}
\hline \multirow{2}{*}{ Additional Term } & \multicolumn{2}{|c|}{ Shallow $(0.1$ to $0.5 \mathrm{~m})$} & \multicolumn{2}{c|}{ Mid-depth $(0.5$ to $1.0 \mathrm{~m})$} \\
\cline { 2 - 5 } & Bias & Spread & Bias & Spread \\
\hline Bottom Stress & $64 \%$ to $68 \%$ & $8 \%$ to $16 \%$ & $72 \%$ to $82 \%$ & $20 \%$ to $38 \%$ \\
\hline Wave Rollers & $-38 \%$ to $28 \%$ & $4 \%$ to $74 \%$ & $-56 \%$ to $10 \%$ & $10 \%$ to $110 \%$ \\
\hline Wave Reflection & $8 \%$ to $24 \%$ & $6 \%$ to $18 \%$ & $8 \%$ to $16 \%$ & $8 \%$ to $20 \%$ \\
\hline Wave Nonlinearities & $-2 \%$ to $6 \%$ & $8 \%$ to $12 \%$ & $-14 \%$ to $-8 \%$ & $16 \%$ to $32 \%$ \\
\hline
\end{tabular}

\subsubsection{Primary Terms}

Including bottom stress results in a positive bias of about $65 \%$ in shallow water and $77 \%$ in mid-depth water at all three experiments (Table 3-2). Small spreads and $r^{2}$ values close to 1 indicate a consistent bias with little scatter over a wide range of incident wave and bathymetric conditions. 
Addition of a roller can cause significant negative or positive biases, along with spreads up to about $100 \%$ (Table 3-2), depending on the water depth and formulation used. Rollers have a bigger effect when offshore waves are large. Furthermore, the effects of rollers depend on the surfzone bathymetry. For example, although all roller formulations decrease setup in mid-depth water and increase setup in shallow water on the near-planar SwashX and NCEX profiles, predicted setup can increase or decrease on the nonplanar profiles observed during SandyDuck depending on the roller formulation used, presumably owing to the barred bathymetry.

\subsubsection{Secondary Terms}

Including either infragravity wave reflection or wave nonlinearities in the model can cause a 10-25\% bias in shallow and mid-depth water (Table 3-2). The increase in setup owing to reflection was larger at SandyDuck (24\%) than at SwashX and NCEX (10\%), possibly owing to the steeper foreshore at SandyDuck. However, the corrections used here for infragravity wave reflection (which neglects the sloping bed) and lineartheory underprediction of $E_{w}$ (which is based empirically on limited observations) are crude, and these terms may be more important than estimated.

\subsubsection{Negligible Terms}

Including the Coriolis term, wind stress, convective acceleration of the cross-shore current, wave directional spreads, alongshore variations in the wave radiation stress, and wave skewness results in biases smaller than 5\%. Furthermore, including a wind stress based on $15 \mathrm{~m} / \mathrm{s}$ winds throughout the experiments results in biases smaller than $10 \%$.

\subsection{Conclusions}

Accurate measurement of the cross-shore water-depth and wave-height profiles is important when predicting setup. Tidal water-level fluctuations can affect setup significantly, and accurate measurement of the nearshore bathymetry is particularly important on barred beaches. Including bottom stress and wave rollers is important for predicting the setup. Infragravity wave reflection may have a smaller, yet important, effect on setup in shallow water, especially on a beach with a steep foreshore. 


\subsection{References}

Apotsos, A., B. Raubenheimer, S. Elgar, R.T. Guza, and J.A. Smith, Effects of wave rollers and bottom stress on wave setup, J. Geophys. Res., 112, C02003, doi:10.1029/2006JC003549, 2007.

Baldock, T.E., P. Holmes, S. Bunker, and P. Van Weert, Cross-shore hydrodynamics within an unsaturated surf zone, Coastal Eng., 34, 173-196, 1998.

Battjes, J.A. and J.P.F.M. Janssen, Energy loss and set-up due to breaking of random waves, Proceedings of the 14th International Conference on Coastal Engineering, ACSE, 466-480, 1978.

Battjes, J.A. and M.J.F. Stive, Calibration and verification of a dissipation model for random breaking waves, J. Geophys. Res., 90, 9159-9167, 1985.

Feddersen, F., Effect of wave directional spread on the radiation stress: Comparing theory and observations, Coastal Eng., 51, 473-481, 2004.

Hendersen, S.M., R.T. Guza, S. Elgar, and T.H.C. Herbers, Refraction of surface gravity waves by shear waves, J. Phys. Oceanogr., 36, 629-635, 2006.

Johnson, B.D. and N. Kobayashi, Nonlinear time-averaged model in surf and swash zones, Proceedings of the 26th International Conference on Coastal Engineering, ACSE, 2785-2798, 1998.

Lippmann, T.C., A.H. Brookins, and E.B. Thornton, Wave energy transformation on natural profiles, Coastal Eng., 27, 1-20, 1996.

Longuet-Higgins, M.S. and R.W. Stewart, Radiation stress and mass transport in gravity waves, with application to 'surf-beats,' J. Fluid Mech., 13, 481-504, 1962.

Longuet-Higgins, M.S. and R.W. Stewart, Radiation stresses in water waves: A physical discussion with application, Deep Sea Res., 11, 529-562, 1964.

Nairn, R.B., Prediction of cross-shore sediment transport and beach profile evolution. PhD Thesis, Imperial College, 1990.

Raubenheimer, B., S. Elgar, and R.T. Guza, Observations of swash zone velocities: A note on friction coefficients, J. Geophys. Res. 109, C01027, doi:10.1029/2003JC001877, 2004. 
Ruessink, B.G., J.R. Miles, F. Feddersen, R.T. Guza, and S. Elgar, Modeling the alongshore current on barred beaches, J. Geophys. Res., 106, 22451-22463, 2001.

Ruessink, B.G., D.J.R. Walstra, and H.N. Southgate, Calibration and verification of a parametric wave model on barred beaches, Coastal Eng., 48, 139-149, 2003.

Tajima, Y. and O.S. Madsen, Modeling near-shore waves and surface rollers, Proceedings of the 2nd International Conference on Asian and Pacific Coasts, ISBN 981-238-588-4, 2003.

Thornton, E.B. and R.T. Guza, Transformation of wave height distribution, J. Geophys. Res., 88, 5925-5938, 1983.

Whitford, D.J., Wind and wave forcing of longshore currents across a barred beach, Ph.D Thesis, Naval Postgraduate School, Monterey, 1988.

Wu, J., Wind-stress coefficients over sea surface near neutral conditions - A revisit, $J$. Phys. Oceanogr., 10, 727-740, 1980. 


\title{
Chapter 4: A Comparison of Setup Predictions and Observations
}

Parts of this chapter were reprinted with permission from:

Apotsos, A., B. Raubenheimer, S. Elgar, R. T. Guza, and J. A. Smith, Effects of wave

rollers and bottom stress on wave setup, J. Geophys. Res., 112, C02003,

doi:10.1029/2006JC003549, 2007.

Copyright 2007, American Geophysical Union.

and

Apotsos, A., B. Raubenheimer, S. Elgar, R.T. Guza, and J. Smith, A Note on Setup Sensitivity

and Prediction Accuracy, Proc. of the 30th International Conference on Coastal Engineering, ASCE, 946-

958, 2006.

Copyright 2007, World Scientific Publishing Co. Pte. Ltd.

http://www.worldscibooks.com/engineering/6439.html

\begin{abstract}
Setup, the increase in the mean water level associated with breaking waves, observed between the shoreline and about 6-m water depth on an ocean beach is predicted well by a model that includes the effects of wave rollers and the bottom stress owing to the mean flow. Over the 90-day observational period, the measured and modeled setup are correlated (squared correlation above 0.59 ), and agree within about $30 \%$. Although rollers may affect setup significantly on beaches with large amplitude (several meters high) sandbars and may be important in predicting the details of the cross-shore profile of setup, for the data discussed here, rollers have only a small effect on the amount of setup. Conversely, bottom stress (calculated using eddy viscosity and undertow formulations based on the surface dissipation, and assuming that the eddy viscosity is uniform throughout the water column) significantly affects setup predictions. Neglecting bottom stress results in underprediction of the observed setup in all water depths, with maximum underprediction near the shoreline where the observed setup is largest.
\end{abstract}

\subsection{Introduction}

Assuming alongshore uniform waves and bathymetry and negligible wind stress, the cross-shore pressure gradient associated with the time-averaged wave setup $\bar{\eta}$ 
theoretically balances the cross-shore gradient of the time- and depth-averaged crossshore momentum flux owing to waves (the wave radiation stress, $S_{x x}$ ) and rollers $R_{x x}$, and the bottom stress, $\tau_{b}$ [Longuet-Higgins and Stewart, 1962, 1964; Stive and Wind, 1982]

$$
\frac{\partial}{\partial x} S_{x x}+\frac{\partial}{\partial x} R_{x x}+\rho g(\bar{\eta}+d) \frac{\partial}{\partial x} \bar{\eta}+\tau_{b}=0
$$

where $x$ is the cross-shore coordinate (positive onshore), $d$ is the time-averaged still water depth, $\rho$ is the water density, and $g$ is the gravitational acceleration. The wave and roller momentum fluxes are

$$
S_{x x}=E_{w}\left\{\left[\cos ^{2}(\theta)+1\right] \frac{c_{g}}{c}-\frac{1}{2}\right\},
$$

and

$$
R_{x x}=2 E_{r}\left[\cos ^{2}(\theta)\right]
$$

respectively, where $\theta$ is the mean wave direction (relative to beach normal), $c_{g}$ is the group speed, $c$ is the phase speed, $E_{r}$ is the wave roller energy, and $E_{w}$ is the wave energy estimated from linear theory as $E_{w}=1 / 8\left(\rho g H_{r m s}^{2}\right)$, where $H_{r m s}$ is the root-mean-square wave height (defined as $2 \sqrt{2}$ times the standard deviation of the sea-surface elevation fluctuations)

Field studies of alongshore currents [Ruessink et al., 2001] and laboratory studies of undertow and setup [Svendsen, 1984a \& b; Dally and Brown, 1995] suggest that although linear models of the momentum flux based solely on the waves (i.e., $S_{x x}$ ) are robust outside the surfzone, nonlinearities in the wave forcing associated with the wave rollers (passive regions of circulating water carried onshore by breaking waves) may be important to breaking wave-driven setup [Reniers and Battjes, 1997]. Rollers cause a lag between the dissipation of wave energy and the transfer of momentum to the water column, and thus an onshore shift in the location of the maximum wave forcing [Svendsen, 1984a].

In the absence of breaking waves, an onshore-directed streaming flow in the viscous bottom boundary layer [Phillips, 1966] results in an offshore-directed bottom 
stress [Longuet-Higgins, 2005; Dean and Bender, 2006]. However, breaking waves in the surfzone drive an offshore-directed current (undertow) that dominates the onshore streaming [Haines and Sallenger, 1994; Reniers et al., 2004] resulting in an onshoredirected bottom stress that increases setup in shallow water.

Laboratory studies suggest that the mean cross-shore momentum balance (4-1) is dominated by radiation stress, roller momentum flux, and setup gradients, with negligible contributions from bottom stress [Bowen et al., 1968; Stive and Wind, 1982; Dally and Brown, 1995]. However, bottom stresses and the corresponding forcing of setup may be relatively more important in the field than in the laboratory owing to bedforms, suspended sediments, and alongshore flows.

Field observations in water depths greater than a few meters agree with (4-1) when $\tau_{b}=0$ [Battjes and Stive, 1985; Lentz and Raubenheimer, 1999], but setup is underpredicted near and at the shoreline [Guza and Thornton, 1981; Raubenheimer et al., 2001]. Here, comparisons of (4-1) through (4-3) with field observations are used to investigate the importance of rollers and bottom stress to setup on a natural beach.

Here, a new setup model that includes wave rollers (previously only examined in the laboratory with regards to setup) and bottom stress (calculated with an explicit form of the eddy viscosity instead of based on a quadratic drag coefficient) is examined on three natural alongshore-homogeneous beaches. After roller and bottom stress formulations are discussed (section 4.2), the observations are described (section 4.3), and compared with model predictions (section 4.4). The results, including the validity of the bottom stress formulation, model applicability at two other field sites, and other processes that may be important to the setup balance, are discussed (section 4.5), and conclusions are presented (section 4.6).

\subsection{Theory}

The wave roller energy $E_{r}$ is estimated as [Svendsen, 1984a \& b; Reniers and Battjes, 1997] 


$$
\frac{\partial}{\partial x}\left(2 E_{r} \cos (\theta) c\right)=-\frac{2 g E_{r} \sin (\beta)}{c}+D_{b r},
$$

in which $\beta$, the front slope of the wave, is approximated as a constant of 0.1 , and the wave dissipation $D_{b r}$ is

$$
D_{b r}=-\frac{\partial}{\partial x}\left(E_{w} c_{g} \cos (\theta)\right)
$$

To evaluate effects of alternative roller formulations, three additional models with different forms for $E_{r}$ (i.e., 4-4) [Lippmann et al., 1996; Smith, unpublished] and different values of $\beta$ [Tajima and Madsen, 2003] were tested. Average setup predictions differ by less than $10 \%$ among the four models.

The bottom stress, $\tau_{b}$, is estimated from an eddy viscosity formulation as

$$
\tau_{b}=\left.\rho v_{e} \frac{\partial U}{\partial z}\right|_{z=-d}
$$

where $U$ is the mean depth-dependent cross-shore flow averaged over many surface wave periods, and $z$ is the vertical coordinate with $z=-d$ at the bed. The depth- and timeindependent eddy viscosity, $v_{e}$, is estimated as [Reniers and Battjes, 1997]

$$
v_{e}=\left(\frac{H_{r m s}}{14}\right)\left(\frac{c \tau_{s}}{\rho}\right)^{\frac{1}{3}}
$$

where the constant of 1/14 is based on deep-water wave dissipation [Terray et al., 1996] and observations of Langmuir circulation [Smith, 1998]. The results are not sensitive to the eddy viscosity formulation provided that $v_{e}$ is similar to values found in prior field studies (see section 4.5.2.2). Furthermore, model tuning demonstrates that the constant of $1 / 14$ in (4-7) produces the best agreement between model predictions and the observations (see section 4.5.5).

The surface shear stress, $\tau_{s}$, assumed to be owing to breaking-wave-induced dissipation, is [Deigaard, 1993]

$$
\tau_{s}=-\frac{1}{c}\left\{\frac{\partial}{\partial x}\left[E_{w} c_{g} \cos (\theta)\right]+2 \frac{\partial}{\partial x}\left[E_{r} c \cos (\theta)\right]\right\} .
$$

The undertow is driven by a local (in the vertical) imbalance between the wave and roller forcing and the pressure gradient. Using the time-averaged momentum 
equation for steady, two-dimensional flow, and further assuming the Reynolds stresses that result from this local imbalance can be modeled using the eddy viscosity concept, and that the eddy viscosity and the local imbalance are independent of depth results in a quadratic vertical variation of the mean flow, such that the undertow can be found from [Stive and Wind, 1986; Garcez-Faria et al., 2000]

$$
\frac{\partial^{2} U}{\partial(z+d)^{2}}=a(x)
$$

where $a(x)$ is determined from a boundary condition or specified as a forcing term. Note that (4-9) and (4-1) are both based on the cross-shore momentum balance, but that (4-1) was integrated with respect both to time and depth, where as (4-9) was integrated only with respect to time. Integrating (4-9) twice over the water column using a no-slip bottom boundary condition, a surface stress upper boundary condition

$$
\tau_{s}=\left.\rho v_{e} \frac{\partial U}{\partial z}\right|_{z=\eta}
$$

and conservation of mass

$$
-\left(M_{w}+M_{r}\right)=\int_{-d}^{\eta} \rho U d z,
$$

where $M_{w}=E_{w} / c$ is the mass flux of the wave, and $M_{r}=2 E_{r} / c$ is the mass flux of the roller, yields

$$
U(z)=a(x)(z+d)^{2}+b(x)(z+d)
$$

with

$$
a(x)=\frac{3}{2 h \rho}\left(\frac{\tau_{s}}{2 v_{e}}+\frac{M_{w}+M_{r}}{h^{2}}\right),
$$

and

$$
b(x)=-\frac{1}{\rho}\left(\frac{\tau_{s}}{2 v_{e}}+\frac{3\left(M_{w}+M_{r}\right)}{h^{2}}\right),
$$

where $h$ is the total water depth $(h=d+\bar{\eta})$.

Using (4-6) and (4-12) - (4-14), the bottom shear stress is 


$$
\tau_{b}=\left.\rho v_{e} \frac{\partial U}{\partial z}\right|_{z=-d}=-\left[\frac{1}{2} \tau_{s}+\frac{3 v_{e}\left(M_{w}+M_{r}\right)}{h^{2}}\right] .
$$

\subsection{Observations}

Wave-induced pressures and velocities were measured at $2 \mathrm{~Hz}$ for $10752 \mathrm{~s}(179.2$ min) starting every 3 hours using pressure gages and near-bed current meters colocated at 11 cross-shore locations between the shoreline and about 6-m water depth for 90 days during Sep to Nov 1997 (SandyDuck experiment) on a barred beach near Duck, NC (Figure 4-1a). Mean water levels (i.e., setup) were measured at 10 cross-shore locations using pressure gages that were buried to reduce flow noise [Raubenheimer et al., 2001, which includes additional description of the setup observations]. The 3-hr-long data records were subdivided into 8.5-min-long sections for processing to ensure stationarity in the presence of tidally induced depth changes. The bathymetry was surveyed approximately every other day from above the shoreline to 8-m water depth along crossshore transects located about $20 \mathrm{~m}$ alongshore (north and south) of the instrumented transect. Additionally, altimeters colocated with the pressure gages and current meters were used to estimate the seafloor location every $3 \mathrm{hrs}$ [Gallagher et al., 1998].

Root-mean-square (rms) wave heights ranged from 0.20 to $2.10 \mathrm{~m}$. Mean crossshore flows ranged from -0.71 to $0.38 \mathrm{~m} / \mathrm{s}$ (positive onshore) with $95 \%$ of the flows between -0.40 and $0.10 \mathrm{~m} / \mathrm{s}$. The estimated measurement error of the mean flows is \pm 0.05 $\mathrm{m} / \mathrm{s}$. Setup ranged from -0.03 to $0.50 \mathrm{~m}$ with an estimated measurement error of \pm 0.005 $\mathrm{m}$, increasing to $\pm 0.020 \mathrm{~m}$ for the three most shoreward sensors. Centroidal frequencies ranged from 0.08 to $0.21 \mathrm{~Hz}$. Incident wave angles ranged between $\pm 35^{\circ}$ relative to beach normal. The nearshore wave field was approximately alongshore uniform and unaffected by the pier, located approximately $340 \mathrm{~m}$ south of the instrumented transect, except when the waves approached from the south [Elgar et al., 2001].

The distance between the current meters and the seafloor fluctuated throughout the experiment as the bottom accreted and eroded. The 9 offshore sensors usually were in the lower $40 \%$ of the water column, whereas the vertical locations of the 2 sensors nearest 
the shoreline ranged from near the bottom to near the water surface. For $h>1 \mathrm{~m}$, the bathymetry and circulation were approximately alongshore uniform [Feddersen and Guza, 2003], and observations of rip currents were infrequent. For $h<1 \mathrm{~m}$, comparisons of the surveys $20 \mathrm{~m}$ north and south of the instrumented transect suggest errors in the estimated distance between the sensor and the seafloor may be as large as $25 \%$ of the water depth. Additionally, in the shallowest depths the seafloor location changed by as much as $50 \%$ of $h$ between consecutive profiles.
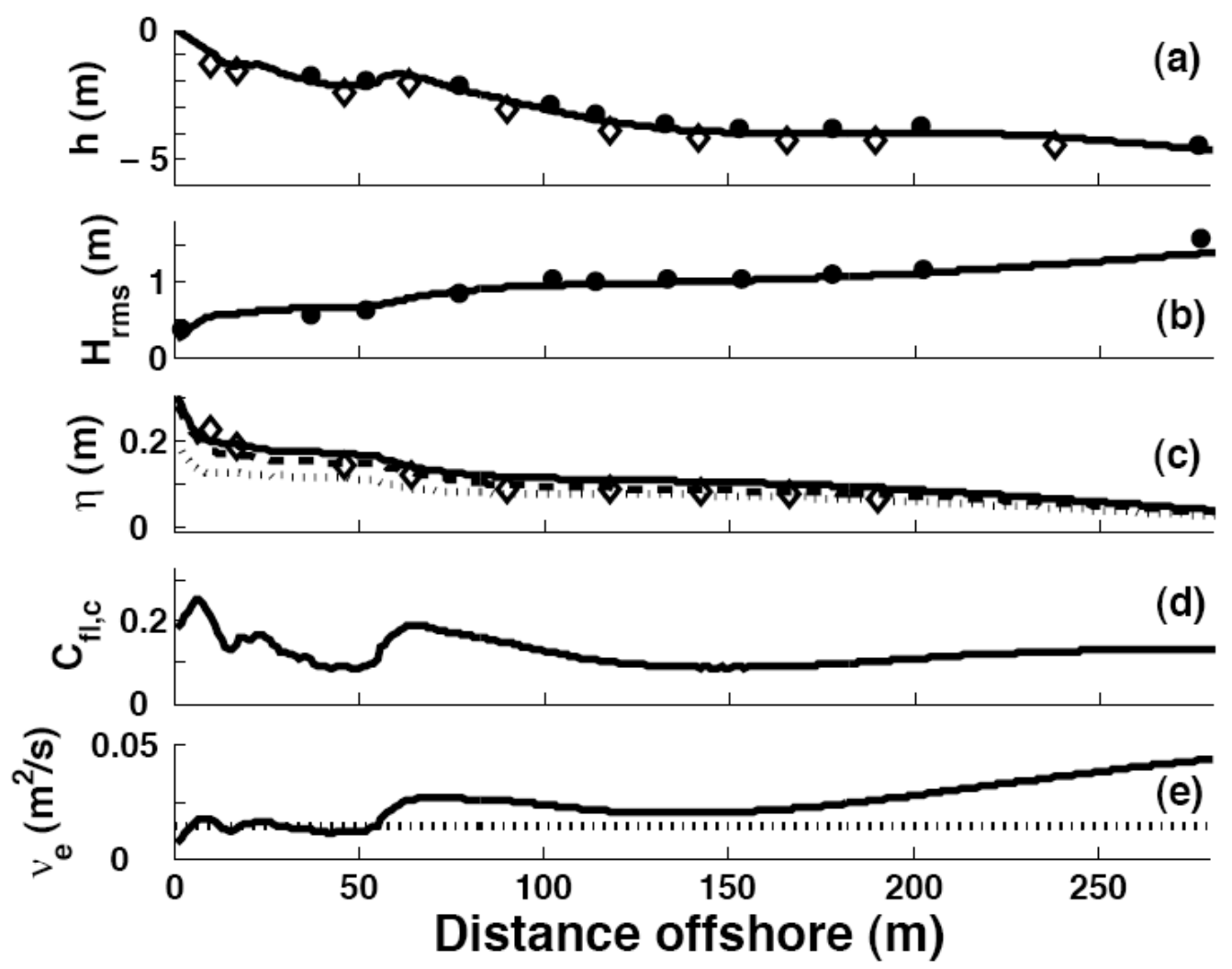

Figure 4-1: (a) Beach profile (solid curve) relative to still water level, colocated pressure and velocity sensors (circles), and buried pressure sensors (diamonds), (b) observed (circles) and modeled (solid curve) rms wave heights, (c) observed setup (diamonds) and setup predicted using the full model [(4-1) through (4-3), solid curve], the model without the roller term (dashed curve), and the model without bottom stress (dotted curve), (d) quadratic friction coefficient, $C_{f l, c}$, used with the linear bottom stress model, and (e) modeled eddy viscosity [e.g., (4-7)] versus distance offshore for the 8.5-min data record beginning Nov 13 20:59 hrs EST when the offshore wave height was $2.05 \mathrm{~m}$ and the tidal stage was $0.58 \mathrm{~m}$ above mean sea level. The horizontal dotted line in (e) is the constant eddy viscosity estimated by Garcez-Faria et al. [2000]. 
Three wave transformation models [Thornton and Guza, 1983; Church and Thornton, 1993; Lippmann et al., 1996] with a free parameter, $\gamma$, were fit to the data over a physically realistic range (i.e., $0.1<\gamma<1$ ). The rms percent error between the observations and predictions was minimized for each wave model for each data record (see Chapter 2). Three wave transformation models [Baldock et al., 1998; Tajima and Madsen, 2003; Ruessink et al., 2003] without free parameters also were used to predict the wave heights, and rms errors were calculated for each data record. The wave model with the smallest cross-shore rms error was selected for each data record. The Thornton and Guza [1983], Lippmann et al. [1996], Church and Thornton [1993], Baldock et al. [1998], Ruessink et al. [2003], and Tajima and Madsen [2003] models were used for $48 \%, 23 \%, 21 \%, 5 \%, 2 \%$, and $1 \%$ of the data records, respectively. The resulting modeled cross-shore wave heights are typically within $13 \%$ of the observations (e.g., Figure $1 b$ ) and have a mean error of $\approx 6 \%$.

\subsection{Results}

\subsubsection{Full Model}

The setup model predictions are consistent with the observations [Figures 4-1c (compare solid curve with diamonds), 4-2, and 4-3]. The model overpredicts setup by about $20 \%$ for $h>1 \mathrm{~m}$, and underpredicts setup by about $30 \%$ for $h<1 \mathrm{~m}$. In water depth ranges $3.0<h<6.0 \mathrm{~m}, 1.0<h<3.0 \mathrm{~m}$, and $0.3<h<1.0 \mathrm{~m}$, the best fit slopes between the model predictions and the observations are $1.22 \pm 0.05,1.11 \pm 0.04$, and $0.68 \pm 0.08$, respectively (Table 4-1), where values less than 1 indicate underprediction. The error bars on the regression slopes are based on the $95 \%$ confidence intervals and an estimated independence time scale for the setup measurements of 15 hours. The independence time scale is based on the observation that setup in shallow water varies with both tidal fluctuations (6 hour time scales) [Raubenheimer et al., 2001] and weather events $(\approx 3$ day time scales) [Lentz and Raubenheimer, 1999]. For all water depths, the full model results in linear regression slopes significantly (at the $95 \%$ confidence level) closer to 1 than a model that neglects rollers and bottom stress (Table 4-1). Setup and setdown in the 
deepest water (Figure 4-3, right hand panels) often were smaller than the measurement error, and thus the slope of the linear regression may be inaccurate. Furthermore, the slope is biased by the few cases with large waves and significant observed setup. In all depths, squared correlations $\left(r^{2}\right)$ between model predictions and observations are greater than about 0.59 , mean errors are less than $0.012 \mathrm{~m}$, and rms errors are less than $0.050 \mathrm{~m}$ (Table 4-1).

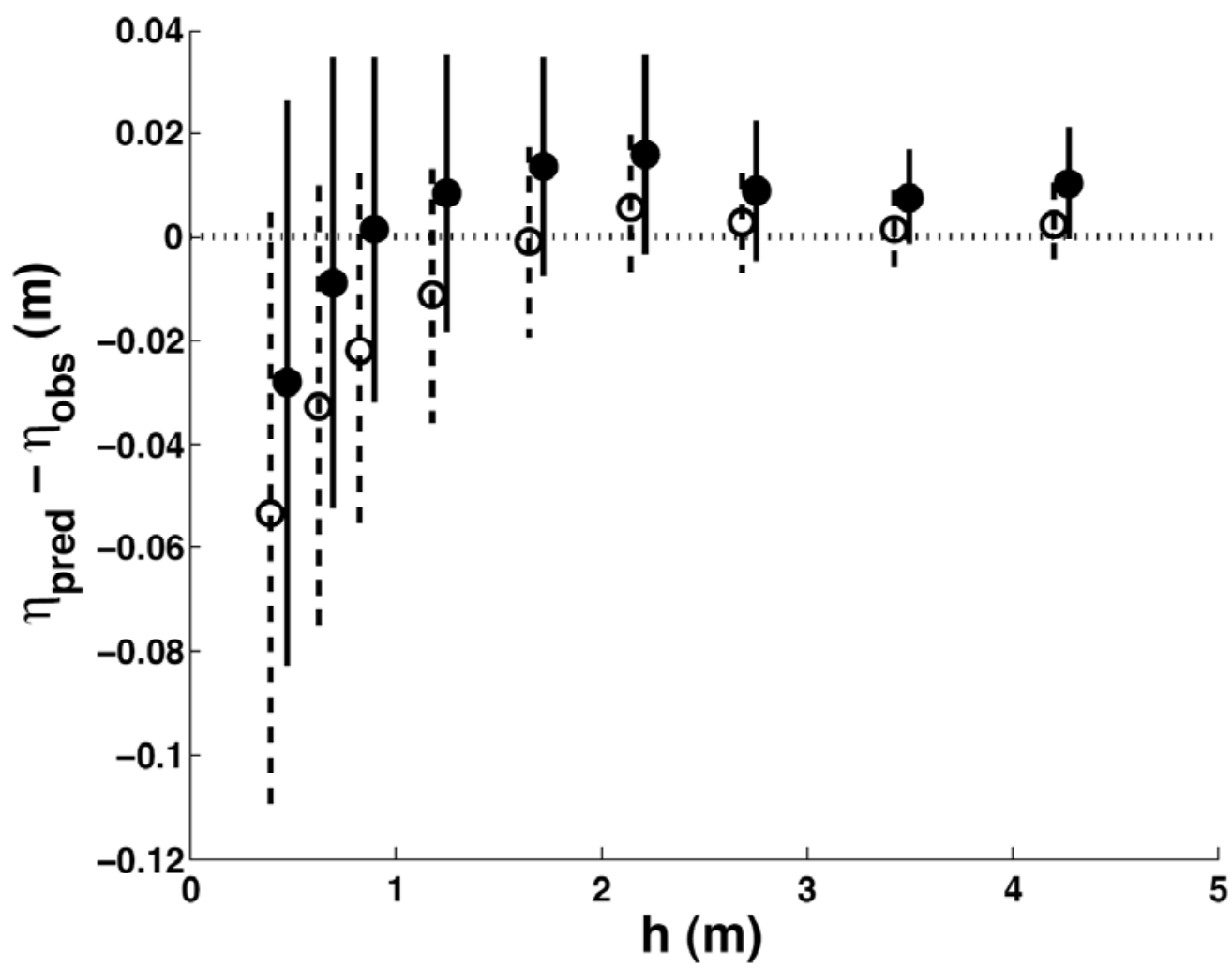

Figure 4-2: Mean errors and standard deviations for the full setup model (solid circles and lines, respectively) and for the model without either rollers or bottom stress (open circles and dashed lines, respectively) versus depth. Dashed lines and open circles are plotted offset by $0.1 \mathrm{~m}$ in $h$ for clarity.

\subsubsection{Effects of Wave Rollers}

Excluding wave rollers [i.e., $R_{x x}=0$ in (4-1)] does not affect the setup predictions significantly (e.g., Figure 4-1c, compare the dashed curve with the solid curve; Table 4- 
1). The mean and rms errors between model predictions and observations are the same as those for $R_{x x}$ estimated from (4-3), while the best-fit slopes decrease by about $10 \%$ (Table 4-1). Although the roller has little effect on the magnitude of the nearshore setup, including the roller shifts the transition from setdown to setup onshore anywhere from 0 to $30 \mathrm{~m}$ relative to model predictions without rollers. Therefore, accurate modeling of the roller may be important in predicting the cross-shore profile of setup.

Increasing (decreasing) $\sin (\beta)$ shifts the setup forcing offshore (onshore), resulting in increased (decreased) setup offshore of the sandbar (not shown). However, onshore of the bar, momentum may be advected into the deeper water of the trough, resulting in decreased setup. Thus, depending on the magnitude of $\sin (\beta)$, the height of the bar, and the depth of the trough, setup onshore of the trough may be increased or decreased by increasing $\sin (\beta)$. Average setup predictions at SandyDuck differ by less than $10 \%$ for $\sin (\beta)=0.05,0.10$, or 0.20 .

Table 4-1: Squared correlation coefficients, best fit slopes, intercepts, root-meansquared (rms) errors, and mean errors for water depths $0.3<h<1.0,1.0<h<3.0$, and $3.0<h<6.0 \mathrm{~m}$.

\begin{tabular}{|c|c|c|c|c|c|c|}
\hline Model & Depths & $r^{2}$ & Slope & Intercept $(\mathrm{m})$ & $\begin{array}{c}\text { rms } \\
\text { error }(\mathrm{m})\end{array}$ & $\begin{array}{c}\text { Mean } \\
\text { error }(\mathrm{m})\end{array}$ \\
\hline \multirow{3}{*}{ Full Model } & $0.3-1 \mathrm{~m}$ & 0.59 & $0.68 \pm 0.08$ & 0.010 & 0.048 & -0.012 \\
\cline { 2 - 7 } & $1-3 \mathrm{~m}$ & 0.83 & $1.11 \pm 0.04$ & 0.006 & 0.023 & 0.009 \\
\cline { 2 - 7 } & $3-6 \mathrm{~m}$ & 0.77 & $1.22 \pm 0.05$ & 0.001 & 0.007 & 0.002 \\
\hline & & & & & & \\
\hline \multirow{2}{*}{$\begin{array}{c}\text { Model w/o } \\
\text { Roller }\end{array}$} & $0.3-1 \mathrm{~m}$ & 0.59 & $0.61 \pm 0.07$ & 0.014 & 0.048 & -0.012 \\
\cline { 2 - 7 } & $1-3 \mathrm{~m}$ & 0.78 & $1.00 \pm 0.04$ & 0.009 & 0.023 & 0.009 \\
\cline { 2 - 7 } & $3-6 \mathrm{~m}$ & 0.73 & $1.16 \pm 0.06$ & 0.002 & 0.007 & 0.002 \\
\hline & & & & & & \\
\hline \multirow{3}{*}{$\begin{array}{c}\text { Model w/o } \\
\text { Bottom Stress }\end{array}$} & $0.3-1 \mathrm{~m}$ & 0.57 & $0.42 \pm 0.05$ & 0.002 & 0.061 & -0.037 \\
\cline { 2 - 7 } & $1-3 \mathrm{~m}$ & 0.85 & $0.69 \pm 0.03$ & 0.001 & 0.018 & -0.006 \\
\hline & $3-6 \mathrm{~m}$ & 0.80 & $0.76 \pm 0.03$ & 0.000 & 0.004 & -0.001 \\
\hline \multirow{3}{*}{$\begin{array}{c}\text { Moller or Bottom Stress* } \\
\text { Model w/o }\end{array}$} & $0.3-1 \mathrm{~m}$ & 0.58 & $0.38 \pm 0.05$ & 0.007 & 0.061 & -0.036 \\
\cline { 2 - 7 } & $1-3 \mathrm{~m}$ & 0.79 & $0.62 \pm 0.03$ & 0.004 & 0.020 & -0.004 \\
\cline { 2 - 7 } & $3-6 \mathrm{~m}$ & 0.75 & $0.72 \pm 0.03$ & 0.000 & 0.005 & -0.000 \\
\hline
\end{tabular}

* corrects an error in Raubenheimer et al. [2001]. 
Depth

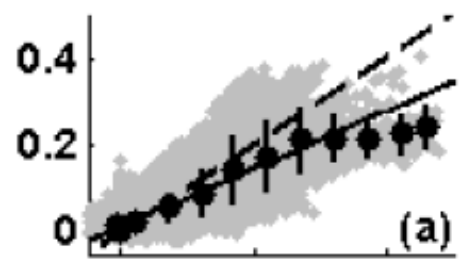

(a)
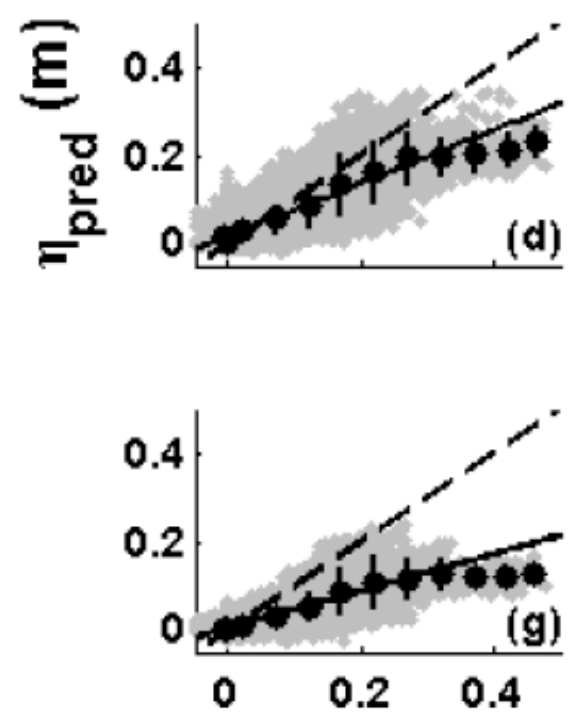

1.0 - $3.0 \mathrm{~m}$

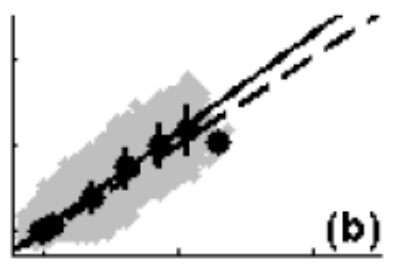

(b)
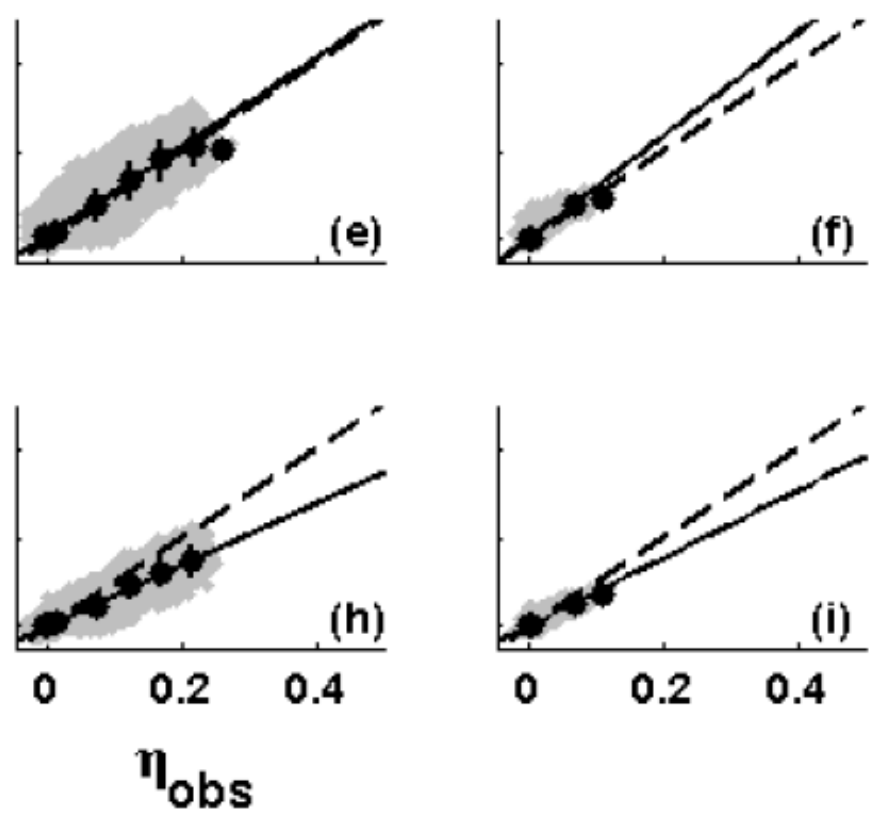

$3.0 \mathrm{~m}-6.0 \mathrm{~m}$

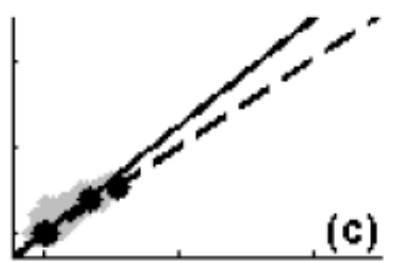

Figure 4-3: Predicted versus observed setup for the entire 90 day data set for the full model $(a-c)$, the model without rollers $(d-f)$, and the model without bottom stress $(g-i)$ for water depths $0.3<h<1.0(\mathrm{a}, \mathrm{d}, \mathrm{g}), 1.0<h<3.0(\mathrm{~b}, \mathrm{e}, \mathrm{h})$, and $3.0<h<6.0 \mathrm{~m}(\mathrm{c}, \mathrm{f}, \mathrm{i})$. Light grey clouds are unbinned 8.5 -min values. Black circles and vertical hashes are the means ( $0.05 \mathrm{~m}$-wide bins) and standard deviations, respectively. The solid and dashed black lines are the least squares fits to the unbinned values and the perfect fits (i.e., 1 to 1 comparison), respectively. 


\subsubsection{Effects of Bottom Stress}

Excluding bottom stress in the momentum balance [i.e., $\tau_{b}=0$ in (4-1)] significantly degrades setup predictions in shallow water (e.g., Figure 4-1c, compare the dotted curve with the solid curve; Table 4-1). For $0.3<h<1.0 \mathrm{~m}$, the mean setup error is 3 times larger when bottom stress is neglected than when it is included (Table 4-1). Although changes in the squared correlations between predictions and observations are small, neglecting bottom stress results in a 38\% decrease (i.e., underprediction increases) of the best fit slopes and a $27 \%$ increase in rms errors (Table 4-1). However, excluding bottom stress causes the transition from setdown to setup to occur farther onshore, eliminating the overprediction of setup observed for $h>1 \mathrm{~m} \mathrm{(e.g.,} \mathrm{for} 1<h<3 \mathrm{~m}$, the mean error decreases by $33 \%$ and the best fit slope decreases from 1.11 to 0.69$)$. The overprediction of setup when bottom stress is included may result from a poor representation of stress in the deeper water offshore of the bar. Also, the undertow and eddy viscosity models are not valid outside the surfzone, and thus (4-15) may be inaccurate in this region. Including the roller partly balances the offshore shift of the transition from setdown to setup that results from including bottom stress.

\subsection{Discussion}

\subsubsection{Observational Errors}

Scatter in the 8.5-min setup observations may be partly owing to the presence of 'surfbeat' or infragravity waves (periods $>30 \mathrm{~s}$ ). However, results using 34-min and 1-hr averages suggest this scatter does not affect the trends and biases in the model-data comparisons presented here. Setup predictions based on bathymetric profiles generated from a cubic spline of the 3-hr altimeter measurements are similar to those based on the surveyed bathymetry, suggesting that bathymetric errors are not affecting the results. The accuracy of parametric wave models decreases over bar troughs [Ruessink et al., 2003] and in shallow water, which may cause errors in the setup predictions. However, 
interpolating the observed waves with a cubic spline instead of with a wave transformation model has little effect on the results. Excluding records with southerly swell (offshore waves arriving more than $15^{\circ}$ south of shore normal) that might be affected by the pier has a negligible effect on the results.

\subsubsection{Bottom Stress}

\subsubsection{Drag Coefficients}

Bottom stress, which is equivalent to the near-bottom Reynolds shear stress, is often parameterized using a non-linear quadratic bottom drag law [Longuet Higgins, 1970; Feddersen et al., 1998; many others]

$$
\tau_{b}=C_{f} \rho\langle|\vec{u}|(u, v)\rangle,
$$

where $|\vec{u}|$ is the magnitude of the total instantaneous velocity, $u$ and $v$ are the instantaneous velocities in the cross- and alongshore directions, <> is time averaging, and $C_{f}$ is a non-dimensional drag coefficient that depends on and increases with local turbulence levels [Feddersen et al., 1998]. The instantaneous velocities, $u$ and $v$, are composed of mean (i.e., $\bar{u}$ and $\bar{v}$ ) and wave (i.e., $\tilde{u}$ and $\tilde{v}$ ) components such that $u=\bar{u}+\tilde{u}$ and $v=\bar{v}+\tilde{v}$.

Owing to the difficulty of measuring instantaneous velocities in situ, (4-16) is often linearized assuming the mean currents are weak [i.e., $(\bar{u}, \bar{v})<<\tilde{u}$ ], the wave angle is small (i.e., $\tilde{v}<<\tilde{u}$ ), and the wave motion is sinusoidal (i.e., $\tilde{u}=u_{o r b} \cos \omega t$, where $u_{o r b}$ is the maximum wave orbital velocity, $\omega$ is the radian wave frequency, and $t$ is time), such that [Wu et al., 1985]

$$
\tau_{b}=C_{f l} \rho u_{o r b}\left(\frac{4}{\pi} \bar{u}, \frac{2}{\pi} \bar{v}\right),
$$

where $C_{f l}$ is the drag coefficient for the linear bottom drag law, and may not have the same numeric value as $C_{f}$ if the assumptions on which (4-17) are based are violated. The factors of $4 / \pi$ and $2 / \pi$ come from time averaging the absolute value of the sinusoidal 
motion of the wave induced velocities (i.e., $|\cos \omega t|)$, and the factor of 2 difference is owing to the orientation of the mean currents relative to the wave motion.

The present bottom stress estimates can be compared with estimates based on the linear drag law. The cross-shore drag coefficients, $C_{f l, c}$, needed to obtain bottom stresses similar to those calculated by (4-15) are estimated as

$$
C_{f l, c}=\frac{\tau_{b}}{u_{o r b} \bar{u} \rho} \frac{\pi}{4}
$$

where $u_{\text {orb }}$ is calculated from the wave height and water depth using linear, shallow water wave theory, and a Rayleigh wave height distribution [Thornton and Guza, 1986]

$$
u_{o r b}=\frac{1}{2}\left(\frac{g}{h}\right)^{1 / 2}\left\lfloor\frac{\sqrt{\pi}}{2} H_{r m s}\right\rfloor .
$$

The mean current $\bar{u}$ can be approximated as the predicted mean return current, $U_{m}$, which is estimated from the shoreward flux of mass in the wave and roller

$$
U_{m}=\frac{M_{w}+M_{r}}{\rho h},
$$

or as the measured mean current at the location of the velocity sensors.

Using $U_{m}$ in (4-18) for the 8.5-min data record shown in Figure 4-1, $0.05<C_{f l, c}<$ 0.24 (Figure 4-1d). For the full 3 month data set, the mean value of $C_{f l, c}$ in the surfzone is 0.17 , with a range of $0<C_{f l, c}<0.53$. Note that $C_{f l, c}$ can approach 0 in the bar trough where breaking ceases and $\tau_{\mathrm{b}} \approx 0$. If the observed current is used in (4-18) instead of $U_{m}$, the average $C_{f l, c}$ in the surfzone over the duration of the experiment is approximately 0.07. The difference between the two estimates of $C_{f l, c}$ may be owing to the location in the water column at which the observations were measured, errors in estimates of the water mass carried shoreward (i.e., $M_{w}+M_{r}$ ), or errors in estimates of the height of the water column through which the return current flows (i.e., $h$ ).

A Darcy-Weisbach equation with a Manning coefficient can be used to estimate $C_{f l, c}\left[\right.$ Dally and Brown, 1995]. Using a Manning coefficient of $0.030 \mathrm{~s} / \mathrm{m}^{1 / 3}$ [Arcement and Schneider, 1990], a value approximately in the middle of the range for slightly rough, natural sandy channels $\left(0.026-0.035 \mathrm{~s} / \mathrm{m}^{1 / 3}\right), C_{f l, c}$ is estimated as $0.017,0.011$, and 
0.008 for $0.3-, 1.0-$, and 3.0-m water depths, respectively. While these values are almost an order of magnitude smaller than found from (4-18), the Darcy-Weisbach equation does not account for the turbulence generated by breaking waves, bedforms, or wavecurrent interactions, and thus drag coefficients estimated from the Darcy-Weisbach equation are likely biased low. Observations [Carstens et al., 1969] and theoretical calculations [Longuet-Higgins, 1981] have shown that the drag coefficient can be larger by an order of magnitude or more over rippled sand beds.

Similarly, $C_{f l, c}$ can be compared with alongshore drag coefficients, $C_{f l, a}$, estimated from alongshore studies and a linear drag law. Previous studies have estimated $C_{f l, a}$ to be 0.007 - 0.020 [Longuet-Higgins, 1970], 0.008-0.010 [Thornton and Guza, 1986]; 0.015 [Reniers and Battjes, 1997]; and 0.007-0.025 [Goda, 2005]. The difference in magnitude between the along- and cross-shore drag coefficients is addressed below.

Recently, in situ measurements of the instantaneous velocities has allowed use of the fully non-linear drag law. To compare the present bottom stress estimates with prior estimates based on (4-16), the cross-shore drag coefficients, $C_{f, c}$, needed to obtain bottom stresses similar to those calculated by (4-15) are estimated as

$$
C_{f, c}=\frac{\tau_{b}}{<|\vec{u}| u>\rho}
$$

Equation (4-15) always predicts an onshore-directed bottom stress, and thus a time-averaged onshore-directed flow results in an unrealistic negative $C_{f, c}$ in (4-21). These negative coefficients, which account for $32 \%$ of the surfzone estimates and $50 \%$ of the estimates seaward of the surfzone, may be caused by inaccuracies in the flow measurements for small velocities, local non-uniformities in the bathymetry, or velocity measurements in the upper water column where onshore flow is expected. Based on a linear regression between the modeled $\tau_{\mathrm{b}}[$ e.g., (4-15)] and the measured $\langle|\vec{u}| u\rangle$ at the location of each sensor, and neglecting negative values of $C_{f, c}$ [e.g., Feddersen et al., 1998], the squared correlations between $\tau_{b}$ and $\langle|\vec{u}| u\rangle$ inside and seaward of the surfzone are $r^{2}=0.19$ and $r^{2}=0.51$, respectively (Figure 4-4). Similar to previous results 
[Feddersen et al., 1998], the best fit $C_{f, c}$ is higher inside the surfzone (0.022) than seaward of the surfzone (0.018). Inside the surfzone, $C_{f, c}$ is not dependent on the water depth, and dividing the surfzone data up into $h<1 \mathrm{~m}$ and $h>1 \mathrm{~m}$ does not produce significantly different $C_{f, c}$ 's.
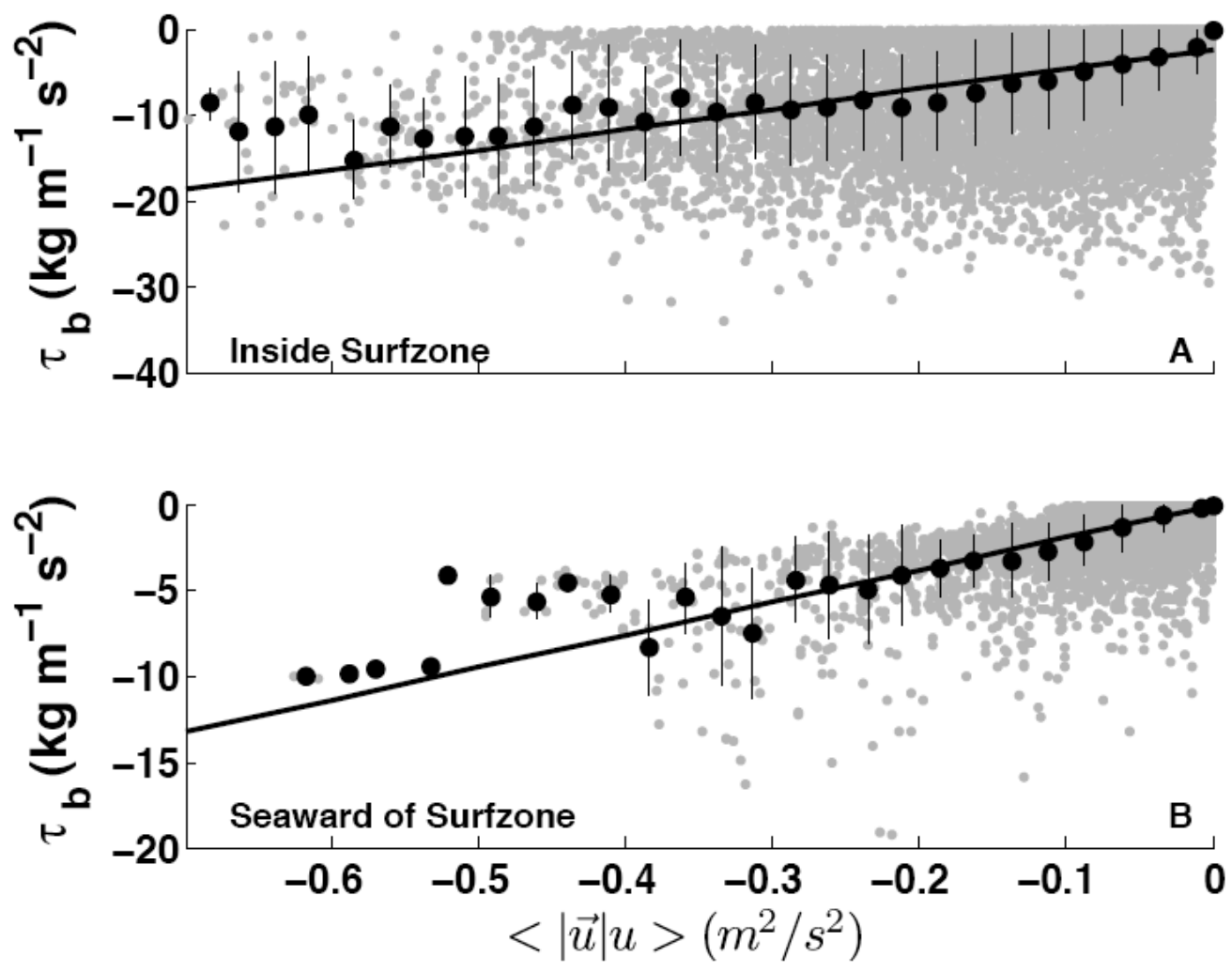

Figure 4-4: Bottom stress, $\tau_{b}$, from (4-15) versus $<|\vec{u}|$ u for (A) the surfzone and (B) seaward of the surfzone. Light grey dots are unbinned $8.5-\mathrm{min}$ values. Black circles and vertical hashes are the means $\left(0.025 \mathrm{~m}^{2} / \mathrm{s}^{2}\right.$ - wide bins) and standard deviations, respectively. The solid lines are the least squares fits to the unbinned values. The results do not change if $3-\mathrm{hr}$ averages are used instead of the $8.5-\mathrm{min}$ averages.

Here, care must be taken to only compare $C_{f, c}$ with drag coefficients estimated previously from a non-linear drag law, as using the linearized version (i.e., 4-17) can affect significantly the drag coefficient [Thornton and Guza, 1986; Feddersen et al., 2000]. The cross-shore drag coefficients estimated here are typically within a factor of two of previous estimates of the cross-shore drag coefficient: 0.008 [Raubenheimer et al., 
1995]; 0.007-0.026 [Cox et al., 1996]; 0.005-0.015 [Archetti and Brocchini, 2002]; and 0.010 - 0.030 [Raubenheimer et al., 2004], but are typically larger than previous estimates of the alongshore drag coefficient: 0.006 [Thornton and Guza, 1986]; 0.007 [Reniers and Battjes, 1997]; 0.001 - 0.012 [Garcez-Faria et al., 1998]; 0.002 - 0.003 [Feddersen et al., 1998, 2003, 2004]; 0.005 - 0.018 [Haas et al., 1998]; 0.003 - 0.004 [Ruessink et al., 2001]; 0.001-0.002 [Trowbridge and Elgar, 2001]; and 0.01 [Johnson and Smith, 2005].

The cross-shore drag coefficients $C_{f, c}$ estimated from (4-21) also can be compared with alongshore drag coefficients, $C_{f, a}$, determined from an alongshore momentum balance. Assuming alongshore uniformity, neglecting mixing, and using a quadratic alongshore bottom stress formulation similar to (4-21) [Feddersen et al., 1998]

$$
\tau_{b, a}=C_{f, a} \rho\langle|\vec{u}| v\rangle,
$$

the time-averaged alongshore momentum balance is

$$
-C_{f, a} \rho\langle|\vec{u}| v\rangle=\frac{\partial}{\partial x} S_{x y}+\frac{\partial}{\partial x} R_{x y}+\tau_{w},
$$

where $S_{x y}$ is the off-diagonal term of the wave radiation stress tensor [Longuet-Higgins, 1970]

$$
S_{x y}=E_{w} \cos \theta \sin \theta \frac{c_{g}}{c}
$$

$R_{x y}$ is the momentum flux owing to the wave roller [Ruessink et al., 2001]

$$
R_{x y}=2 E_{r} \cos \theta \sin \theta,
$$

and $\tau_{w}$ is the wind stress found following $W u$ [1980].

The alongshore forcing $\left(d S_{x y} / d x+d R_{x y} / d x+\tau_{w}\right)$ is correlated with the velocity term $(-\langle\mid \vec{u} v\rangle)$ in the bottom stress formulation, with $r^{2}=0.63$ and 0.56 inside and seaward of the surfzone, respectively (Figure 4-5). Based on a linear regression between the forcing and velocity terms, $\mathrm{C}_{f, a} \approx 0.002$ and 0.001 inside and seaward of the surfzone. These estimates compare well with Feddersen et al. [1998], who integrated (4-23) across the surfzone instead of using local estimates, even though the approaches differs slightly. 


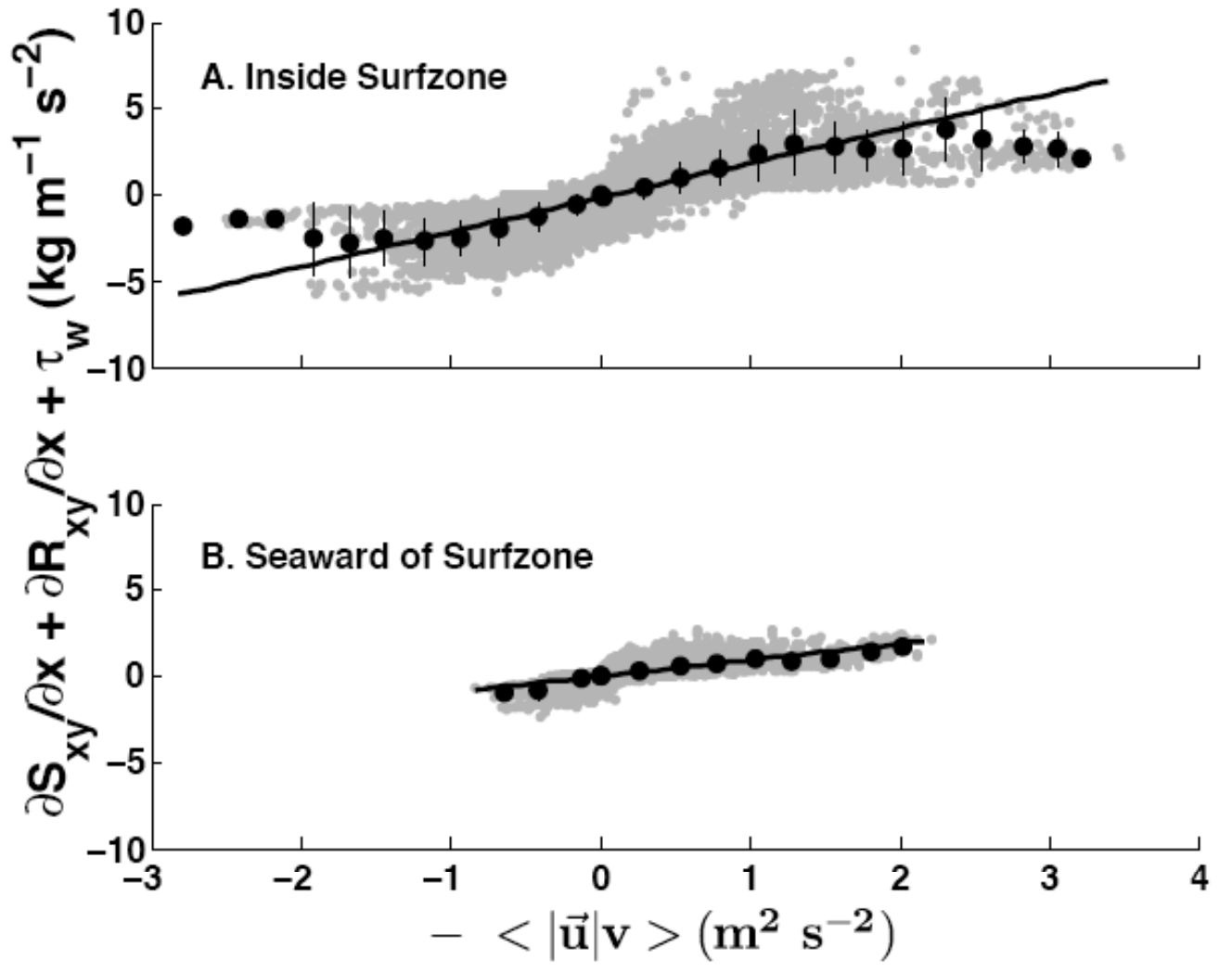

Figure 4-5: The total alongshore forcing $\left(d S_{x y} / d x+d R_{x y} / d x+\tau_{w}\right)$ versus the velocity term $\langle|\vec{u}| v\rangle$ in the bed stress formulation for sensors $(A)$ inside the surfzone and (B) seaward of the surfzone. The light grey dots are the $8.5 \mathrm{~min}$ values. Solid circles and vertical hashes are the means $\left(0.025-\mathrm{m}^{2} \mathrm{~s}^{2}\right.$ - wide bins) and standard deviations, respectively. The solid lines are the least squares fits to the unbinned values.

It is unknown why the alongshore drag coefficients are approximately an order of magnitude smaller than the cross-shore drag coefficients. The difference may be related to the orientation of bedforms, which frequently are observed on this beach [Gallagher et al., 1998; Hay and Mudge, 2005]. Linear transition ripples occurred at least $40 \%$ of the time at SandyDuck, with the ripple crests oriented parallel to shore [Hay and Mudge, 2005]. Linear bedforms may influence cross- and alongshore flows differently [Barrantes and Madsen, 2000], and consequently, significantly smaller drag coefficients may be estimated for alongshore flows than for cross-shore flows. This result suggests that $C_{f}$ may be a function of the angle $\phi$ between the current and the waves [i.e., $C_{f}=C_{f}(\phi)$ ]. This 
hypothesis is supported by theories for wave-current interaction, which determine the total bottom stress from the superposition of the bottom stresses owing to the waves and to the currents. Thus, the total bottom stress will be larger when the waves and currents are co-directional than when $\phi$ approaches $90^{\circ}$. However, a study conducted in approximately $12 \mathrm{~m}$ water depth off the coast of New Jersey suggests that $C_{f}$ over a rippled bed does not depend on the wave-current orientation [Styles and Glenn, 2002].

Along- and cross-shore drag coefficients in the surfzone are not understood well and prior studies have estimated a wide range of values (i.e., 0.001-0.030). The alongshore drag coefficient for the non-linear drag law has been estimated previously to be $0.001-0.018$, with the majority of values falling between 0.003 and 0.010 . Alongshore studies that do not specifically determine a drag coefficient, but instead employ it as a model parameter, typically use a value around 0.010 [Schmidt et al., 2005].

The cross-shore drag coefficient has only been determined in the inner surf and swash zones. In two field studies [Raubenheimer et al., 1995, 2004], the cross-shore drag coefficient was determined to be between 0.005 and 0.030 in $h<0.5 \mathrm{~m}$. Similar values of the cross-shore drag coefficient were found in the laboratory [Cox et al., 1996, 2001; Petti and Longo, 2001; Archetti and Brochinni, 2002]. Cross-shore studies that employ a drag coefficient as a model parameter typically use a value around 0.010 [Garcez-Faria et al., 2000].

Both $C_{f, c}(0.022)$ and $C_{f, a}(0.002)$ determined at SandyDuck fall within the range (0.001 - 0.030) previously determined. The cross-shore drag coefficient estimated here is similar to cross-shore estimates from the inner surf and swash zones, whereas $C_{f, a}$ is similar to the drag coefficients determined from alongshore current studies.

It is possible that the simplified cross-shore momentum balance (4-1) used to calculate setup neglects one or more important physical processes. The good agreement between the predicted and observed setup using (4-1) and a large $\mathrm{C}_{f, c}$ could then be owing to a larger than necessary bottom stress compensating for these neglected processes. Reducing $\mathrm{C}_{f, c}$ by a factor of 10 makes the bottom stress of negligible importance in (4-1). However, reducing $\mathrm{C}_{f, c}$ by a factor of 2 to 4 does not change the conclusion that bottom 
stress is important to setup. Furthermore, most of the alongshore current studies were conducted in $h>2 \mathrm{~m}$ where bottom stress is of minor importance in the present study, which focuses on the cross-shore momentum balance. Excluding bottom stress (or reducing $C_{f, c}$ by a factor of 10) for $h>2$ m changes the mean error between model predictions and observations in $2<h<4 \mathrm{~m}$ by less than $0.003 \mathrm{~m}$. Therefore, the bottom stress formulation could easily be modified to produce a $C_{f, c}$ in deeper water of the same order of magnitude as $C_{f, a}$ without significantly degrading the model-data accuracy in shallow water, where bottom stress is most important.

\subsubsection{Eddy Viscosity}

The eddy viscosity $v_{e}$ is assumed to be proportional to turbulence intensity [Garcez-Faria et al., 2000], and varies in the cross-shore as waves change across the surfzone (Figure 4-1e). The range of $v_{e}$ over the entire 3 month period, $0<v_{e}<0.056$ $\mathrm{m}^{2} / \mathrm{s}$, is consistent with prior undertow studies [Haines and Sallenger, 1994; GarcezFaria et al., 2000].

The modeled bottom stress and setup are only weakly sensitive to the cross-shore dependence of $v_{e}$ and to $50 \%$ changes in its magnitude, because increasing $v_{e}$ decreases the shear of the mean flow near the bed. Reducing $v_{e}$ by $50 \%$ or using a constant $v_{e}$ of $0.014 \mathrm{~m}^{2} / \mathrm{s}$ [Garcez-Faria et al., 2000] has a much smaller effect on the modeled setup than excluding the bottom stress (a 9\% decrease compared with a 38\% decrease in the best-fit slopes, and a $33 \%$ increase compared with a $208 \%$ increase in the mean errors, respectively for $0.3<h<1.0 \mathrm{~m}$ ).

If wave-breaking induced turbulence reaches the bed [e.g., Cox and Kobayashi, 2000], a vertically constant eddy viscosity (such as that used here) may be appropriate. However, if the water column is not well mixed, the eddy viscosity may be significantly smaller in the bottom boundary layer than in the mid-water-column [e.g., Svendsen et al., 1987; Reniers et al., 2004] greatly reducing the effect of the bottom stress on setup. For example, the effect of the bottom stress is near zero using the bottom boundary layer eddy viscosity proposed by Reniers et al. [2004]. In deep water, the penetration depth of 
surface turbulence is proportional to the wave height, with little reduction in turbulence strength to a depth below the surface of $0.71 H_{r m s}$ [Terray et al., 1996]. In shallow water, surface-generated turbulence can penetrate to the bottom boundary layer, increasing the local bottom shear stress [Fredsøe et al., 2003]. Based on these results and the observation that at breaking $H_{r m s} / h \approx 0.4$ and increases toward the shoreline [Raubenheimer et al., 1996], breaking-wave generated turbulence may be reaching the bottom inside the surfzone.

However in the outer surfzone, surface generated turbulence does not penetrate to the bed [Trowbridge and Elgar, 2001]. Similarly, $C_{f, a}$ (an indicator of bottom stress) for alongshore currents is inversely proportional to water depth [Feddersen and Trowbridge, 2005], which may be a proxy for the strength of wave breaking. Thus, it is possible that surface generated turbulence may reach the bottom only during significant wave breaking or in the inner to mid- surfzone. If bottom stress is included in the model only during intense dissipation (defined here to be when wave energy is decreasing $3 \%$ per meter in the cross-shore), setup is predicted more accurately for $h>1 \mathrm{~m}$ (for $1.0<h<3.0 \mathrm{~m}$, the mean error is $-0.002 \mathrm{~m}$ and the best fit slope is 0.84 , for $3.0<h<6.0 \mathrm{~m}$ the mean error is $-0.001 \mathrm{~m}$ and the best fit slope is 0.80 , compare with the values in Table 4-1), but less accurately for $h<1 \mathrm{~m}$ (for $0.3<h<1.0$ the mean error is $-0.024 \mathrm{~m}$ and best fit slope is 0.56). The selection of $3 \%$ per meter as the threshold of intense dissipation was based on visual observations of the cross-shore distribution of the modeled wave heights. For values $<3 \%$ per meter the bottom stress tended to be turned on and off randomly seaward of the surfzone owing to small errors in the bathymetric profile, and for values $>3 \%$ per meter significant sections of wave breaking were excluded.

\subsubsection{Mean Cross-shore Flows}

Using only flows greater than the sensor accuracy (i.e., magnitude greater than $0.05 \mathrm{~m} / \mathrm{s}$ ), it is found that modeled mean cross-shore flows at the elevations of the current meters are within a factor of 3 of the observed flows (Figure 4-6), and on average the model underpredicts the observed undertow. Underprediction of the undertow may be 
partly owing to an overestimate of the eddy viscosity, $v_{e}$. Reducing $v_{e}$ gives a more parabolic undertow profile and larger mean flows at most sensor elevations.

Differences between modeled and observed mean flows $\left(r^{2}<0.2\right)$ may be owing to inaccurate measurements of the bottom profile, leading to incorrect elevations of the sensors above the bed. Alternatively, the assumption of a parabolic vertical profile for the undertow [e.g., (4-9)] may be invalid in the trough region [Garcez-Faria et al., 2000; Reniers et al., 2004], resulting in undertow prediction errors. Seaward of the surfzone, near-bottom onshore streaming flow and inaccurate estimates of non-zero eddy viscosities owing to small, inaccurate values of dissipation calculated from the wave models also may produce errors in flow predictions.
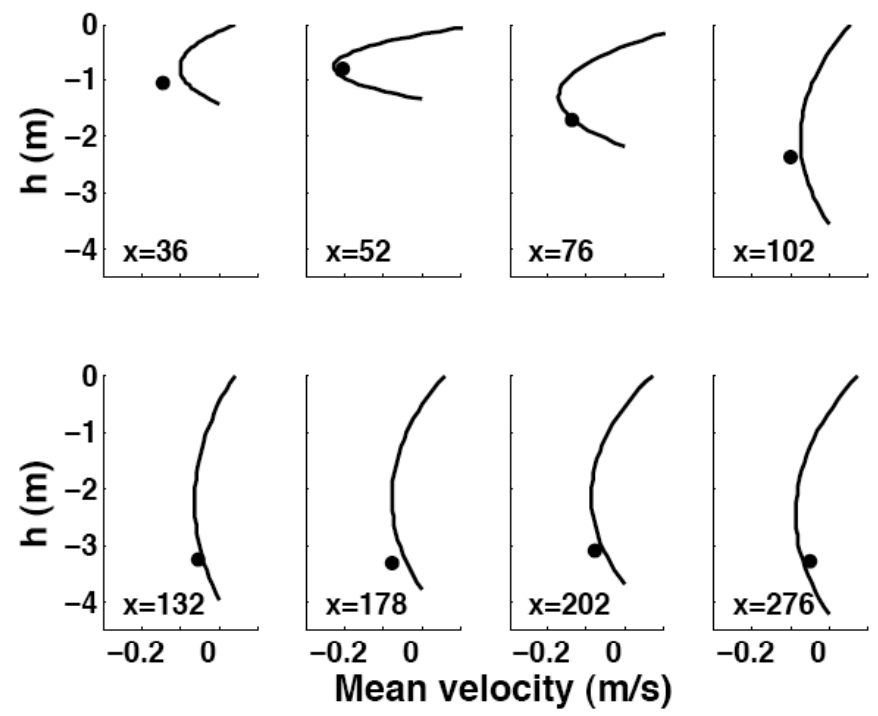

Figure 4-6: Observed (circles) and predicted (curves) mean cross-shore flows (undertow) as a function of water depth for the 8.5-min data record beginning Sep 27 19:51 hrs EST.

When the undertow results are restricted to cases for which the rms error between the local altimeter depth measurements and the bathymetry surveyed $20 \mathrm{~m}$ north and south of the instrumented transect is less than $0.1 \mathrm{~m}$ and $H_{r m s}$ in deep water is greater than $0.6 \mathrm{~m}$, and if the undertow prediction elevations are allowed to vary from the sensor 
elevation by up to $\pm 0.2 \mathrm{~m}$ (the average difference in elevation for consecutive and bracketing profiles), the agreement between the modeled and observed mean flows is greatly improved, with most of the improvement owing to the variation in the sensor elevation. However, the modeled undertow can change significantly over a vertical range of $0.4 \mathrm{~m}$. Based on the sensitivity of the undertow predictions to the sensor elevations and the water depth, the single vertical measurements of undertow used here are insufficient to test undertow profile models, and it is unknown how accurate the present formulation is.

The bottom stress [i.e., (4-15)] depends on the near bottom velocity gradient (i.e., $\partial U / \partial z$ at $z=-d$ ). Therefore, as long as this gradient is not biased consistently high or low, the undertow model used should not affect significantly the average affect of the bottom stress in (4-1). The effect of inaccurately modeled mean flows, and the associated near bottom velocity gradients, on the bottom stress estimates is investigated in two ways. First, several undertow models [Haines and Sallenger, 1994; Garcez-Faria et al., 2000; Reniers et al., 2004] were used to estimate the near-bottom velocity gradients. As long as the models include a no-slip bottom boundary condition [e.g., Garcez-Faria et al., 2000 was modified to include one] and a depth-averaged eddy viscosity representative of the entire water column [e.g., (4-7)], the choice of undertow model does not alter the conclusion that bottom stress significantly affects setup. Second, modeled bottom stresses [e.g., (4-15)] were compared with estimates, $\tau_{b, o b s}$. Here the bottom stress, $\tau_{b, \text { obs }}$, is not observed per se, but determined using the observed mean flows, a no-slip bottom boundary condition, the eddy viscosity estimated from the model [e.g. (4-7)], and by assuming a linear variation of the mean flow between the bed and the measurement location. Prior field studies show that the undertow reaches a maximum below the middle of the water column [Reniers et al., 2004]. Thus, only flow measurements in the lower $40 \%$ of the water column are used to ensure that flows decrease monotonically towards the bed. The nine offshore sensors were in the bottom $40 \%$ of the water column $96 \%$ of the time, whereas the two sensors nearest the shoreline were in the bottom $40 \%$ of the water column $34 \%$ of the time. The unbinned 8.5 -min values of $\tau_{b, o b s}$ are poorly 
correlated $\left(r^{2}=0.21\right.$, not shown) with (4-15), possibly owing to the low correlation between the observed and modeled flows. Based on the approximations made in estimating $\tau_{b, o b s}$, the uncertainty in the sensor elevations above the seafloor, and the poor spatial resolution of the current meters, extrapolating these point observations to comment on the individual model runs or driving the setup model with stresses estimated from the observed flows is not possible. However, the average estimates of bottom stress from the modeled and observed flows agree well (Figure 4-7, $r^{2}=0.93$, rms error $=2.49$ $\mathrm{kg} / \mathrm{ms}^{2}$ ), suggesting that on average the undertow formulation, and the associated near bottom velocity gradients, does not bias the bottom stress estimates significantly.

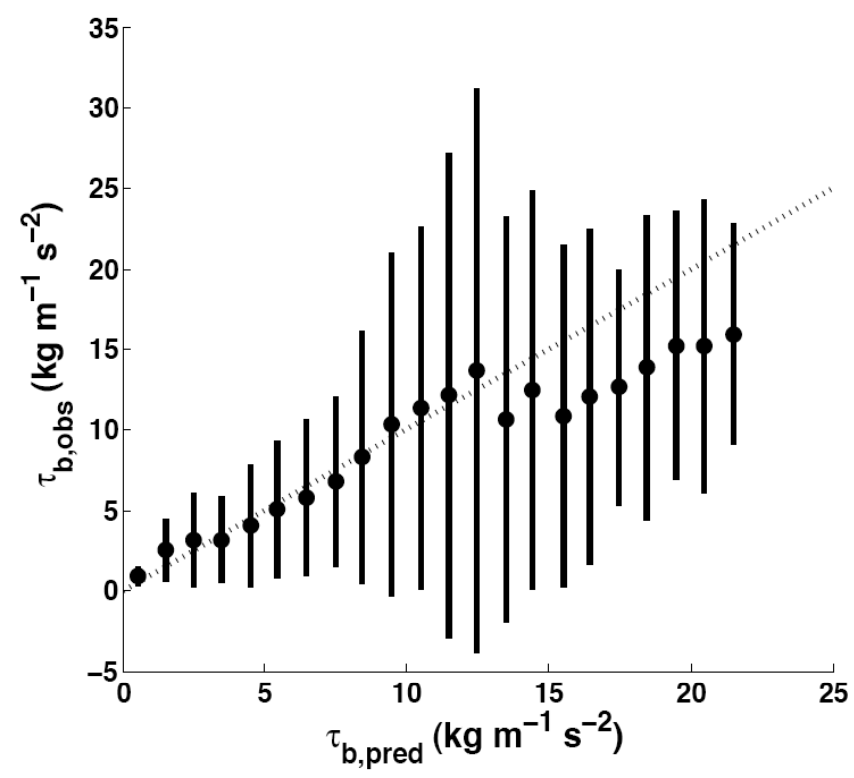

Figure 4-7: Means (circles, $1 \mathrm{~kg} \mathrm{~m}^{-1} \mathrm{~s}^{-2}$-wide bins) and standard deviations (solid lines) of $\tau_{\mathrm{b}, \text { obs }}$ calculated from the observed undertow assuming a linear variation with depth and a no-slip bottom boundary condition versus $\tau_{b, \text { pred }}$ modeled using (4-15). The dotted line is perfect agreement.

\subsubsection{Effects of a Large Offshore Bar}

The presence of a large amplitude sandbar increases the importance of rollers to setup.

Numerical simulations over bathymetry observed near Egmond, The Netherlands on 18

October 1998 when a large bar (height $>3 \mathrm{~m}$ ) was present [Ruessink et al., 2001] (Figure 4-8B) show that the change in setup owing to neglecting the roller relative to the setup 
predicted with the full model was often $15 \%$ when $H_{r m s}>1 \mathrm{~m}$, and in some cases exceeded 22\% (Figure 4-8A, compare solid with dashed curve). However, for small waves or high tidal states (when the bar was located farther offshore and in deeper water), the effect of rollers on the setup is similar to that found at SandyDuck. Furthermore, the effect of the roller for eight days during SandyDuck when a bar (height $>0.50 \mathrm{~m}$ and width $>20 \mathrm{~m}$ ) was present, as well as for numerical simulations using the barred (height $\approx 1 \mathrm{~m}$ and width $\approx 80 \mathrm{~m}$ ) bathymetry from 26 October 1994 (Duck94 experiment [Elgar et al., 1997]) is similar to the effect for all bathymetries at SandyDuck. The numerical simulations over the Egmond and Duck94 bathymetry suggest that the effect of bottom stress on setup also is significant on beaches with large offshore bars (Figure 4-8A, compare solid with dotted curve).
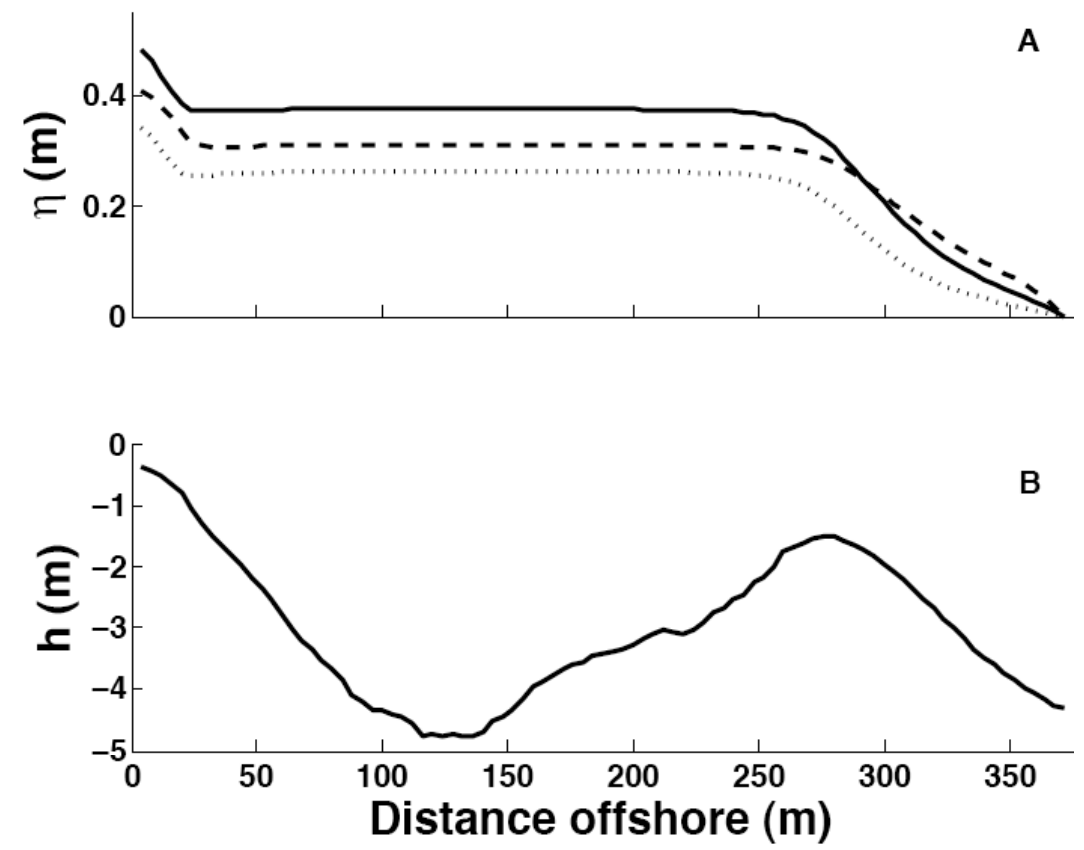

Figure 4-8: (A) Setup simulated using the full model [(4-1) through (4-3), solid curve], the model without the roller term (dashed curve), and the model without the bottom stress term (dotted curve) for (B) the barred beach profile near Egmond, The Netherlands on 18 October, 1998 relative to still water level versus the distance offshore. For this simulation, the offshore wave height was $2.1 \mathrm{~m}$ and the still water (tidal) level was -1.7 $\mathrm{m}$ relative to MSL.

\subsubsection{Evaluation of model applicability at SwashX and NCEX}

The setup model developed using the SandyDuck data is evaluated on two near planar 
beaches near La Jolla, CA. Wave-induced pressures and velocities and mean water levels (i.e., setup) were measured for $3072 \mathrm{~s} \mathrm{(51.2} \mathrm{min}$ ) starting every hour at 8 cross-shore locations for 14 days during Sep and Oct 2000 (SwashX) and 23 days during Oct and Nov 2003 (NCEX) (Figure 4-9A \& B, respectively). The 1-hr-long data records were subdivided into 8.5-min-long sections for processing to ensure stationarity in the presence of tidally induced depth changes.

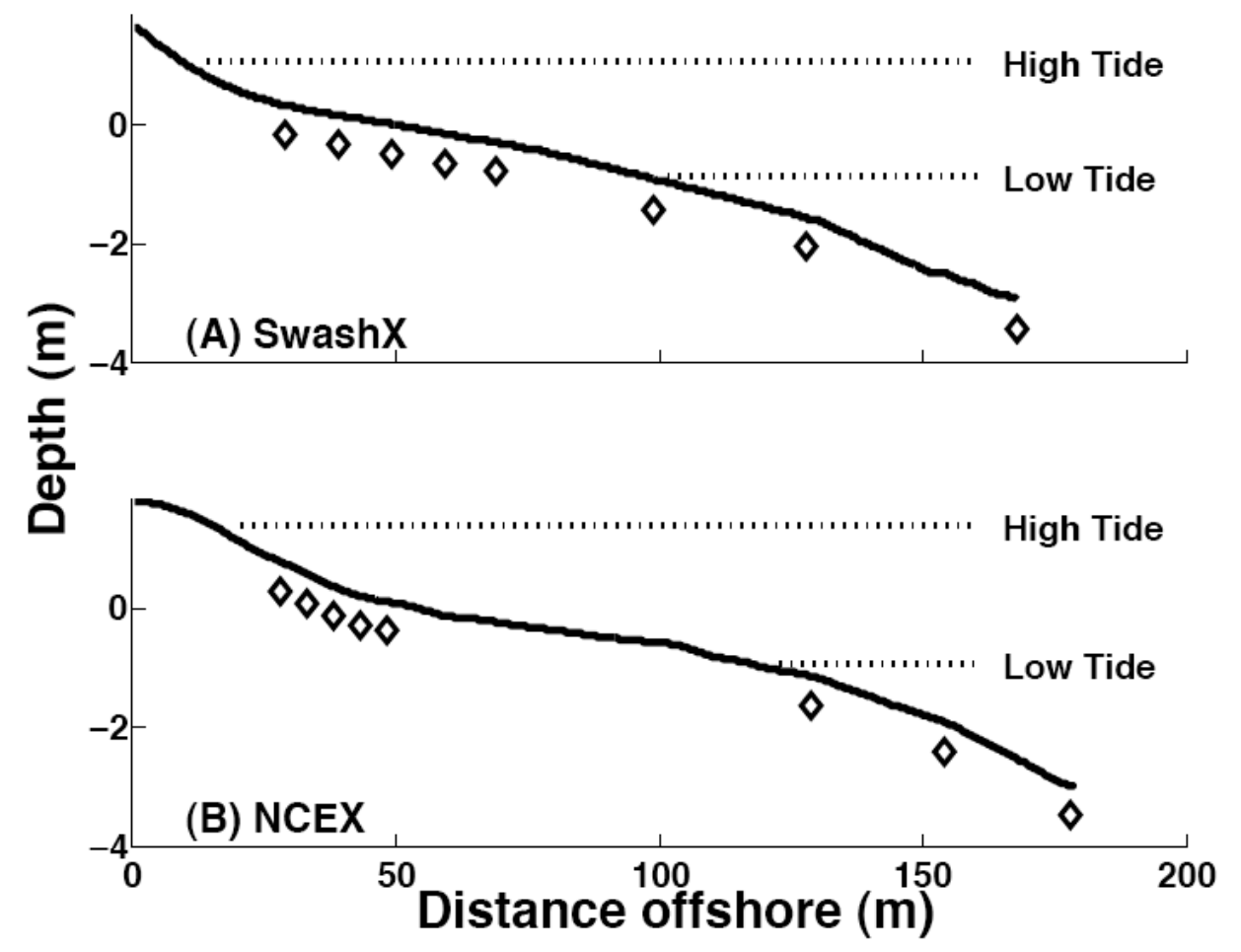

Figure 4-9: Beach profile (solid curves), sensor locations (diamonds), and tidal levels (dotted lines) for (A) SwashX and (B) NCEX.

Offshore rms wave heights ranged from 0.19 to $1.05 \mathrm{~m}$ (SwashX) and 0.20 to $1.00 \mathrm{~m}$ (NCEX). Setup ranged from -0.01 to $0.18 \mathrm{~m}$ (SwashX) and -0.01 to $0.21 \mathrm{~m}$ (NCEX). Centroidal wave frequencies ranged from 0.09 to $0.20 \mathrm{~Hz}$ (SwashX) and 0.08 to $0.21 \mathrm{~Hz}$ (NCEX). Waves were near-normally incident (ranging from about $\pm 5^{\circ}$ with respect to shore normal) during both experiments.

Cross-shore bathymetric profiles were measured relative to mean sea level approximately every other day using a sonar and GPS mounted on a waverunner. The 
tidal ranges, estimated at the most offshore sensor, were -0.87 to $1.04 \mathrm{~m}$ (SwashX) and 0.96 to $1.40 \mathrm{~m}$ (NCEX) relative to mean sea level.

Model applicability is assessed by comparing predictions from the full model with predictions from a model that neglects wave rollers and bottom stress [Longuet-Higgins and Stewart, 1962] (labeled the LHS model) with the observations. Owing to the fact that most of the sensors at SwashX and NCEX were located in shallow water (e.g., Figure 49), and the offshore wave height was typically less than $1.0 \mathrm{~m}$, the depth bins used in this section to evaluate the models are smaller in width and concentrated in shallower water than those used in section 4.4.

The LHS model underpredicts setup for all water depths (i.e., negative mean errors and slopes less than 1, solid curves in Figures 4-10A-C and 4-10G-I, respectively). Addition of the roller and bottom stress in the full model increases predicted setup, and typically results in smaller mean errors and similar $r^{2}$ values relative to the LHS model. In water depth ranges $0.3<h<0.5 \mathrm{~m}, 0.5<h<1.0 \mathrm{~m}$, and, $1.0<h<2.0 \mathrm{~m}$, the best-fit linear slopes between the full model predictions and observations are $0.66 \pm 0.17,0.74 \pm$ 0.09, and 1.06 \pm 0.05 (SandyDuck), $1.13 \pm 0.39,1.13 \pm 0.23$, and $1.42 \pm 0.53$ (SwashX), and $0.90 \pm 0.42,0.74 \pm 0.23,0.84 \pm 0.17$ (NCEX), respectively. Setup and setdown in the deepest water at SwashX and NCEX often were smaller than the measurement error, and thus the slope of the linear regression may be inaccurate (e.g., Figure 4-10H \& I, see values in $2.25 \mathrm{~m}$ water depth). For $h<2 \mathrm{~m}$, the $r^{2}$ values between model predictions and observations are greater than about 0.59 (SandyDuck), 0.67 (SwashX), and 0.47 (NCEX).

At all three experiments the linear regression slopes are significantly (at the $95 \%$ confidence level) closer to 1 than those of the LHS model in $h<2 \mathrm{~m}$. The uncertainty of the slopes is greater at NCEX and SwashX than at SandyDuck owing to the smaller number of data records. Furthermore, at SandyDuck and NCEX the full model reduces the mean and rms errors relative to the LHS model, and results in slopes closer to 1 for $h$ $<1.5 \mathrm{~m}$. At SwashX, the full model results in larger rms errors in mid-depth water, and overpredicts setup in most water depths, possibly owing to poor representation of the bottom stress in deeper water. The waves are smaller at SwashX than at SandyDuck, and 
thus the bottom stress formulation may not be valid until approximately $1 \mathrm{~m}$ water depth at SwashX. A model that includes bottom stress only when $h<1 \mathrm{~m}$ has smaller rms errors than the LHS model in all depths, and results in no overprediction of the observed setup (not shown).
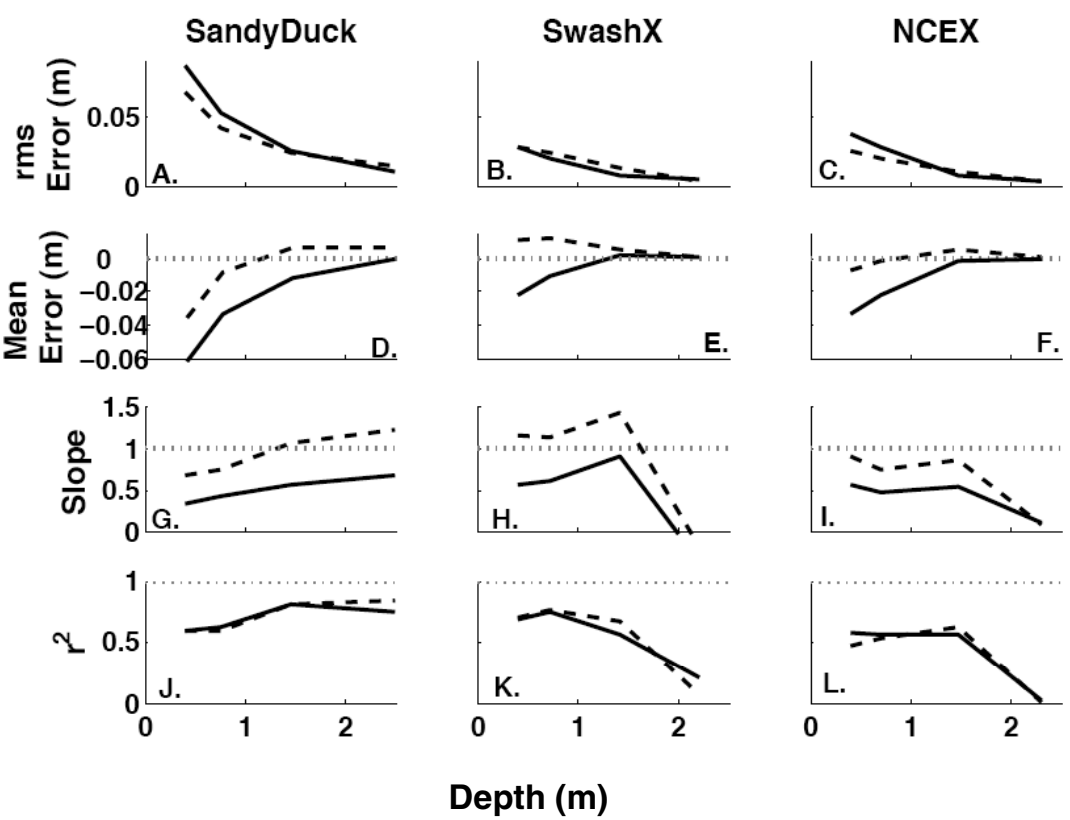

Figure 4-10: (A-C) Root-mean square (rms) and (D-F) mean errors, and (G-I) best-fit slopes and $(\mathrm{J}-\mathrm{L})$ correlations $\left(r^{2}\right)$ between the observations and predictions for the LHS model (solid curve) and the full model (dashed curve) for (A, D, G, and J) SandyDuck, (B, E, H, and K) SwashX, and (C, F, I, and L) NCEX versus water depth. The horizontal dotted lines represent either zero (mean errors) or 1 (slope and $r^{2}$ values).

The along- and cross-shore drag coefficients at NCEX and SwashX were determined from (4-21) and (4-23), respectively, similar to at SandyDuck (see section 4.5.2.1). At NCEX and SwashX, respectively, $C_{f, c}$ (i.e., 0.029 and 0.021 ) and $C_{f, a}$ (i.e., 0.001 and 0.002) found inside the surfzone are similar to those found at SandyDuck, and differ by approximately an order of magnitude.

\subsubsection{Model Tuning}

Although the full model has been shown to agree well with observations from 3 field experiments, the eddy viscosity formulation (4-7) used in the bottom stress 
component of the model is poorly understood. Furthermore, as explained in section 4.2, the constant 1/14 used in (4-7) was determined outside of the surfzone, and thus from different physical processes than those that dominate the surfzone .

Here, the setup observations are used to tune $v_{e}$ given by (4-7) by multiplying the eddy viscosity by $1 / 10,1 / 6,1 / 3,1 / 2,1,11 / 2,2,3$, and 5 . The full model was run on all data records using each of the multiplication factors, and the slopes and mean and rms errors between the predicted and observed setup in $0.3<h<1.0 \mathrm{~m}$ and $1.0<h<2.0 \mathrm{~m}$ were compared (Figure 4-11). In addition to (4-7), eight additional formulations of $v_{e}$ are examined: $10^{-2} \mathrm{ch}$ [Stive and Wind, 1986], $\left(H_{r m s} / 2\right)^{2} f$ [Thornton, 1970], $h(\varepsilon / \rho)^{1 / 3}[$ Battjes,

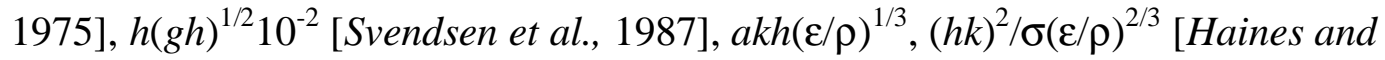
Sallenger, 1994], and $0.101 H_{r m s}(\varepsilon / \rho)^{1 / 3}$ [Reniers et al., 2004], where $f$ is the wave frequency, $a$ is the wave amplitude $\left(H_{r m s} / 2\right), \sigma$ is the wave radian frequency, $k$ is the wave number, and $\varepsilon$ is the dissipation owing to wave breaking (see Chapter 2).

Using (4-7), the best agreement between model predictions and observations is achieved using a multiplication factor of 1 (Figure 4-11), suggesting that the constant $1 / 14$ may be appropriate inside the surfzone. Although most of the other $v_{e}$ formulations can be multiplied by an arbitrary factor to achieve similar agreement with the observations, no $v_{e}$ formulation predicts setup significantly better than (4-7). For each $v_{e}$ formulation, using the tuned multiplication factor overpredicts setup at SwashX, predicts setup well at NCEX, and underpredicts setup at SandyDuck. This result may suggest that the depth at which the bottom stress formulation becomes valid is not fixed, and instead depends on local conditions, such as the bathymetry or the incoming wave field.

Furthermore, to predict setup well in shallow water, setup is typically overpredicted in deeper water (e.g., Figure 4-11D \& F).

As suggested in section 4.5.2.2, the bottom stress formulation may be valid only in shallow water. Here, the full model with each $v_{e}$ formulation and multiplication factor combination was initialized at and run from the deepest sensor located between 1.0- and 1.5-m water depth for each data record. If no sensor was located in these depths, the model was not run and no predictions were recorded for that data record. As the model 
was initialized in $h<1.5 \mathrm{~m}$, no results were recorded for deeper water (i.e., $1.0<h<2.0$ $\mathrm{m})$.
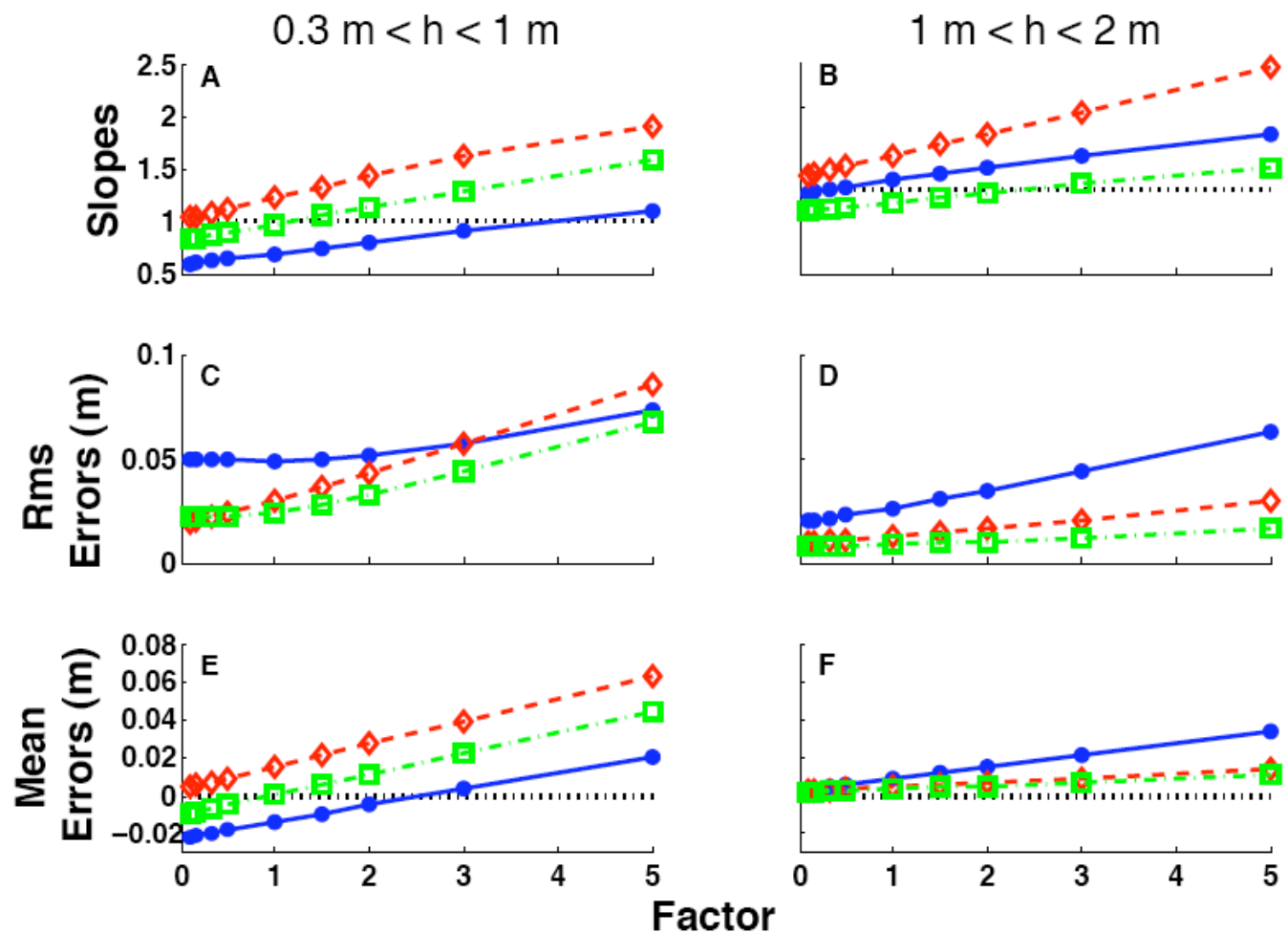

Figure 4-11: (A \& B) Slopes, (C \& D) rms errors, and (E \& F) mean errors between the observed and predicted setup in shallow $(0.3<h<1.0 \mathrm{~m})(\mathrm{A}, \mathrm{C}, \& \mathrm{E})$ and deeper $(1.0<h$ $<2.0 \mathrm{~m})(B, D, \&$ F) water versus the factor by which (4-7) was multiplied for SandyDuck (solid blue curves and circles), SwashX (dashed red curves and diamonds), and NCEX (dashed-dotted green curves and squares). The symbols indicate the multiplication factors used, and the curves represent linear interpolation between the symbols. The dotted black lines indicate a slope of 1 (A \& B) or a mean error of 0 (E \& F). The model was initialized at the deepest sensor at each experiment.

A much larger multiplication factor is needed to obtain similar agreement with the observations in shallow water (Figure 4-12). This result may suggest that either $v_{e}$ is larger than previously estimated in shallow water, or that the wave-breaking-generated turbulence begins to influence the bottom stress gradually from a depth greater than 1.5 m. Assuming the latter, the gradual inclusion of the bottom stress formulation (4-6) may be necessary to accurately predict setup in all water depths. However, the inclusion of 
two unknown variables is (4-1) (i.e., $R_{x x}$ and $\tau_{b}$ ) precludes using the observations of $\bar{\eta}$ and $S_{x x}$ to estimate the cross-shore distribution of the bottom stress.
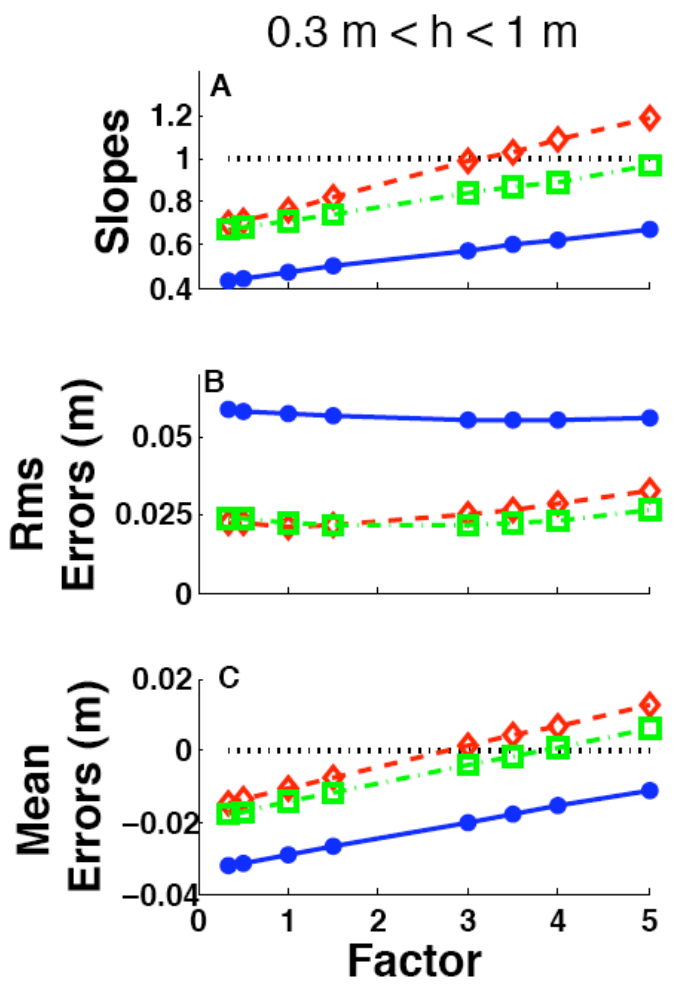

Figure 4-12: Same as 4-11A, $C$ and E, but with the model initialized at the deepest sensor between 1.0 and $1.5 \mathrm{~m}$ water depth. (A) Slopes, (B) rms errors, and (C) mean errors between the observed and predicted setup in shallow $(0.3<h<1.0 \mathrm{~m})$ water versus the factor by which (4-7) was multiplied for SandyDuck (solid blue curves and circles), SwashX (dashed red curves and diamonds), and NCEX (dashed-dotted green curves and squares). The symbols indicate the multiplication factors used, and the curves represent linear interpolation between the symbols. The dotted black lines indicate a slope of $1(A)$ or a mean error of 0 (C).

\subsubsection{Modeling Setup without Observational Inputs}

The accuracy of setup predicted with (4-1) through (4-3) and based on limited knowledge of the observational inputs (i.e., wave height, period, and angle, and water depth) is examined by assuming only the offshore wave height and water depth are known. The full model is driven assuming the beach profile is planar from the known offshore water depth to the shoreline, and using an experiment-averaged wave period, 
normally incident waves, and a constant mean sea level (i.e., no tidal fluctuations). The resulting setup predictions from this "simulation" model are significantly less accurate than the predictions of the full model driven with all the observational inputs.

For all three experiments, the $r^{2}$ values between the observations and the simulation

model predictions are small (e.g., $r^{2}<0.25$ in $h<1 \mathrm{~m}$ ), and the mean and rms errors are approximately 5 times larger than those between the observations and the full model. For the data considered here, almost all of the reduction in model skill is owing to the assumptions of a planar profile and a constant mean sea level. At SwashX and NCEX, where the profile is nearly planar, addition of tidally fluctuating water levels greatly increases the skill of the model. In contrast, at SandyDuck accurate representation of the barred profile is of equal importance to accurate measurement of the tidal levels. For all experiments, using an experiment-averaged wave period or assuming normally incident waves does not affect the setup predictions significantly.

Thus, setup models based on (4-1) through (4-3) are sensitive to the accuracy of the observations used to drive them, and setup predictions based on limited knowledge of the offshore conditions or bathymetry should be used with caution.

\subsubsection{Other Terms}

It has been suggested that broad wave directional spreads, wave skewness, large wind stresses, convective accelerations of the current, wave-generated near-bottom flow asymmetry, onshore-directed streaming flow, and alongshore inhomogeneous bathymetry or wave conditions could affect setup predictions in shallow water. Incorporating terms that correct the radiation stress estimates for the observed directional spreads [Feddersen, 2004] and for wave skewness [Johnson and Kobayashi, 1998] has a negligible effect on the setup predictions. Wind speeds and convective accelerations of the current (estimated following Dally and Brown [1995]) are small, and the estimated setup forcing owing to these terms is negligible. Neglecting wave-generated flow asymmetry and onshoredirected streaming flow [e.g., Longuet-Higgins, 2005; Dean and Bender, 2006] may explain partly the overprediction of setup in the shoaling and outer surfzone regions 
where the undertow is relatively small. The two-dimensional setup forcing term $\left(\frac{\partial S_{x y}}{\partial y}\right)$ was estimated from differences between $S_{x y}$ calculated using the wave models and Snell's Law along two cross-shore transects approximately 20 meters north and south of the instrumented transect. For $h<1 \mathrm{~m}$, on average $\frac{\partial S_{x y}}{\partial y}$ is less than $1 \%$ of the cross-shore term $\left(\frac{\partial S_{x x}}{\partial x}\right)$ and exceeds $\frac{\partial S_{x x}}{\partial x}$ by $5 \%$ less than $2 \%$ of the time, and thus does not affect the setup model results presented here. For more details on most of these terms, see Chapter 3.

\subsubsection{Some Final Thoughts on the Cross-shore Momentum Balance}

The mean and rms errors between the cross-shore sum of $\partial S_{x x}$ (i.e., the LHS model) and the observed setup in shallow water are approximately 0.04 and $0.06 \mathrm{~m}$, respectively, at SandyDuck (Table 4-1). These errors are significantly larger than the accuracy of the pressure sensors (i.e., between 0.005 and $0.020 \mathrm{~m}$ ). Therefore, it is unlikely that the discrepancy between setup predictions based only on the radiation stress divergence $\left(\partial S_{x x} / \partial x\right)$ and the measured setup is owing solely to pressure measurement errors.

Furthermore, the total radiation stress forcing $\left(\sum \partial S_{x x} / \partial x * \Delta x\right)$ based on linear theory estimates of $S_{x x}$ and neglecting rollers is significantly smaller than the total measured pressure gradient (i.e., $\left.\sum(\rho g h) \partial \bar{\eta} / \partial x * \Delta x\right)$ in shallow water at NCEX and SwashX, where $x$ is the spacing between two adjacent sensors. Assuming the bathymetry, mean water levels, and radiation stresses vary linearly between sensor locations so that the forcing and pressure terms can be calculated directly from the measurements, the average discrepancy between $\sum \partial S_{x x} / \partial x * \Delta x$ and $\sum(\rho g h) \partial \bar{\eta} / \partial x * \Delta x$ at the shallowest sensor outside the swash zone $(h>0.30 \mathrm{~m})$ is approximately $50 \%$ of the measured pressure gradient (i.e., the same order of magnitude as $\sum \partial S_{x x} / \partial x * \Delta x$ ) at both 
experiments. A comparison of the cross-shore profiles of the two terms indicates that the transition from setdown to setup predicted by the radiation stress forcing occurs farther offshore than the transition observed in the measured pressure gradient, consistent with previous studies that have shown a roller-like process is needed to shift at least some of the forcing shoreward.

A roller can be included in the frictionless model that shifts all excess forcing shoreward, resulting in better agreement between the estimated forcing and the measured setup. However, a roller only shifts the forcing in the cross-shore, and thus it does not decrease the total discrepancy between the two terms. Therefore, even with a completely efficient roller, setup is underpredicted in shallow water at these two experiments. Thus, the LHS model must either neglect an important term in the momentum balance equation (e.g., bottom stress) or linear theory estimates of the radiation stress divergence underpredict the actual setup forcing in shallow water.

The discrepancy between the LHS model predictions and observations increases with increasing $\bar{\eta}$ for a given water depth at SandyDuck (Figure 4-3g), suggesting that any missing physics in the model may increase in importance with increasing $\bar{\eta}$. For example, bottom stress may be increasingly important with increasing wave energy (and thus increasing setup) because either nearbed wave generated turbulence increases, or the wider surfzone enables bottom stress to affect setup over a larger area. Thus, neglecting bottom stress during large wave events may result in increased underprediction of $\bar{\eta}$.

However, $\bar{\eta} / \bar{\eta}$ is approximately constant, and it is possible that linear theory increasingly underestimates the radiation stress divergence in the surfzone with increasing wave energy. Although linear theory often provides reasonable estimates of wave processes in the surfzone [Guza and Thornton, 1980, 1981], the linear assumptions often are invalid. In particular, the assumptions that waves change shape slowly, that wave amplitudes are small relative to the water depth, and that the bottom slope is small, often are violated.

Bases on these observations it is clear that the LHS model, based solely on the radiation stress divergence as estimated from linear theory, is inadequate for predicting 
setup in the surfzone, and that including a roller cannot decrease the discrepancy observed between the total wave forcing and the setup. Therefore, model improvements such as the inclusion of additional terms (as was done in this study) or more accurate estimates of the radiation stress divergence through the use of nonlinear wave theories may be necessary to predict setup well on natural beaches.

\subsection{Conclusions}

Field observations of wave setup are compared with model predictions that include the effects of wave rollers and bottom stress. At a barred beach, the modeled and observed setup are correlated ( $r^{2}$ above 0.59 ), and agree within about $30 \%$. Rollers typically have only a small effect on the magnitude of setup, but may be important to the cross-shore setup profile and to setup on beaches with larger amplitude sandbars. Bottom stress significantly affects the setup predictions. For $0.3<h<1.0 \mathrm{~m}$, excluding bottom stress increases the mean error in setup predictions by a factor of about 3 . Although excluding bottom stress does not change the correlation between model predictions and observations, the best-fit slope decreases by $38 \%$ (i.e., underprediction increases) and the rms error increases by about $27 \%$. Including rollers and bottoms stress in the model also improves predictions of setup at two near-planar beaches, suggesting the model is applicable at many field sites.

Estimated eddy viscosities used to calculate the bottom stress are similar to values found in previous field experiments. Although the estimated cross-shore drag coefficients are similar to those found previously in the swash and inner surf, they are approximately an order of magnitude larger than alongshore drag coefficients found from an alongshore momentum balance. The large cross-shore drag coefficients may be related to the assumption of a vertically constant eddy viscosity (as would be appropriate if breakingwave generated turbulence penetrates to the bed) or to the presence of anisotropic bedforms. Therefore, the bottom stress formulation presented here may only be valid over certain sections of the surfzone. 


\subsection{References}

Arcement, G.J. and V.R. Schneider, Guide for Selecting Manning's Roughness

Coefficients for Natural Channels and Flood Plains, Water-Supply Paper No. 2339,

Department of the Interior, U.S. Geological Survey, Reston, VA, 1990.

Archetti, R. and M. Brocchini, An integral swash zone model with friction: An experimental and numerical investigation, Coastal Eng., 45, 89-110, 2002.

Baldock, T.E., P. Holmes, S. Bunker, and P. Van Weert, Cross-shore hydrodynamics within an unsaturated surf zone, Coastal Eng., 34, 173-196, 1998.

Barrantes, A.I. and O.S. Madsen, Near-bottom flow and resistance for currents obliquely incident to two-dimensional roughness elements, J. Geophys. Res., 105 (C11), 2625326264, 2000.

Battjes, J.A., Modeling of turbulence in the surf zone, Symposium on Modeling Techniques, 1975.

Battjes, J.A. and M.J.F. Stive, Calibration and verification of a dissipation model for random breaking waves, J. Geophys. Res., 90, 9159-9167, 1985.

Bowen, A.J., D.L. Inman, and V.P. Simmons, Wave 'set-down' and set-up, J. Geophys. Res., 73, 2569-2577, 1968.

Carstens, M.R., F.M. Nielson, and H.D. Altinbilek, Bed forms generated in the laboratory under oscillatory flow, Coastal Eng. Res. Center, Fort Belvoir, VA, Tech. Mem., 28, 1969.

Church, J.C. and E.B. Thornton, Effects of breaking wave induced turbulence within a longshore current model, Coastal Eng., 20, 1-28, 1993.

Cox, D.T. and N. Kobayashi, Identification of intense, intermittent coherent motions under shoaling and breaking waves, J. Geophys. Res., 105, 14223-14236, 2000.

Cox, D.T., N. Kobayashi, and A. Okayasu, Bottom shear stress in the surf zone, $J$. Geophys. Res., 101, 14337-14348, 1996.

Cox, D.T., W.A. Hobensack, and A. Sukumaran, Bottom stress in the inner surf and swash zone, International Conference on Coastal Engineering, Sydney, Australia, 2001.

Dean, R.G. and C.J. Bender, Static wave setup with emphasis on damping effects by 
vegetation and bottom stress, Coastal Eng., 53, 149-156, 2006.

Dally, W.R. and C.A. Brown, A modeling investigation of the breaking wave roller with application to cross-shore currents, J. Geophys. Res., 100, 24873-24883, 1995.

Deigaard, R., A note on the three-dimensional shear stress distribution in a surf zone, Coastal Eng., 20, 157-171, 1993.

Elgar, S., R.T. Guza, B. Raubenheimer, T.H.C. Herbers, and E. Gallagher, Spectral evolution of shoaling and breaking waves on a barred beach, J. Geophys. Res., 102, 15797-15805, 1997.

Elgar, S., R.T. Guza, W.C. O'Reilly, B. Raubenheimer, and T.H.C. Herbers, Wave energy and direction observed near a pier, J. Wtrwy., Port, Coast., and Oc. Engr., 127(1), 2-6, 2001.

Feddersen, F., Effect of wave directional spread on the radiation stress: Comparing theory and observations, Coastal Eng., 51, 473-481, 2004.

Feddersen, F. and R.T. Guza, Observations of nearshore circulation: Alongshore uniformity, J. Geophys. Res., 108 (C1), 3006, doi:10.1029/2001JC001293, 2003.

Feddersen, F. and J.H. Trowbridge, The effect of wave breaking on surfzone turbulence and alongshore currents: A modeling study, J. Phys. Oceangr., submitted, 2005.

Feddersen, F., R.T. Guza, S. Elgar, and T.H.C. Herbers, Alongshore momentum balances in the nearshore, J. Geophys. Res., 103, 15667-15676, 1998.

Feddersen, F., R.T. Guza, S. Elgar, and T.H.C. Herbers, Velocity moments in alongshore bottom stress parameterizations, J. Geophys. Res., 105, 8673-8686, 2000.

Feddersen, F., E.L. Gallagher, R.T. Guza, and S. Elgar, The drag coefficient, bottom roughness, and wave breaking in the nearshore, Coastal Eng., 48, 189-195, 2003.

Feddersen, F., R.T. Guza, and S. Elgar, Inverse modeling of the one-dimensional setup and alongshore current in the nearshore, J. Phys. Oceanogr., 34, 920-933, 2004.

Fredsøe, J., B.M. Sumer, A. Kozakiewicz, L.H.C. Chua, and R. Deigaard, Effect of externally generated turbulence on wave boundary layer, Coastal Eng., 49, 155-183, 2003.

Gallagher, E.L., S. Elgar, and R.T. Guza, Observations of sand bar evolution on a natural beach, J. Geophys. Res., 103, 3203-3215, 1998. 
Garcez-Faria, A.F., E.B. Thornton, T.P. Stanton, C.V. Soares, and T.C. Lippmann, Vertical profiles of longshore currents and related bed shear stress and bottom roughness, J. Geophys. Res., 103, 3217-3232, 1998.

Garcez-Faria, A.F., E.B. Thornton, T.C. Lippmann, and T.P. Stanton, Undertow over a barred beach, J. Geophys. Res., 105, 16999-17010, 2000.

Goda, Y., Examination of the influence of several factors on longshore current computation with random waves, Coastal Eng., 53, 157-170, 2005.

Guza, R.T. and E.B. Thornton, Local and shoaled comparisons of sea surface elevations, pressures, and velocities, J. Geophys. Res., 85, 1524-1530, 1980.

Guza, R.T. and E.B. Thornton, Wave set-up on a natural beach, J. Geophys. Res., 86, 4133-4137, 1981.

Haas, K.A., I.A. Svendsen, and M.C. Haller, Numerical modeling of nearshore circulation on a barred beach with rip channels, International Conference on Coastal Engineering, 801-814, New York, 1998.

Haines, J.W. and A.H. Sallenger, Jr., Vertical structure of mean cross-shore currents across a barred surf zone, J. Geophys. Res., 99, 14223-14242, 1994.

Hay, A. and T. Mudge, Principal bed states during SandDuck97: Occurrence, spectral anisotropy, and the bed state storm cycle, J. Geophys. Res., 110, C03013, doi:10.1029/2004JC002451, 2005.

Johnson, B.D. and N. Kobayashi, Nonlinear time-averaged model in surf and swash zones, International Conference on Coastal Engineering, Copenhagen, Denmark, 27852798, 1998.

Johnson, B.D. and J.M. Smith, Longshore current forcing by irregular waves, $J$. Geophys. Res., 110, C06006, doi:10.1029/2004JC002336, 2005.

Lentz, S. and B. Raubenheimer, Field observations of wave setup, J. Geophys. Res., 104, 25867-25875, 1999.

Lippmann, T.C., A.H. Brookins, and E.B. Thornton, Wave energy transformation on natural profiles, Coastal Eng., 27, 1-20, 1996.

Longuet-Higgins, M.S., Longshore currents generated by obliquely incident sea waves, $J$. Geophys. Res., 75, 6778-6789, 1970.

Longuet-Higgins, M.S., Oscillating flow over steep sand ripples, J. Fluid Mech., 107, 1- 
$35,1981$.

Longuet-Higgins, M.S., On wave set-up in shoaling water with a rough sea bed, J. Fluid Mech., 527, 217-234, 2005.

Longuet-Higgins, M.S. and R.W. Stewart, Radiation stress and mass transport in gravity waves, with application to 'surf-beats,' J. Fluid Mech., 13, 481-504, 1962.

Longuet-Higgins, M.S. and R.W. Stewart, Radiation stresses in water waves: A physical discussion with application, Deep Sea Res., 11, 529-562, 1964.

Petti, M. and S. Longo, Turbulence experiments in the swash zone, Coastal Eng., 43, 124, 2001.

Phillips, O.M., The Dynamics of the Upper Ocean, Cambridge University Press, Cambridge, 1966.

Raubenheimer, B., R.T. Guza, S. Elgar, and N. Kobayashi, Swash on a gently sloping beach, J. Geophys. Res., 100, 8751-8760, 1995.

Raubenheimer, B., R.T. Guza, and S. Elgar, Wave transformation across the inner surf zone, J. Geophys. Res., 101, 25589-25597, 1996.

Raubenheimer, B., R.T. Guza, and S. Elgar, Field observations of wave-driven setdown and setup, J. Geophys. Res., 106, 4629-4638, 2001.

Raubenheimer, B., S. Elgar, and R.T. Guza, Observations of swash zone velocities: A note on friction coefficients, J. Geophys. Res., 109, C01027, doi:10.1029/2003JC001877, 2004.

Reniers, A.J. and J.A. Battjes, A laboratory study of longshore currents over barred and non-barred beaches, Coastal Eng., 30, 1-22, 1997.

Reniers, A.J., E.B. Thornton, T.P. Stanton, and J.A. Roelvink, Vertical flow structure during Sandy Duck: observations and modeling, Coastal Eng., 51, 237-260, 2004.

Ruessink, B.G., J.R. Miles, F. Feddersen, R.T. Guza, and S. Elgar, Modeling the alongshore current on barred beaches, J. Geophys. Res., 106, 22451-22463, 2001.

Ruessink, B.G., D.J.R. Walstra, and H.N. Southgate, Calibration and verification of a parametric wave model on barred beaches, Coastal Eng., 48, 139-149, 2003. 
Schmidt, W.E., R.T. Guza, and D.N. Slinn, Surf zone currents over irregular bathymetry: Drifter observations and numerical simulations, J. Geophys. Res., 110, C12015, doi:10.1029/2004JC002421, 2005.

Smith, J.A., Evolution of Langmuir circulation during a storm, J. Geophys. Res., 103, 12649-12668, 1998.

Stive, M.J.F. and H.G. Wind, A study of radiation stress and set-up in the nearshore region, Coastal Eng., 6, 1-25, 1982.

Stive, M.J.F. and H.G. Wind, Cross-shore mean flow in the surfzone, Coastal Eng., 10, 325-340, 1986.

Styles, R. and S.M Glenn, Modeling bottom roughness in the presence of wave-generated ripples, J. Geophys. Res., 107, C8, 3110, doi:10.1029/2001JC000864, 2002.

Svendsen, I.A., Wave heights and set-up in a surf zone, Coastal Eng., 8, 303-329, 1984a.

Svendsen, I.A., Mass flux and undertow in a surf zone, Coastal Eng., 8, 347-365, 1984b.

Svendsen, I.A., H.A. Schäffer, and J. Buhr Hansen, The interaction between the undertow and the boundary layer flow on a beach, J. Geophys. Res., 92, 11845-11856, 1987.

Tajima, Y. and O.S. Madsen, Modeling near-shore waves and surface rollers, Proceedings of the 2nd International Conference on Asian and Pacific Coasts, ISBN 981-238-588-4, 2003.

Terray, E.A., M.A. Donelan, Y.C. Agrawal, W.M. Drennan, K.K. Kahma, A.J. Williams III, P.A. Hwang, and S.A. Kitaigorodski, Estimates of kinetic energy dissipation under breaking waves, J. Phys. Ocean., 26, 792-807, 1996.

Thornton, E.B., Variation of longshore currents across the surfzone, International Conference on Coastal Engineering, 291-308, 1970.

Thornton, E.B. and R.T. Guza, Transformation of wave height distribution, J. Geophys. Res., 88, 5925-5938, 1983.

Thornton, E.B. and R.T. Guza, Surf zone longshore currents and random waves: Field data and models, J. Phys. Ocean., 16, 1165-1178, 1986.

Trowbridge, J. and S. Elgar, Turbulence measurements in the surfzone, J. Phys. Ocean., 31, 2403-2417, 2001. 
Wu, J., Wind-stress coefficients over sea surface near neutral conditions - A revisit, $J$. Phys. Oceanogr., 10, 727-740, 1980.

Wu, C.S., E.B. Thornton, and R.T. Guza, Waves and longshore currents: Comparison of a numerical model with field data, J. Geophys. Res., 90, 4951-4958, 1985. 


\title{
Chapter 5: Alongshore Nonuniform Setup
}

\begin{abstract}
The importance of alongshore gradients in the wave forcing to wave-driven setup, the increase in the mean sea level owing to breaking waves, is investigated using observations from a near planar beach onshore of a deep submarine canyon. Wave heights and radiation stresses estimated with observations at the outer edge of the surfzone (water depth $h \approx 2.5 \mathrm{~m}$ ) varied by up to a factor of 4 and 16 , respectively, along a few hundred meters of the coast owing to focusing and shadowing of the incoming wave field by the canyon. The wave forcing of shallow water setup is dominated by the cross-shore $(x)$ component of the wave radiation stress tensor $\left(S_{x x}\right)$, and alongshore $(y)$ variations in setup can be explained by the alongshore variations in $S_{x x}$ at the seaward edge of the surfzone. When initialized with the wave heights observed on the $2.5-\mathrm{m}$ isobath, a setup model that neglects alongshore gradients in the diagonal component of the wave radiation stress tensor $\left(S_{x y}\right)$ accurately predicts the observed setup and the associated alongshore setup gradients. Comparisons of the observed alongshore flows in the inner surfzone with a momentum balance based on the cross-shore gradient of the wave forcing $\left(\partial S_{x y} / \partial x\right)$ and the alongshore gradient of the pressure suggests that the alongshore gradient of the wave forcing $\left(\partial S_{y y} / \partial y\right)$ may not contribute significantly to the alongshore flow, but that alongshore gradients in setup can force significant alongshore flows.
\end{abstract}

\subsection{Introduction}

Setup, the increase in the mean sea level owing to breaking waves, is predicted well by a one-dimensional (1-D) cross-shore momentum balance on alongshore-uniform coasts [Battjes and Stive, 1985; Lentz and Raubenheimer, 1999; Raubenheimer et al., 2001; Apotsos et al., 2006, 2007]. Although alongshore variations in the surfzone bathymetry have been shown to result in alongshore variations of setup that can drive 
both rip and alongshore currents [Putrevu et al., 1995; Slinn et al, 2000; Haller et al., 2002; Haas et al., 2003; Schmidt et al., 2005], few studies have investigated the effects of alongshore variations in the incident wave field on shallow water setup and alongshore flows. Furthermore, the previous laboratory and field studies did not investigate alongshore changes in the time-averaged setup owing to the pressure-driven currents [i.e., increases (decreases) in setup onshore of (next to) a rip channel].

Here, the relative importance of cross- and alongshore gradients in the wave forcing to wave-driven setup is examined using observations and a numerical model on a beach where the incoming wave field is alongshore inhomogeneous. Additionally, an alongshore momentum balance that includes the alongshore gradients in the modeled (1D) setup and the cross-shore gradients in the wave field, but neglects the alongshore variations in the wave field, is compared with the observed alongshore currents. After the theory is outlined (section 5-2) and the observations are described (section 5-3), the results are presented (section 5-4) and discussed (section 5-5), and conclusions are given (section 5-6).

\subsection{Theory}

\subsubsection{Cross-shore Momentum Balance}

The cross-shore pressure gradient associated with the time-averaged wave setup, $\bar{\eta}$, theoretically balances the sum of the cross- and alongshore gradients of the time and depth-averaged tensor components of the wave radiation stress $\left(S_{x x}\right.$ and $\left.S_{x y}\right)$, the crossand alongshore gradients of the time and depth-averaged momentum fluxes owing to the presence of wave rollers ( $R_{x x}$ and $R_{x y}$ ), and the bottom stress $\tau_{b}$, such that [LonguetHiggins and Stewart, 1962, 1964; Mei, 1989; Haller et al., 2002]

$$
-\rho g h \frac{\partial}{\partial x} \bar{\eta}=\frac{\partial}{\partial x} S_{x x}+\frac{\partial}{\partial y} S_{x y}+\frac{\partial}{\partial x} R_{x x}+\frac{\partial}{\partial y} R_{x y}+\tau_{b},
$$

where $\rho$ is the water density, $g$ is the gravitational acceleration, $h$ is the total water depth (including setup), $x$ is the cross-shore coordinate (positive onshore), and $y$ is alongshore 
coordinate (positive to the north on the west coast). The components of the wave radiation stress tensor can be estimated as [Longuet-Higgins and Stewart, 1962, 1964]

$$
S_{x x}=E_{w}\left\lfloor\left(\cos ^{2} \theta+1\right) \frac{c_{g}}{c}-\frac{1}{2}\right\rfloor,
$$

and [Longuet-Higgins, 1970]

$$
S_{x y}=E_{w} \cos \theta \sin \theta \frac{c_{g}}{c} .
$$

The components of the roller momentum flux are [Svendsen, 1984a \& b]

$$
R_{x x}=2 E_{r}\left(\cos ^{2} \theta\right)
$$

and [Stive and De Vriend, 1994; Ruessink et al., 2001]

$$
R_{x y}=2 E_{r} \cos \theta \sin \theta .
$$

Here, $\theta$ is the mean wave direction relative to beach normal, $c_{g}$ is the group speed, and $c$ is the phase speed. The wave energy $E_{w}$ can be estimated from linear theory as $E_{w}=1 / 8\left(\rho g H_{r m s}^{2}\right)$, where $H_{r m s}$ is the root-mean-square wave height.

The wave roller energy $E_{r}$ is estimated as [Stive and De Vriend, 1994; Ruessink et al., 2001]

$$
\frac{\partial}{\partial x}\left(2 E_{r} c \cos \theta\right)=-\frac{2 g E_{r} \sin (\beta)}{c}+D_{b r},
$$

where $\beta$, the front slope of the wave, is approximated as a constant of 0.1 , and the wave dissipation $D_{b r}$ is

$$
D_{b r}=-\frac{\partial}{\partial x}\left(E_{w} c_{g} \cos \theta\right) .
$$

\subsubsection{Alongshore Momentum Balance}

Neglecting the nonlinear advective terms (following Lentz et al., [1999]), timeaveraged alongshore currents in the surfzone result from a balance between the alongshore pressure gradient owing to variations in setup, $(\rho g h) \partial \bar{\eta} / \partial y$, the sum of the cross- and alongshore gradients of the time and depth-averaged tensor components of the wave radiation stress $\left(S_{x y}\right.$ and $\left.S_{y y}\right)$, the cross-shore gradient of the time and depth- 
averaged momentum flux owing to the presence of wave rollers $\left(R_{x y}\right)$, and the wind and bottom stresses, $\tau_{w}$ and $\tau_{b}[\mathrm{Mei}, 1989]$

$$
0=\rho g h \frac{\partial}{\partial y} \bar{\eta}+\frac{\partial}{\partial x} S_{x y}+\frac{\partial}{\partial y} S_{y y}+\frac{\partial}{\partial x} R_{x y}+\tau_{b}+\tau_{w},
$$

where $S_{y y}$ is [Longuet-Higgins and Stewart, 1962, 1964]

$$
S_{y y}=E_{w}\left\lfloor\left(\sin ^{2} \theta+1\right) \frac{c_{g}}{c}-\frac{1}{2}\right\rfloor .
$$

Since $\partial S_{y y} / \partial y$ is found to be small relative to the other forcing terms in (5-8), no equivalent roller forcing term (i.e., $R_{y y}$ ) is derived. Assuming the wind stress is small, and using a quadratic bottom friction formulation [Feddersen et al., 1998, 2004; Ruessink et al., 2001],

$$
\tau_{b}=\rho c_{d}\langle|\vec{u}| v\rangle
$$

where $c_{d}$ is a drag coefficient, $|\vec{u}|$ is the magnitude of the total instantaneous velocity, $v$ is the instantaneous velocity in the alongshore direction, and is time-averaging, the alongshore momentum equation (5-8) becomes

$$
-\rho c_{d}\langle|\vec{u}| v\rangle=\rho g h \frac{\partial}{\partial y} \bar{\eta}+\frac{\partial}{\partial x} S_{x y}+\frac{\partial}{\partial y} S_{y y}+\frac{\partial}{\partial x} R_{x y} \cdot
$$

\subsection{Observations}

\subsubsection{Measurements}

Wave-induced pressures and velocities were measured at 28 locations between the 5.0-m isobath and the shoreline along approximately $2 \mathrm{~km}$ of coast for 48 days during Oct and Nov 2003 [Nearshore Canyon Experiment (NCEX)] on a near planar beach near La Jolla, CA just onshore of a deep submarine canyon (Figure 5-1) [Thomson et al., 2006, 2007]. Data were sampled at 2 or $16 \mathrm{~Hz}$ for $3072 \mathrm{~s} \mathrm{(51.2} \mathrm{min)} \mathrm{starting} \mathrm{every} \mathrm{hour.}$ Unless noted otherwise, the 1-hr-long data records were subdivided into 8.5-min-long sections, reducing nonstationarity associated with tidally induced depth changes. 
Of the 28 pressure sensors, 18 were buried on approximately the $1.0-$ and $2.5-\mathrm{m}$ isobaths at 9 alongshore locations (Figure 5-1, roughly $y=2700,2450,2321,2069$, 1911, 1450, 1300, 1149, and $1000 \mathrm{~m}$, respectively). Two pressure sensors were buried on approximately the 3.0- and 3.5-m isobaths at $y=1300 \mathrm{~m}$. Eight additional pressure sensors were deployed about $0.5 \mathrm{~m}$ above the bed along approximately the $5.0-\mathrm{m}$ isobath at 8 of the alongshore locations (no sensor was located on the 5.0-m isobath at $y=1000$ $\mathrm{m})$. A current meter was deployed between 0.2 and $1.0 \mathrm{~m}$ above the bed at the location of each pressure sensor.

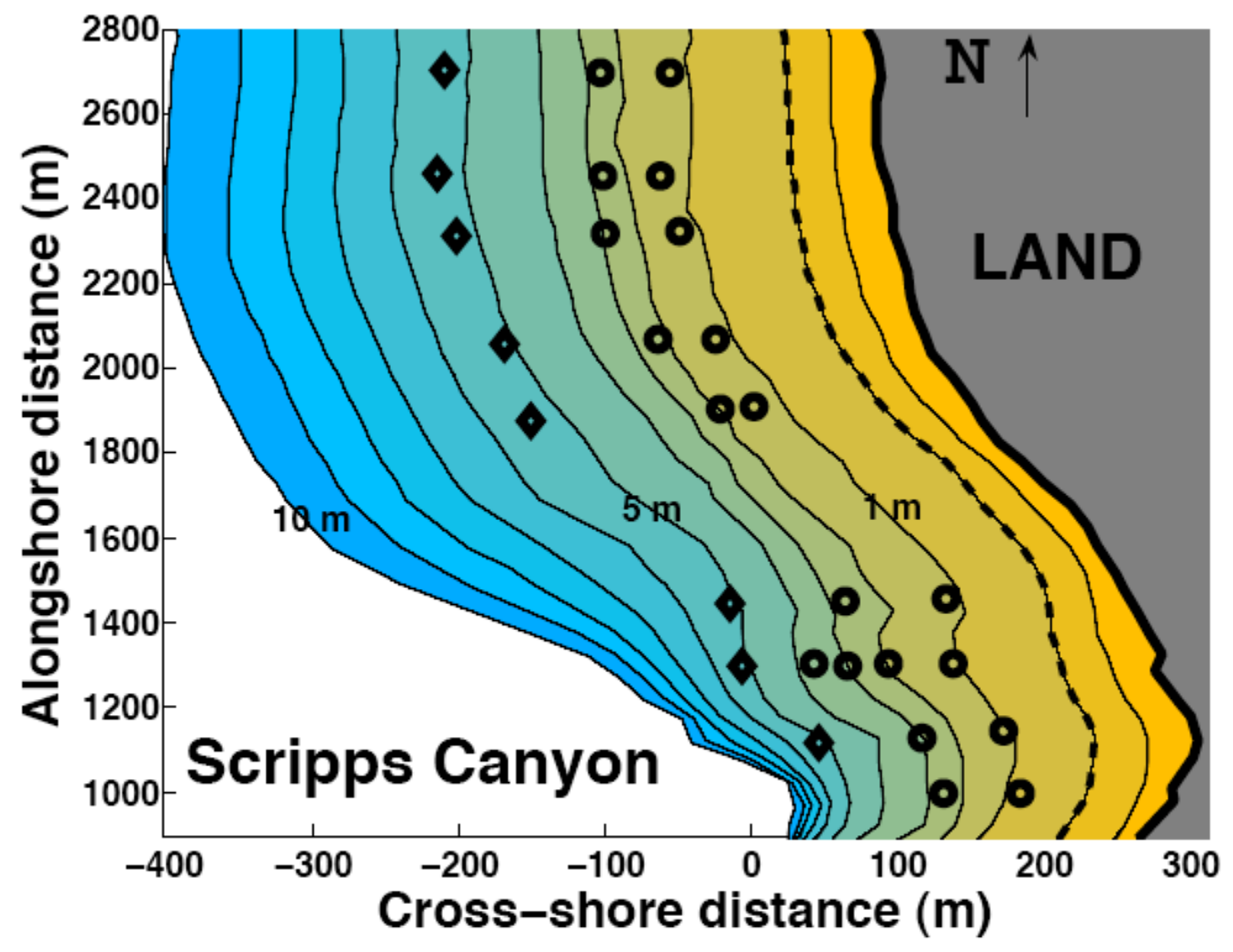

Figure 5-1: Nearshore bathymetry showing the isobaths in $1.0 \mathrm{~m}$ intervals (black curves) and the locations of the current meters colocated with buried (circles) and unburied (diamonds) pressure sensors. The dashed curve is the mean sea level shoreline. The bathymetry extends from $2 \mathrm{~m}$ above (darkest yellow) to $10 \mathrm{~m}$ below (darkest blue) mean sea level. North is approximately at the top of the figure. 
Root-mean-square wave heights $\left(H_{r m s}\right)$ at each sensor were estimated as $2 \sqrt{2}$ times the standard deviation of the sea-surface elevation fluctuations calculated from the time series of pressure (band pass filtered between 0.05 and $0.30 \mathrm{~Hz}$ ) assuming linear wave theory and exponential decay of wave fluctuations through the bed [Raubenheimer et al., 1998]. Mean wave angles were estimated from colocated pressure and velocity observations [Kuik et al., 1988; Herbers and Guza, 1990; Elgar et al., 1994]. Mean water levels were estimated at all 20 buried pressure sensors assuming hydrostatic pressure. The increase in mean sea level owing to breaking waves (i.e., setup) was determined relative to the water level measured on the $3.5-\mathrm{m}$ isobath at $y=1300 \mathrm{~m}$.

The bathymetry was surveyed between about 10-m water depth and the shoreline with roughly 25- to 50-m alongshore spacing (i.e., within 5 to $30 \mathrm{~m}$ alongshore of each instrumented transect) approximately weekly using a GPS and altimeter mounted on a personal watercraft. Although the nearshore bathymetry $(h<10 \mathrm{~m})$ was approximately alongshore uniform (Figure 5-1), refraction over the complex offshore bathymetry (e.g., Scripps Submarine Canyon) results in strong alongshore gradients in the incident wave field [Magne et al., 2007; Thomson et al., 2007].

Root-mean-square wave heights along the $2.5-\mathrm{m}$ isobath ranged from 0.16 to 1.52 $\mathrm{m}$ (Figure 5-2A), and varied by up to a factor of 4 in the alongshore (Figure 5-2A, compare the orange with the magenta curve). Centroidal frequencies (the frequency corresponding to the centroid of the sea-surface elevation spectrum between 0.05 and $0.30 \mathrm{~Hz}$ ) along the $2.5-\mathrm{m}$ isobath ranged from 0.07 to $0.19 \mathrm{~Hz}$. Although waves were near-normally incident (i.e., $\pm 5^{\circ}$ relative to local shore normal based on the 1.0- and 2.5$\mathrm{m}$ isobaths) along most of the cross-shore transects (Figure 5-2B, blue and magenta curves), reflection and refraction of the incoming wave field by Scripps Canyon often resulted in mean wave angles of $10^{\circ}$ to $15^{\circ}$ relative to shore normal near the canyon head [e.g., at $y=1450 \mathrm{~m}$ (Figure 5-2B, orange curve) and $1300 \mathrm{~m}$ ]. Setup ranged from $-0.02 \mathrm{~m}$ to $0.20 \mathrm{~m}$, and varied by up to a factor of 10 in the alongshore (e.g., Figure 5-3A). The tide ranged from -0.96 to $1.36 \mathrm{~m}$ relative to mean sea level. 

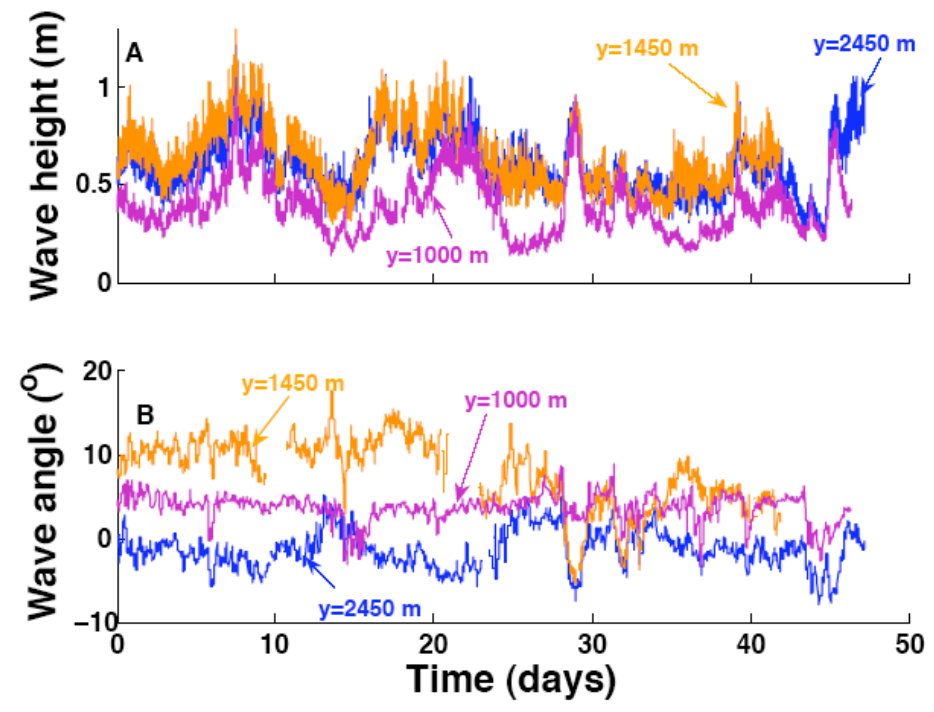

Figure 5-2: (A) The root-mean-square wave height and (B) the mean wave angle versus time observed on the $2.5-\mathrm{m}$ isobath at $y=2450 \mathrm{~m}$ (blue curves), $y=1450 \mathrm{~m}$ (orange curves), and $y=1000 \mathrm{~m}$ (magenta curves). Time is days after 0:00 October 3, 2003 local time.

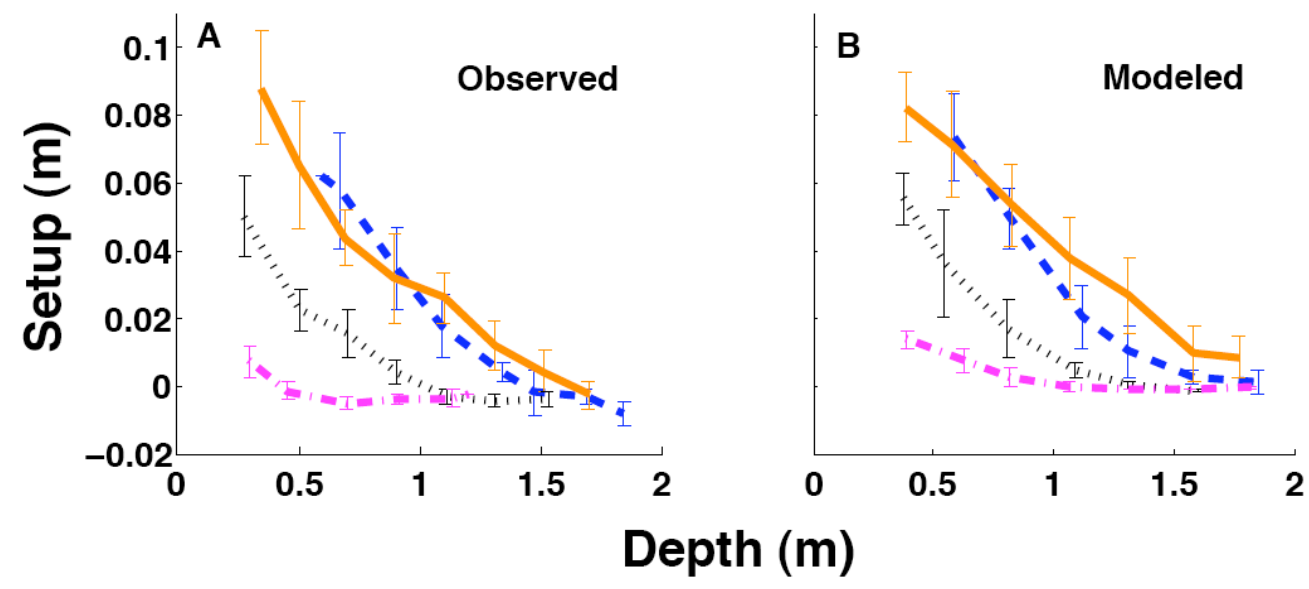

Figure 5-3: Means (curves, $\pm 0.1 \mathrm{~m}$ depth bins) and standard deviations (horizontal bars) of the (A) observed and (B) modeled setup versus water depth for the 144 data records from 0:00 to 23:42 October 27, 2003 for the sensors located along the 1.0-m isobath at $y$ $=2450 \mathrm{~m}$ (dashed blue curve), $y=1450 \mathrm{~m}$ (solid orange curve), $y=1300 \mathrm{~m}$ (dotted black curve), and $y=1000 \mathrm{~m}$ (dashed-dotted magenta curve). The mean and standard deviation of $H_{r m s}$ on the $2.5-\mathrm{m}$ isobath at $y=1450 \mathrm{~m}$ were $0.53 \mathrm{~m}$ and $0.07 \mathrm{~m}$, respectively. The Oct 27 tidal range was -0.92 to $1.35 \mathrm{~m}$ relative to mean sea level. 


\subsubsection{Estimates of $S_{x x}, S_{x y}$, and $S_{y y}$}

The components of the wave radiation stress tensor $\left(S_{x x}, S_{x y}\right.$, and $\left.S_{y y}\right)$ are estimated at each sensor with (5-2), (5-3), and (5-9), respectively, using $H_{r m s}$ and $\theta$ estimated from the observations. The results are not sensitive to the method used to estimate the momentum fluxes [Ruessink et al., 2001; Feddersen, 2004], possibly owing to the relatively narrow directional distributions of the incident wave field. The phase and wave speeds, $c_{g}$ and $c$, at each sensor are estimated using linear theory, the centroidal frequency $f$, and the local water depth. For the analyses using observation-based estimates, the effects of the roller, which shifts the forcing in the cross-shore, are not resolved and therefore are neglected [i.e., $R_{x x}$ and $R_{x y}=0$ in (5-1) and (5-11)]. Roller effects are included in all numerical model predictions.

All three components of the radiation stress tensor can vary by more than a factor of 16 in the alongshore (e.g., Figure 5-4). Estimates of $S_{x x}$ (Figure 5-4A, C \& D) and $S_{y y}$ (not shown) are dominated by the local wave height, and are nearly uniform (i.e., $80 \%$ of the estimates are within approximately $30 \%$ of each other) north of the canyon head (i.e., $y>1400 \mathrm{~m}$, Figure 5-4A \& C). However, near and south of the canyon head $(1000<y<$ $1400 \mathrm{~m}$ ) refraction and reflection can cause focusing and shadowing of the incoming wave field. Estimates of $S_{x x}$ and $S_{y y}$ south of the canyon head typically are $60 \%$ smaller (and can be as much as 85\% smaller) than those farther north (e.g., Figure 5-4A and D, compare estimates at $y=1000 \mathrm{~m}$ with those at $y=1450 \mathrm{~m}$ ).

Estimates of $S_{x y}$ have a stronger dependence on $\theta$ than on $H_{r m s}$. Owing to the small wave angles observed along most transects (Figure 5-2B, blue and magenta curves), $S_{x y}$ is small at most locations. However, at $y=1450$ and $1300 \mathrm{~m}$ where $\theta$ can be $10^{\circ}$ or more (Figure 5-2B, orange curve), $S_{x y}$ can be more than a factor of 16 larger than estimates elsewhere, and is usually at least twice as large as estimates at $y=1000$ and $2700 \mathrm{~m}$ (Figure 5-4B, E \& F). Negative ratios of $S_{x y}$ (Figure 5-4E \& F) result when waves observed at two sensors along different cross-shore transects approach the shoreline from opposite sides of shore normal. 

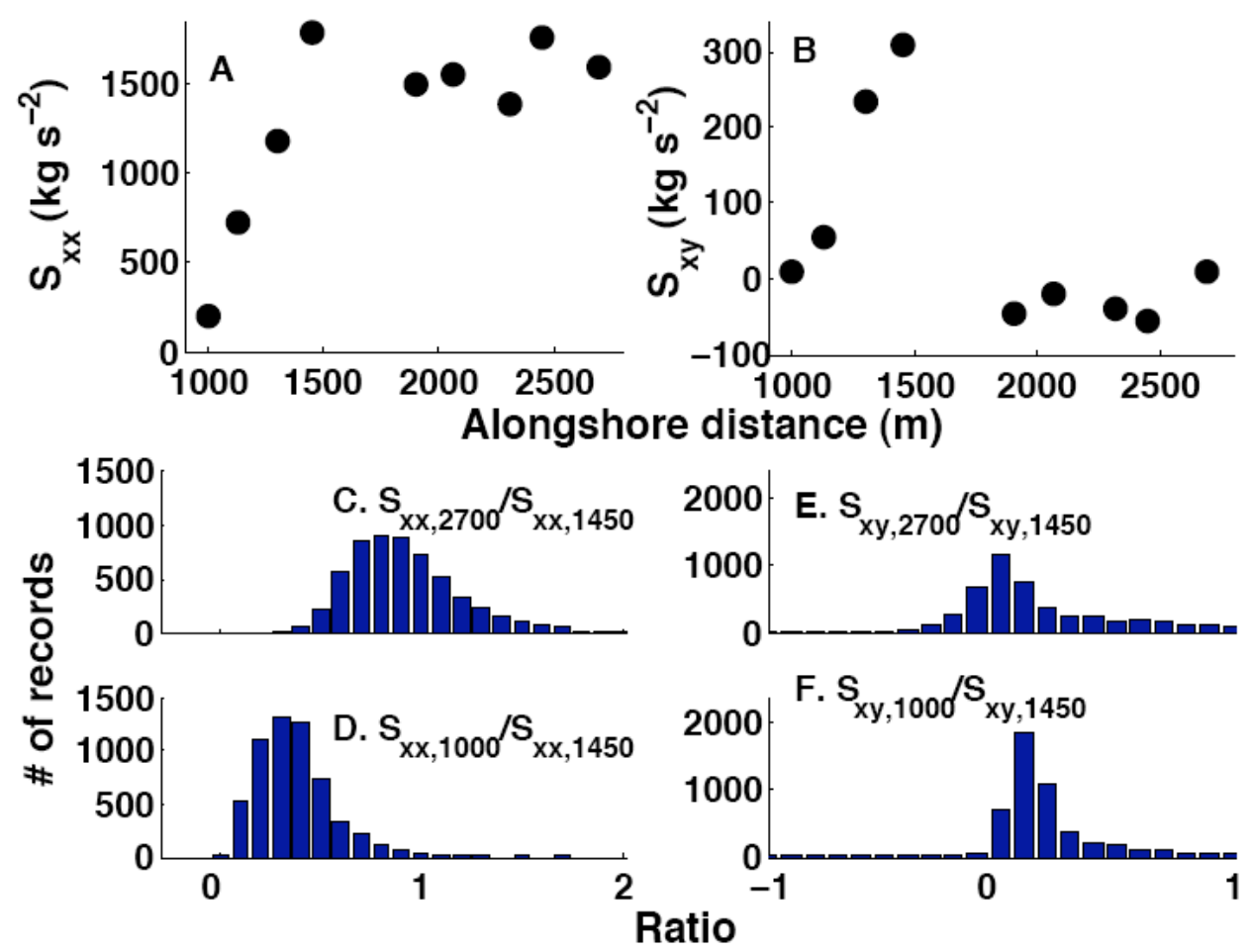

Figure 5-4: (A) $S_{x x}$ and (B) $S_{x y}$ estimated at the sensors along the 2.5-m isobath for 16:08 Oct. 19, 2003, and the ratios of $S_{x x}$ at (C) $y=2700 \mathrm{~m}$ and (D) $y=1000 \mathrm{~m}$ to $S_{x x}$ at $y=$ 1450 , and of $S_{x y}$ at (E) $y=2700 \mathrm{~m}$ and (F) $y=1000 \mathrm{~m}$ to $S_{x y}$ at $y=1450 \mathrm{~m}$ for all data records.

\subsection{Results}

\subsubsection{Cross-shore Momentum Balance}

The relative importance to shallow water setup of alongshore gradients in the wave and roller forcing [i.e., $\partial S_{x y} / \partial y$ and $\partial R_{x y} / \partial y$ in (5-1)] is determined using the observations and using a numerical model. First, observation-based, surfzone-averaged estimates of $\partial S_{x y} / \partial y$ and $\partial S_{x x} / \partial x$ are compared with each other. Next, setup predictions based on (5-1) through (5-5) including $\partial S_{x y} / \partial y$ and $\partial R_{x y} / \partial y$ (2-D setup model) are compared with predictions neglecting $\partial S_{x y} / \partial y$ and $\partial R_{x y} / \partial y$ (1-D setup model) and with the observations. 


\subsubsection{Observational Estimates}

The surfzone-averaged cross-shore gradient of the wave forcing, $\partial S_{x x} / \partial x$, is estimated by using the observations from the sensors on both the 2.5- and 1.0-m isobaths to estimate $S_{x x}$, and by assuming that $S_{x x}$ is 0 at the shoreline (defined as the location where the still water level intersects the measured sand level). The cross-shore distance $\partial x$ is estimated as the distance between the shoreline and either the sensor location (if the sensor is in the surfzone) or the outer edge of the surfzone (defined as the most seaward location where $h=H_{r m s} \gamma$, with $\gamma=0.42$ ) (if the sensor is seaward of the surfzone). The conclusions are not changed if different values of $\gamma$ are used (see 5.5.2).

The alongshore gradient of the wave forcing, $\partial S_{x y} / \partial y$, is estimated for each data record along both the 2.5- and 1.0-m isobaths with a central differencing scheme for data between $1000<y<2700 \mathrm{~m}$, and with a backwards and a forwards differencing scheme at the northern and southern ends of the sensor array, respectively. The more than 2-m tidal change with respect to mean sea level provides a range of water depths at each isobath. The alongshore distance $\partial y$ is estimated as the along-isobath distance separating the sensor locations. The conclusions are not changed if different definitions of $\partial y$ are used (see Section 5.5.2).

The ratio of $\partial S_{x y} / \partial y$ to $\partial S_{x x} / \partial x$ is less than 0.1 on all cross-shore transects (Figure 55 , almost all the data points fall within the dashed lines), suggesting that the contribution to setup from the alongshore gradient of the wave forcing is small for these observations. Consequently, the observed alongshore variations of setup in shallow water (Figure 5$3 \mathrm{~A}$ ) result primarily from alongshore variations of $S_{x x}$ observed at the outer edge of the surfzone (Figure 5-4A). 


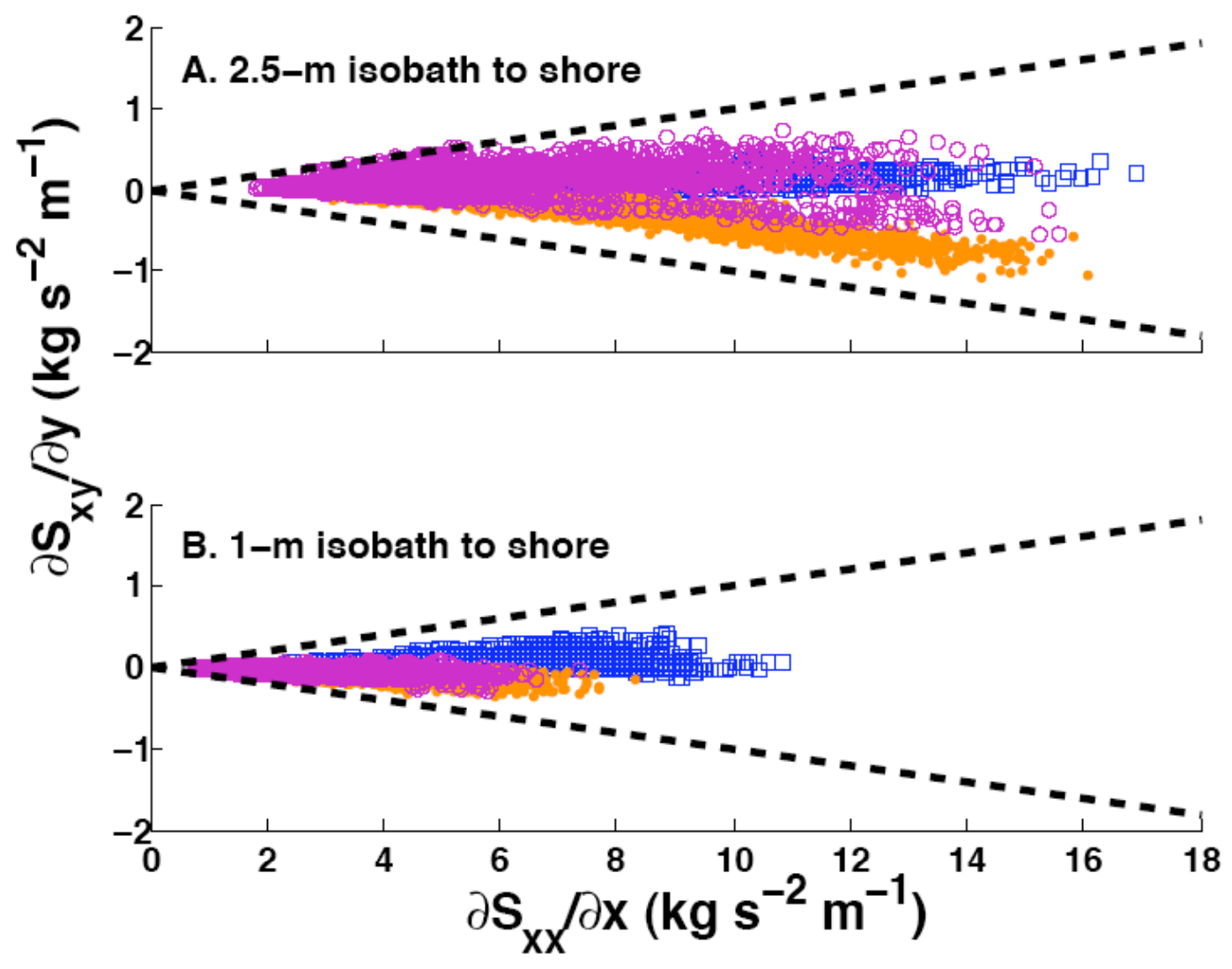

Figure 5-5: The alongshore gradient of the wave forcing $\partial S_{x y} / \partial y$ along versus the crossshore gradient of the wave forcing $\partial S_{x x} / \partial x$ to the shoreline from (A) the 2.5- and (B) the 1.0-m isobaths for $y=2450 \mathrm{~m}$ (open blue squares), $y=1450 \mathrm{~m}$ (solid orange circles), and $y=1000 \mathrm{~m}$ (open magenta circles). For symbols within the dashed black lines, $\partial S_{x y} / \partial y<0.1 \partial S_{x x} / \partial x$.

\subsubsection{Numerical Model Predictions}

The 1-D [i.e., (5-1) without $\partial S_{x y} / \partial y$ and $\partial R_{x y} / \partial y$ ] and 2-D [i.e., (5-1)] setup models are initialized at the location of the $2.5-\mathrm{m}$ isobath sensors with the measured water depth and the observed wave height, centroidal frequency, mean wave angle, and mean water level. Wave heights are interpolated shoreward using a wave transformation model [Thornton and Guza, 1983], with the free parameter $\gamma$ estimated from the deep-water wave height (determined from the observations at the most offshore sensor on each transect and the conservation of energy flux) [Apotsos et al., submitted] (see Chapter 2). Wave angles are refracted shoreward using Snell's Law. The group and phase speeds are estimated from the water depth (including the predicted setup) and the centroidal wave 
frequency (which is assumed constant along each transect). At each cross-shore location, the roller energy $E_{r}$ is determined from (5-6) and (5-7), and $R_{x x}$ and $R_{x y}$ are determined from (5-4) and (5-5), respectively.

The 1-D setup model is run independently along each cross-shore transect, and the cross-shore profile of setup is calculated from local estimates of $\partial S_{x x} / \partial x, \partial R_{x x} / \partial x$, and $\tau_{b}$ [e.g., Apotsos et al., 2007]. Setup predictions for the 2-D setup model are calculated using local estimates of $\partial S_{x x} / \partial x, \partial R_{x x} / \partial x$, and $\tau_{b}$, and $\partial S_{x y} / \partial y$ and $\partial R_{x y} / \partial y$ estimated along the appropriate isobath using a central, backwards, or forwards differencing scheme (similar to section 5.4.1.1) and $S_{x y}$ and $R_{x y}$ from the neighboring transects.
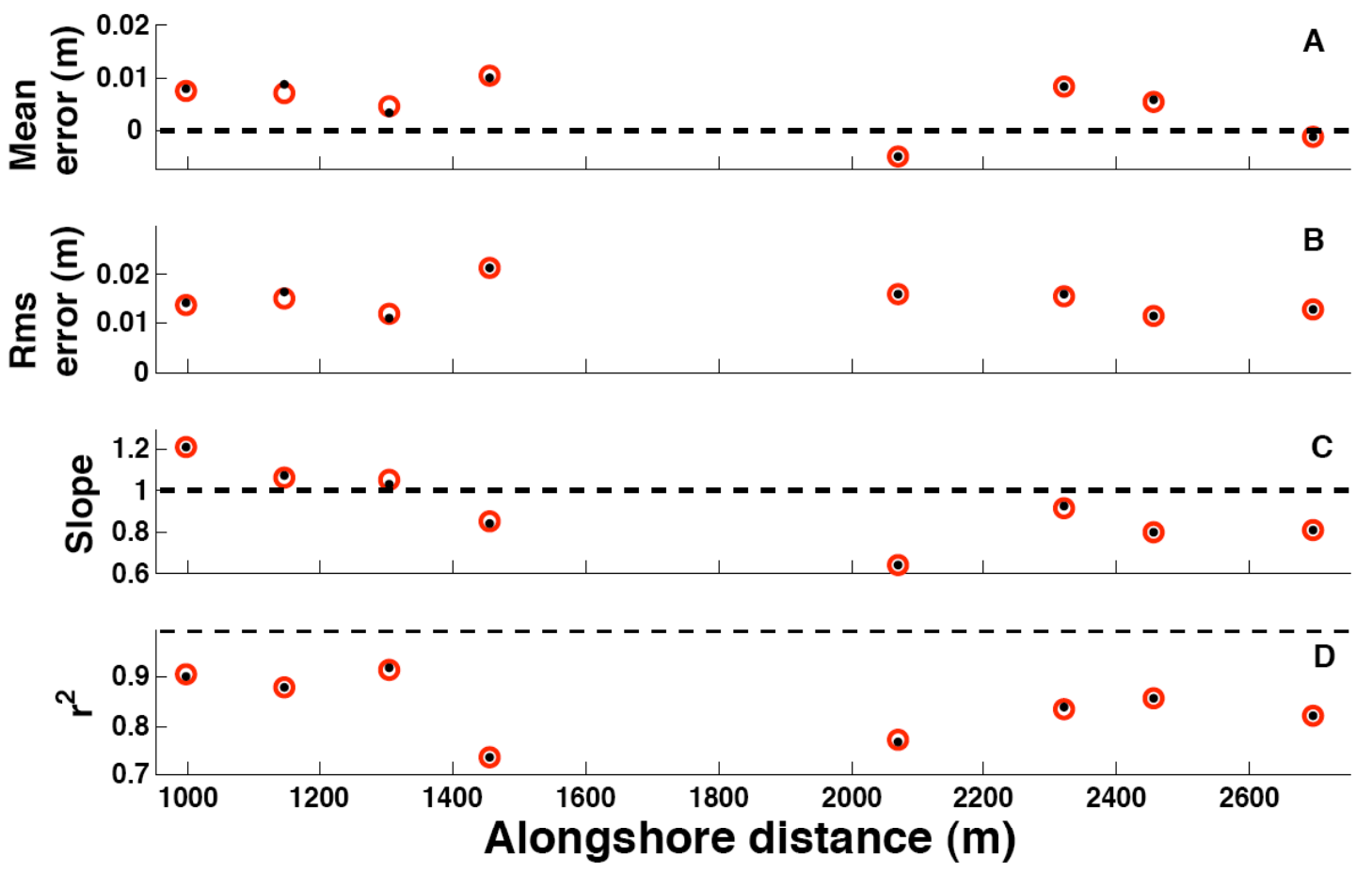

Figure 5-6: (A) Mean and (B) rms errors, (C) best-fit linear slopes, and (D) squared correlations between model predictions and observations of setup in $0.3<h<1.0 \mathrm{~m}$ for the 1-D model (open red circles) and the 2-D model (solid black circles) versus alongshore distance for all data records. Data are not shown at $y=1911 \mathrm{~m}$ because the small cross-shore separation between the sensors on the $2.5-$ and $1.0-\mathrm{m}$ isobaths results in inaccurate setup predictions.

The 1-D setup model accurately predicts the alongshore variations in the observed setup (compare Figure 5-3A \& B; Figure 5-6 open red circles). Errors between the model 
predictions and the observations are similar to those found on alongshore homogeneous beaches (e.g., [Apotsos et al., 2006; 2007]), and do not vary greatly along the coast. Including estimates of $\partial S_{x y} / \partial y$ and $\partial R_{x y} / \partial y$ (i.e., the 2-D model) changes setup predictions in $0.3<h<1.0 \mathrm{~m}$ by less than $5 \%$ (Figure 5-6, compare open red circles and solid black circles), suggesting the shallow water setup observed here can be predicted accurately using a 1-D model.

\subsubsection{Alongshore Momentum Balance}

The importance of large alongshore gradients in setup to alongshore flows is examined by using observations to evaluate the alongshore momentum balance (5-11) with and without the setup term. Additionally, the accuracy of the 1-D setup model is examined by comparing the observed alongshore flows with 1-D model estimates of the setup and wave forcings.

\subsubsection{Observational Estimates}

Data from Oct 27, 2003, when the wave conditions remained constant throughout the day and the alongshore wave height gradients near the canyon head were large $\left(H_{r m s}\right.$ at $y=1450 \mathrm{~m}$ was approximately 3 times larger than $H_{r m s}$ at $y=1000 \mathrm{~m}$ ), are used to generate 24-hr average curves of $\bar{\eta}$ (Figure 5-3A) and $S_{y y}$ (not shown) versus water depth for each cross-shore transect. Based on these curves, the alongshore gradients of pressure $(\rho g h) \partial \bar{\eta} / \partial y$ and the wave forcing $\partial S_{y y} / \partial y$ are estimated at the tidally varying depth of

the 1.0-m sensors using a central difference scheme for each data record. The cross-shore gradient of the wave forcing, $\partial S_{x y} / \partial x$, is estimated between the sensors on the 2.5- and 1.0-m isobaths and the shoreline similar to $\partial S_{x x} / \partial x$ (Section 5.4.1.1), and the average of the two values is used to approximate $\partial S_{x x} / \partial x$ at the depth of the 1.0-m isobath. All terms are estimated only for data records when the 1.0-m isobath sensor was in the surfzone.

Far from the canyon (e.g., along $y=2321 \mathrm{~m}$ ) all three forcing terms typically are small in all water depths (Figure 5-7A) owing to small incident wave angles and alongshore-uniform wave conditions. Near the canyon (e.g., along $y=1450 \mathrm{~m}$ ), $\partial S_{x y} / \partial x$ is slightly larger than $(\rho g h) \partial \bar{\eta} / \partial y$ and $\partial S_{y y} / \partial y$ in the outer surfzone (Figure 5-7B, $h>1.3$ 
$\mathrm{m})$. However, the setup gradients increase shoreward, and $(\rho g h) \partial \bar{\eta} / \partial y$ is significantly larger than both $\partial S_{x y} / \partial x$ and $\partial S_{y y} / \partial y$ for $h<1 \mathrm{~m}$, suggesting surfzone currents near the canyon may be dominated by the setup-induced pressure gradient. Along $y=1450 \mathrm{~m}$, where alongshore gradients are expected to be important, $\partial S_{y y} / \partial y$ is approximately an order of magnitude smaller than $(\rho g h) \partial \bar{\eta} / \partial y$, and thus $\partial S_{y y} / \partial y$ is neglected in all further analyses. Therefore, for the observation-based estimates the wave-only and total forcing of the alongshore current are assumed to be $\partial S_{x y} / \partial x$ and $\partial S_{x y} / \partial x+(\rho g h) \partial \bar{\eta} / \partial y$, respectively.

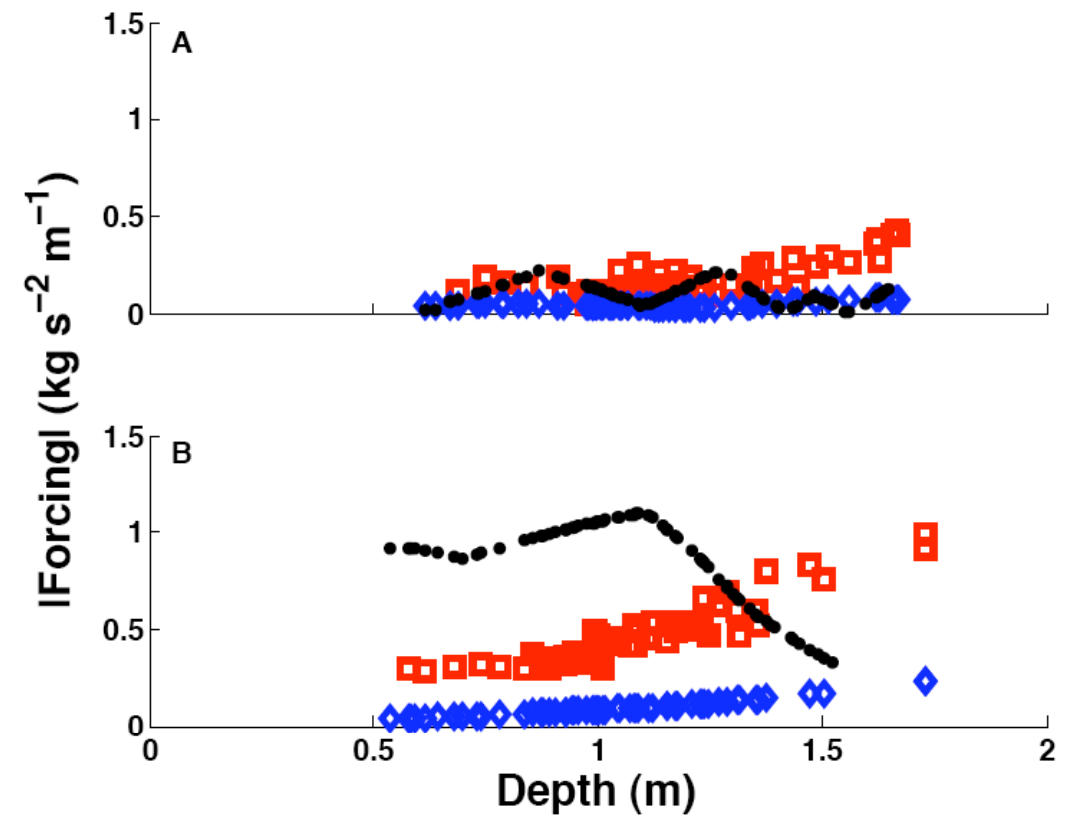

Figure 5-7: Absolute magnitude of the alongshore current forcing owing to alongshore setup gradients, $(\rho g h) \partial \bar{\eta} / \partial y$, (solid black circles), the cross-shore gradient of the wave forcing, $\partial S_{x y} / \partial x$ (open red squares), and the alongshore gradient of the wave forcing, $\partial S_{y y} / \partial y$ (open blue diamonds) for (A) $y=2321 \mathrm{~m}$ and (B) $y=1450 \mathrm{~m}$ using the 144 data records from 0:00 to 23:42 October 27, 2003.

The waves at the outer edge of the surfzone on Oct 27, 2003 were predominately from the south, creating a negative wave forcing that should drive positive, or northward, alongshore flows. Away from the canyon head (e.g., $y=2321 \mathrm{~m}$ ), where the setup gradient is small, the direction of the alongshore current in the surfzone agrees well with 
the direction of the wave forcing (Figure 5-8, green squares). However, close to the canyon (e.g., $y=1450 \mathrm{~m}$ ), the direction of the alongshore current (southward) opposes the wave forcing (northward) (Figure 5-8, orange circles), suggesting that large positive pressure gradients, which will drive negative (southward) currents, dominate the alongshore momentum balance.

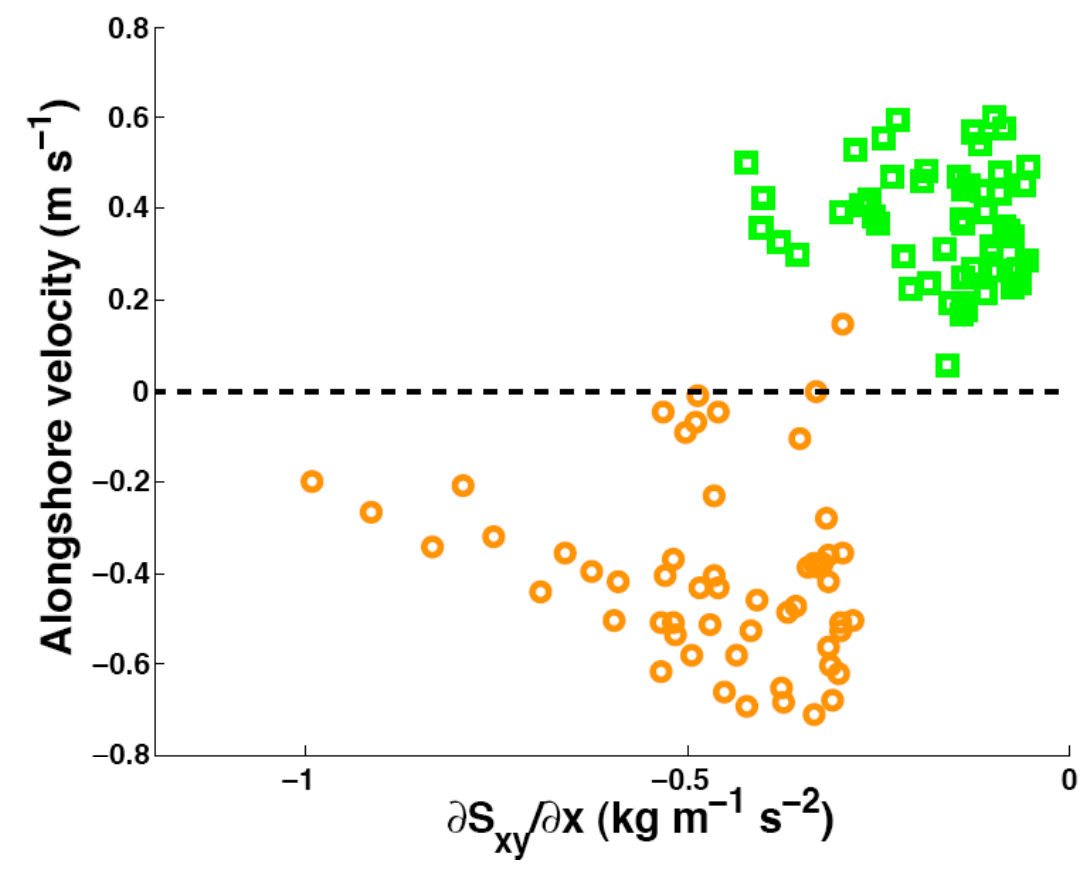

Figure 5-8: The alongshore velocity measured with the $1.0-\mathrm{m}$ isobath sensors versus the wave forcing $\partial S_{x y} / \partial x$ at $y=2321 \mathrm{~m}$ (green squares) and $1450 \mathrm{~m}$ (orange circles) on Oct 27,2003 . Only data records when the $1.0-\mathrm{m}$ isobath sensor was in the surfzone were used. The horizontal black dashed line is zero alongshore velocity. Negative wave forcing (waves from the south) is expected to drive positive (northward) flows.

Observational estimates of the total forcing $\partial S_{x y} / \partial x+(\rho g h) \partial \bar{\eta} / \partial y$ are correlated with $-\rho\langle|\vec{u}| v\rangle\left(r^{2}=0.68\right.$, Figure 5-9), suggesting that the momentum balance (5-11) neglecting $\partial S_{y y} / \partial y$ is approximately valid for the conditions on Oct 27 . The correlations are low for each transect individually (i.e., Figure 5-9, little correlation between the orange and green symbols separately and the velocity term) owing to the specified conditions (constant waves result in nearly uniform wave forcing) and the method used to 
estimate the alongshore terms (24-hr average curves result in nearly constant pressure gradients). The high correlation (i.e., 0.68) found using two transects is owing to the large difference in magnitude of the pressure gradient at the two transects.

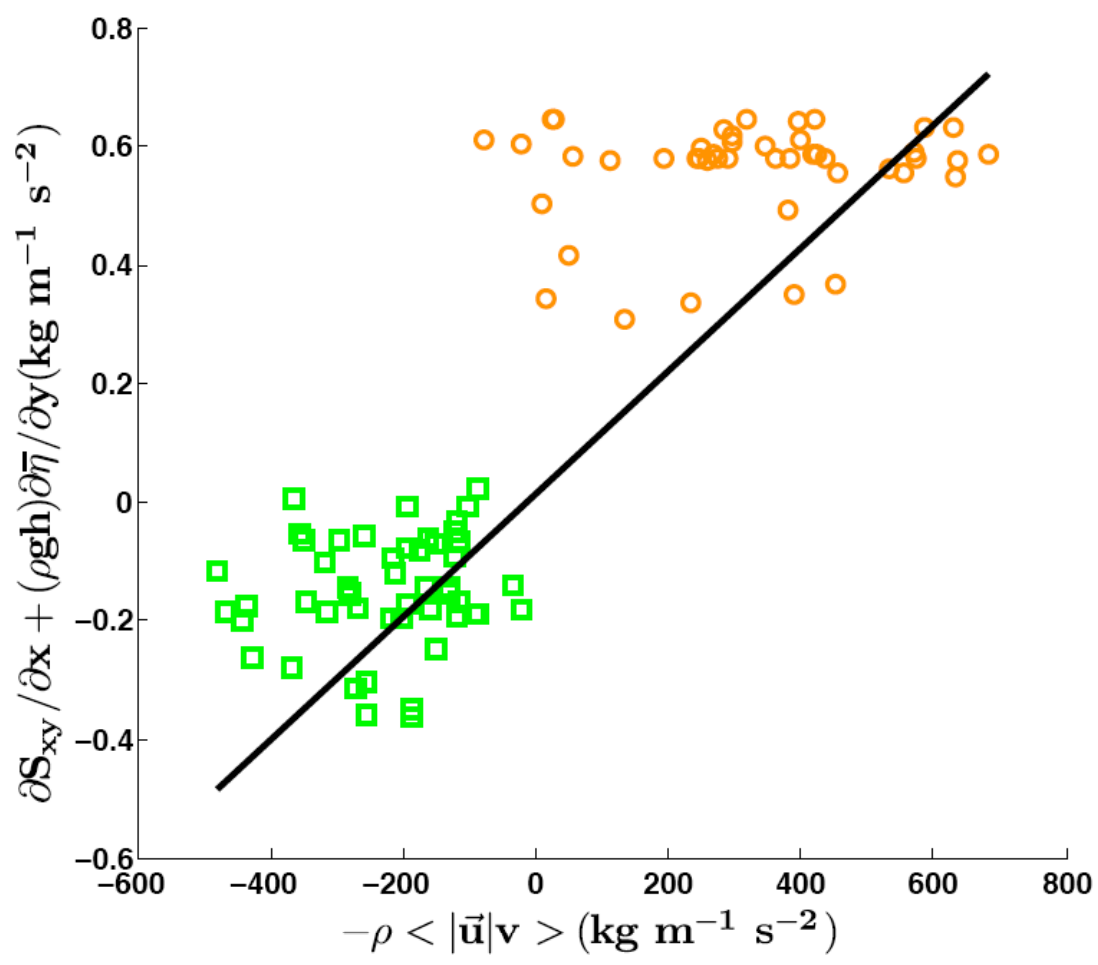

Figure 5-9: The total forcing $\left(\partial S_{x y} / \partial x+(\rho g h) \partial \bar{\eta} / \partial y\right)$ versus the velocity term $(-\rho\langle|\vec{u}| v\rangle)$

in the bed stress formulation estimated at the $1.0-\mathrm{m}$ isobath sensors for $y=2321 \mathrm{~m}$ (green squares) and $1450 \mathrm{~m}$ (orange circles). The black line is the least squares fit, and has a slope (i.e., $c_{d}$ ) of $\approx 0.001$. Only data records when the $1.0-\mathrm{m}$ isobath sensor was in the surfzone were used.

The slopes of the least squares fit (if the least squares fit is forced through the origin so that zero forcing results in no current) between the total forcing and the velocity term (black line in Figure 5-9) implies a drag coefficients $c_{d}$ of 0.001 , which is at the lower end of the range determined in previous studies [Feddersen et al., 1998, 2004; Ruessink et al., 2001]. Including $\partial S_{y y} / \partial y$ in the total forcing does not affect the results (i.e., $r^{2}=0.70$ and $c_{d} \approx 0.001$ ), further suggesting that for these observations $\partial S_{y y} / \partial y$ may not be important to driving alongshore flows in the surfzone at NCEX. The low values of $c_{d}$ may result from excluding the nonlinear advective and wind stress terms in (5-11), 
from the sparseness of the data used, or from the crudeness of the surfzone-width and 24hr averages. Similar results (i.e., $r^{2}=0.67$ and $c_{d} \approx 0.001$ ) are found if predicted (by the 1D setup model) $\bar{\eta}$ is used instead of observed $\bar{\eta}$ (i.e., if $\partial \bar{\eta} / \partial y$ is estimated from Figure $5-3 \mathrm{~B}$ instead of 5-3A).

\subsubsection{Numerical Model Predictions}

To determine if setup predicted by the 1-D setup model can be used to simulate the observed alongshore flows, $\partial S_{x y} / \partial x, \partial R_{x y} / \partial x$, and $\partial \bar{\eta} / \partial y$ are estimated for all times when large wave height gradients were observed near the canyon head (defined as the 2001 -hr runs when $H_{r m s}$ at $y=1450 \mathrm{~m}$ was at least $50 \%$ larger than $H_{r m s}$ at $y=1300 \mathrm{~m}$ ), the $1.0-\mathrm{m}$ isobath sensors were in the surfzone, and the bathymetry measured by the GPSsystem was within $0.3 \mathrm{~m}$ of that measured by altimeters colocated with the current meters (resulting in 30 and $50 \mathrm{hrs}$ of data at $y=1450$ and $2321 \mathrm{~m}$, respectively). The model is driven with hourly estimates (rather than 8.5 min estimates) of the wave characteristics and water depth to reduce small-time-scale fluctuations in $\bar{\eta}$. The wave, $\partial S_{x y} / \partial x$, and roller, $\partial R_{x y} / \partial x$, forcings are estimated over a cross-shore distance of $10 \mathrm{~m}$ centered on the sensor location, but the results are unchanged if these estimates are over distances between 5 and $40 \mathrm{~m}$. The setup gradient $\partial \bar{\eta} / \partial y$ is found using a central differencing method with predictions of $\bar{\eta}$ on neighboring cross-shore transects. The forcing terms are compared with 1-hr averages of the velocity term $-\rho\langle|\vec{u}| v\rangle$ obtained from the observations.

Far from the canyon $(1800<y<2700$ m, e.g. green squares in Figure 5-10), where $(\rho g h) \partial \bar{\eta} / \partial y$ is expected to be small [i.e., the right hand side of (5-11) is dominated by $\partial S_{x y} / \partial x$ and $\left.\partial R_{x y} / \partial x\right]$ the squared correlation between the total forcing $\left[\partial S_{x y} / \partial x+\partial R_{x y} / \partial x+(\rho g h) \partial \bar{\eta} / \partial y\right]\left(r^{2}=0.75\right)$ and the velocity term $\left.(-\rho /|\vec{u}| v\rangle\right)$ is similar to the correlation between the wave and roller-only forcings $\left(\partial S_{x y} / \partial x+\partial R_{x y} / \partial x\right)$ and the velocity term $\left(r^{2}=0.78\right)$. Here, the wave forcing $\left(S_{x y}\right)$ at the outer edge of the surfzone varies significantly over the data records used, and thus the correlation between the 
forcing and velocity terms for a single transect is significantly larger than observed in Figure 5-9. The slopes of the least squares fits forced through 0 (lines in Figure 5-10) between the forcings and the velocity term imply drag coefficients $c_{d}$ of 0.0024 and 0.0019 for the total and wave and roller-only forcings, respectively. Both the correlations and the drag coefficients are consistent with those found in previous studies on beaches with alongshore-homogeneous waves and bathymetry [Feddersen et al., 1998, 2004; Ruessink et al., 2001].

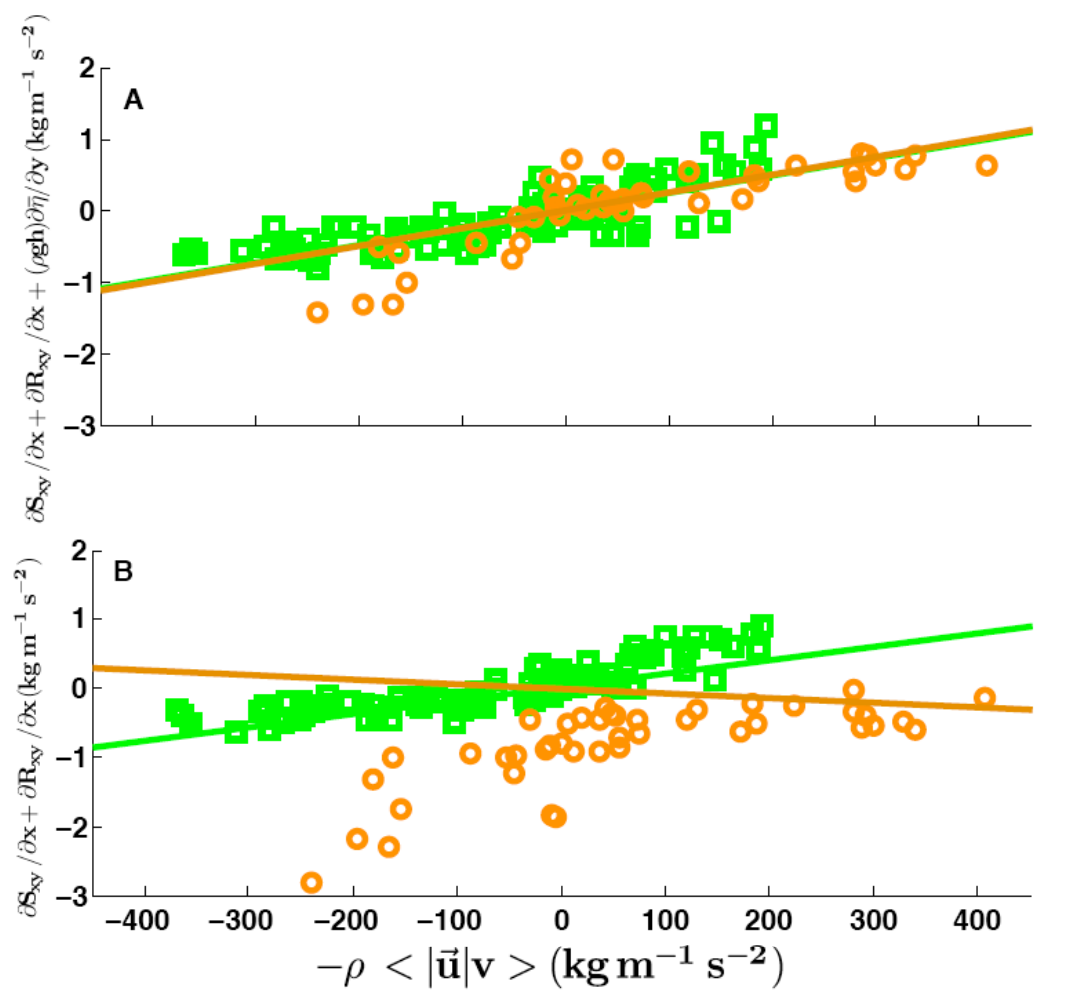

Figure 5-10: (A) The total forcing $\left(\partial S_{x y} / \partial x+\partial \boldsymbol{R}_{x y} / \partial x+(\rho g h) \partial \bar{\eta} / \partial y\right)$ and (B) the wave and roller-only forcing $\left(\partial S_{x y} / \partial x+\partial R_{x y} / \partial x\right)$ versus the velocity term $(-\rho\langle|\vec{u}| v\rangle)$ in the bed stress formulation at the $1.0-\mathrm{m}$ isobath sensors for $y=2321 \mathrm{~m}$ (green squares) and $y=1450 \mathrm{~m}$ (orange circles) when large gradients in $H_{r m s}$ on the $2.5-\mathrm{m}$ isobath were observed for $1300<y<1450 \mathrm{~m}$. The lines are the least squares fits (forced through 0 ) of the symbols with the same color.

Near the canyon head $(1300<y<1450$ m, e.g., orange circles in Figure 5-10), the correlation between the total forcing and the velocity term $\left(r^{2}=0.71\right)$ is significantly greater than the correlation between the wave and roller-only forcing and the velocity 
term $\left(r^{2}=0.47\right)$. The drag coefficient based on the total forcing $\left(c_{d}=0.0025\right)$ is similar to $c_{d}$ estimated from observations far from the canyon. In contrast, the drag coefficient estimated from the wave and roller-only forcing is negative $\left(c_{d}=-0.0007\right)$, suggesting that gradients in setup must be included to predict the alongshore flows near the canyon head accurately.

Alongshore gradients in the incident wave heights along an isobath are reduced in the surfzone where waves are depth limited (i.e., $H_{r m s}=\not h$ ), and thus gradients in $S_{y y}$ likely will be small in the surfzone. For $90 \%$ of the records near the canyon (i.e., $1000<y$ $<1500 \mathrm{~m}$ ) where alongshore gradients are expected to be important, $\partial S_{y y} / \partial y$ at the $1.0-\mathrm{m}$ isobath sensors was less than $20 \%$ of $(\rho g h) \partial \bar{\eta} / \partial y$, and including $\partial S_{y y} / \partial y$ estimated from model predictions (calculated similar to estimates of $\partial \bar{\eta} / \partial y$ ) does not change the correlations or estimates of the drag coefficient significantly.

Order of magnitude estimates based on 1-hr averages of the observed currents suggest that one or both of the nonlinear advective terms (neglected here) could be important to the alongshore momentum balance, consistent with previous results [Putrevu et al., 1995; Haller et al., 2002; Schmidt et al., 2005]. However, the good agreement between the model without the nonlinear advective terms and the observed currents, as well as the corresponding estimates of the drag coefficient, which are similar to those found at other field sites, suggest that the advective terms are small or cancel each other out for these observations.

\subsection{Discussion}

\subsubsection{Effect of Larger Wave Angles}

The relative importance of the alongshore gradients in the wave and roller forcings $\left(\partial S_{x y} / \partial y\right.$ and $\left.\partial R_{x y} / \partial y\right)$ to shallow water setup at NCEX may be small at least partly owing to the small wave angles observed during the experiment (e.g., Figure 52B). To estimate the effect of larger wave angles on the importance of $\partial S_{x y} / \partial y$ and $\partial R_{x y} / \partial y$ in (5-1) two sensitivity analyses were conducted. In both analyses, all the forcing terms [i.e., all the terms on the right hand side of (5-1)] were estimated between and 
along the cross-shore transects at $y=1450$ and $1300 \mathrm{~m}$ using the observations recorded at 20:25 Oct 27, 2003. In the first analysis, the observed values in 5.0-m water depth (considered to be offshore) at $y=1300 \mathrm{~m}$ (i.e., $H_{r m s, o}=0.34 \mathrm{~m}$ and $\theta_{o}=20^{\circ}$ ) were held constant for all simulations. The values in 5.0-m water depth at $y=1450 \mathrm{~m}$ were varied between $0.5 \mathrm{~m}<H_{r m s, o}<2 \mathrm{~m}$ and $-35^{\circ}<\theta_{o}<35^{\circ}$. The centroidal wave frequencies were held constant for all simulations at 0.082 and $0.087 \mathrm{~Hz}$ along $y=1300$ and $1450 \mathrm{~m}$, respectively.

For each pair of $H_{r m s, o}$ and $\theta_{o}$ at $y=1450 \mathrm{~m}$, the 1- and 2-D models were run from 5.0-m water depth to the shoreline along both transects. In the 2-D model, $\partial S_{x y} / \partial y$ and $\partial R_{x y} / \partial y$ were estimated with a backwards differencing scheme.

The importance of alongshore gradients relative to the cross-shore gradients is larger along $y=1300 \mathrm{~m}$ where the wave forcing is smaller (Figure 5-11). Along $y=1300$ $\mathrm{m}$, including $\partial S_{x y} / \partial y$ and $\partial R_{x y} / \partial y$ in (5-1) can change setup predicted in $h \approx 0.10 \mathrm{~m}$ by as much as $35 \%$ compared with that predicted by the 1-D model (Figure 5-11D). However, along $y=1450 \mathrm{~m}$, where the wave forcing is larger, including $\partial S_{x y} / \partial y$ and $\partial R_{x y} / \partial y$ changes the predicted setup by less than 7\% for all simulations (Figure 5-11C).

A second sensitivity analysis was conducted to determine if variations in only the offshore wave angle can affect the importance of the alongshore gradients to (5-1). Here, the same $H_{r m s, o}$, which was varied from 0.5 to $2.5 \mathrm{~m}$, was applied at both transects. The offshore wave angle at $y=1300 \mathrm{~m}$ was held constant at either 0 or $20^{\circ}$, while $\theta_{o}$ at $y=$ $1450 \mathrm{~m}$ was varied between $-45^{\circ}<\theta_{o}<45^{\circ}$. For all simulations, including $\partial S_{x y} / \partial y$ and $\partial R_{x y} / \partial y$ did not affect the setup predicted in $h \approx 0.1 \mathrm{~m}$ by more than $15 \%$ at either transect (not shown). 

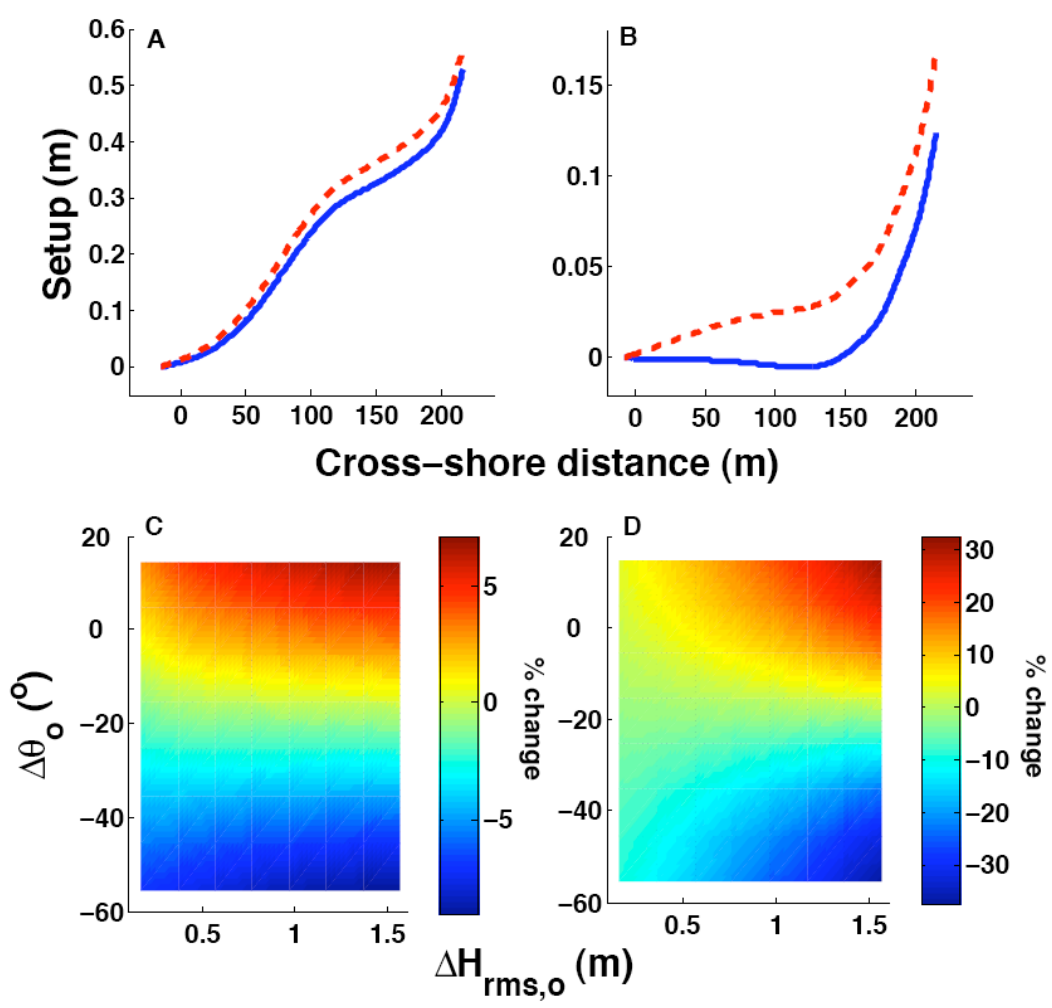

Figure 5-11: The cross-shore profile of setup estimated along $y=1450 \mathrm{~m}(\mathrm{~A})$ and $y=$ $1300 \mathrm{~m}(\mathrm{~B})$ for the observed conditions at $y=1300 \mathrm{~m}$, and $H_{r m s, o}=2 \mathrm{~m}$ and $\theta_{o}=35^{\circ}$ at $y$ $=1450 \mathrm{~m}$ for the 1-D model (solid blue curves) and the 2-D model (red dashed curves) for 20:25 Oct. 27, 2003. Surface plots of the percent change in the setup predicted in approximately $0.1-\mathrm{m}$ water depth owing to including $\partial S_{x y} / \partial y$ and $\partial R_{x y} / \partial y$ along $y=1450$ $\mathrm{m}(\mathrm{C})$ and $1300 \mathrm{~m}$ (D) versus the difference in offshore wave height $\left(H_{r m s, o}\right)$ and offshore wave angle $\left(\theta_{0}\right)$ between the two transects.

The two sensitivity analyses and the results from using the observations (i.e., section 5.4.1.2) suggest that on beaches with alongshore uniform surfzone bathymetry, $\partial S_{x y} / \partial y$ and $\partial R_{x y} / \partial y$ is likely to be important to shallow water setup only when the gradients of both $H_{r m s, o}$ and $\theta_{o}$ are large. Even under these conditions, $\partial S_{x y} / \partial y$ and $\partial R_{x y} / \partial y$ may only affect setup significantly along the transect with the smaller wave forcing.

\subsubsection{Estimating $S_{x x}, S_{x y}, S_{y y}, \partial x$, and $\partial y$}

The components of the wave radiation stress tensor $\left(S_{x x}, S_{x y}\right.$, and $\left.S_{y y}\right)$ were calculated using wave angles $(\theta)$ relative to the local shore normal vector estimated at 
each cross-shore transect. However, the shoreline is not straight (Figure 5-1) and the direction of shore normal can rotate by up to $25^{\circ}$ along the sensor array.

The effect of the alongshore variation in the orientation of shore normal on estimates of $\partial S_{x x} / \partial x$ and $\partial S_{x y} / \partial y$ was estimated in three ways. First, all wave angles were rotated to be relative to a single universal shore normal vector calculated as the average of the vectors at the 9 cross-shore transects. Second, angles along adjacent transects were rotated to be relative to a shore normal vector at the midway point between the two transects before the gradients were estimated. Third, for all cross-shore transects where a central differencing scheme was used $(1000<y<2700 \mathrm{~m})$, angles along all three transects were rotated to be aligned with the middle transect.

The along- and cross-shore gradients of $S_{x y}$ and $S_{x x}$ were then estimated (described in section 5.4.1.1) using the different methods to obtain $\theta$. For over $90 \%$ of the data records $\partial S_{x y} / \partial y$ was less than $10 \%$ of $\partial S_{x x} / \partial x$ no matter which $\theta$ was used. Furthermore, $S_{y y}$ is not sensitive to small changes in the wave angle (at least for the small angles observed here). Therefore, the results are similar regardless of the method used to estimate the wave angles.

When a sensor was seaward of the surfzone, $S_{x x}$ is assumed to be constant between the sensor and the outer edge of the surfzone. Thus, the effects of wave shoaling and refraction between the sensor location and the outer edge of the surfzone are neglected in the observation-based estimates of the radiation stress tensor components. Shoaling increases the wave energy $E_{w}$ and refraction decreases $\theta$, resulting in an increase to $S_{x x}$. However, $S_{x y}$ remains constant, because increases in $E_{w}$ and $\cos (\theta)$ are canceled by decreases in $c_{g}$ (conservation of energy flux requires $E_{w} c_{g} \cos (\theta)=$ constant), and decreases in $\sin (\theta)$ are canceled by decreases in $c$ (Snell's law requires $\sin (\theta) / c=$ constant). Therefore, neglecting wave shoaling and refraction will not change the conclusion that the contribution to setup of the alongshore gradient in the wave forcing $\partial S_{x y} / \partial y$ is small relative to the cross-shore gradient $\partial S_{x x} / \partial x$.

The alongshore distance $\partial y$ used to estimate alongshore gradients can be determined from the distance between sensors along an isobath (including all the 
meanders of the isobath), the magnitude of the vector distance between the sensors $[\partial y=$ $\sqrt{\left(y_{2}-y_{1}\right)^{2}+\left(x_{2}-x_{2}\right)^{2}}$ ], or the alongshore distance between sensor locations $\left(\partial y=y_{1}\right.$ $y_{2}$ ). The results are not sensitive to the method used to estimate $\partial y$, and the distance along the isobath is used here. Sensitivity of the results to estimates of $\partial x$, which are based on the location of the outer edge of the surfzone, was evaluated by using different ratios (i.e., $\gamma=0.32,0.42,0.52$, and 0.62 ) of $H_{r m s}$ to $h$ to estimate where wave breaking begins.

Reducing this ratio increases $\partial x$ by shifting the outer edge of the surfzone seaward, and thus increases $\partial S_{x y} / \partial y$ relative to $\partial S_{x x} / \partial x$. However, the results are not significantly different for any of the $\gamma$ 's tested, and the ratio $\gamma=0.42$ was used here.

\subsection{Conclusions}

Shallow water setup observed on a beach with large alongshore variations in the wave height and direction at the outer edge of the surfzone is predicted accurately by a one-dimensional model that neglects alongshore gradients in the diagonal component of the wave radiation stress tensor, $S_{x y}$, suggesting the observed alongshore variations in setup result primarily from alongshore variations in cross-shore wave forcing, $S_{x x}$. Although the importance of $\partial S_{x y} / \partial y$ will increase with increasing alongshore gradients in incident wave height and angle, simulations suggest that $\partial S_{x y} / \partial y$ is less than $15 \%$ of $\partial S_{x x} / \partial x$ even when wave heights and angles change by $1.5 \mathrm{~m}$ and $50^{\circ}$, respectively, over $150 \mathrm{~m}$ in the alongshore.

In areas onshore of nearly uniform incident wave conditions, alongshore setup variations are small, and momentum balances with or without setup gradients have similar skill predicting alongshore currents. Drag coefficients based on a least squares fit between the forcing (with or without setup gradients) and the alongshore-velocity-based bottom stress are similar to previous estimates of drag coefficients from alongshoreuniform coasts. In areas onshore of large alongshore gradients in the incident wave field, momentum balances that include setup gradients (either observed or predicted by the onedimensional setup model) have significantly higher skill predicting alongshore currents than momentum balances that neglect setup gradients, suggesting that setup gradients are 
important to driving alongshore currents onshore of an inhomogeneous incoming wave field. 


\subsection{References}

Apotsos, A., B. Raubenheimer, S. Elgar, R. T. Guza, and J. A. Smith, A Note on Setup Sensitivity and Prediction Accuracy, Proc. of the 30th International Conference on Coastal Engineering, 946-958, 2006.

Apotsos, A., B. Raubenheimer, S. Elgar, R. T. Guza, and J. A. Smith, Effects of wave rollers and bottom stress on wave setup, J. Geophys. Res., 112(C2), C02003, doi:10.1029/2006JC003549, 2007.

Apotsos, A., B. Raubenheimer, S. Elgar, and R.T. Guza, Testing and Calibrating parametric wave transformation models on natural beaches, Coastal Eng. Submitted.

Battjes, J.A. and M.J.F. Stive, Calibration and verification of a dissipation model for random breaking waves, J. Geophys. Res., 90, 9159-9167, 1985.

Elgar, S., T.H.C. Herbers, and R.T. Guza, Reflection of ocean surface gravity waves from a natural beach, J. Phys. Oceanogr., 24, 1503-1511, 1994.

Feddersen, F., R.T Guza, S. Elgar, and T.H.C. Herbers, Alongshore momentum balances in the nearshore, J. Geophys. Res., 103, 15667-15676, 1998.

Feddersen, F., R.T. Guza, and S. Elgar, Inverse modeling of the one-dimensional setup and alongshore current in the nearshore, J. Phys. Oceangr., 34, 920-933, 2004.

Feddersen, F., Effect of wave directional spread on the radiation stress: Comparing theory and observations, Coastal Eng., 51, 473-481, 2004.

Haas, K.A., I.A. Svendsen, M.C. Haller, and Q. Zhao, Quasi-three-dimensional modeling of rip current systems, J. Geophys. Res., 108(C7), 3217, doi:10.1029/2002JC001355, 2003.

Haller, M.C., R.A. Dalrymple, and I.A. Svendsen, Experimental study of nearshore dynamics on a barred beach with rip channels, J. Geophys. Res., 107(C6), 3061 doi:10.1029/2001JC000955, 2002.

Herbers, T.H.C. and R.T. Guza, Estimation of directional wave spectra from multicomponent observations, J. Phys. Oceanogr., 20, 1703-1724, 1990.

Kuik, A., G. van Vledder, and L. Holthuijsen, A method for routine analysis of pitch-androll buoy data, J. Phys. Oceanogr., 18, 1020-1034, 1988. 
Lentz, S. and B. Raubenheimer, Field observations of wave setup, J. Geophys. Res., 104(C11), 25867-25875, 1999.

Lentz, S., R.T. Guza, S. Elgar, F. Feddersen, and T.H.C. Herbers, Momentum balances on the North Carolina inner shelf, J. Geophys. Res., 104(C8), 18205-18226, 1999.

Longuet-Higgins, M.S., Longshore currents generated by obliquely incident sea waves, $J$. Geophys. Res., 75, 6778-6789, 1970.

Longuet-Higgins, M.S. and R.W. Stewart, Radiation stress and mass transport in gravity waves, with application to 'surf-beats,' J. Fluid Mech., 13, 481-504, 1962.

Longuet-Higgins, M.S. and R.W. Stewart, Radiation stresses in water waves: A physical discussion with application, Deep Sea Res., 11, 529-562, 1964.

Magne, R., K.A. Belibassakis, T.H.C. Herbers, F. Ardhuin, W.C. O'Reilly, and V. Rey, Evolution of surface gravity waves over a submarine canyon, J. Geophys. Res., 112(C1), C01002, doi:10.1029/2005JC003035, 2007.

Mei, C.C., The Applied Dynamics of Ocean Surface Waves, World Sci., River Edge, NJ, 1989.

Putrevu, U., J. Oltman-Shay, and I.A. Svendsen, Effect of alongshore nonuniformities on longshore current predictions, J. Geophys. Res., 100(C8), 16119-16130, 1995.

Raubenheimer, B., S. Elgar, and R.T. Guza, Estimating wave heights from pressure measured in sand bed, J. Waterway, Port, Coastal, and Ocean Engineering, 151-154, 1998.

Raubenheimer, B., R.T. Guza, and S. Elgar, Field observations of wave-driven setdown and setup, J. Geophys. Res., 106(C3), 4629-4638, 2001.

Ruessink, B.G., J.R. Miles, F. Feddersen, R.T. Guza, and S. Elgar, Modeling the alongshore current on barred beaches, J. Geophys. Res., 106(C10), 22451-22463, 2001.

Schmidt, W.E., R.T. Guza, and D.N. Slinn, Surf zone currents over irregular bathymetry: Drifter observations and numerical simulations, J. Geophys. Res., 110(C1), 2015, doi:10.1029/2004JC002421, 2005.

Slinn, D.N., J.S. Allen, and R.A. Holman, Alongshore currents over variable beach topography, J. Geophys. Res., 105(C7), 16971-16998, 2000. 
Stive, M.J.F. and H.J. De Vriend, Shear stress and mean flow in shoaling and breaking waves, Proc. of the 24th International Conference on Coastal Engineering, 594-608, 1994.

Svendsen, I.A., Wave heights and set-up in a surf zone, Coastal Eng., 8, 303-329, 1984a.

Svendsen, I.A., Mass flux and undertow in a surf zone, Coastal Eng., 8, 347-365, 1984b.

Thomson, J., S. Elgar, B. Raubenheimer, T.H.C. Herbers, and R.T. Guza, Tidal modulation of infragravity waves via nonlinear energy losses in the surfzone, Geophysical Research Letters, 33, L05601, doi:10.1029/2005GL025514, 2006.

Thomson, J., S. Elgar, T.H.C. Herbers, B. Raubenheimer, and R.T. Guza, Refraction and reflection of infragravity waves near submarine canyons, J. Geophys. Res., In Press, 2007.

Thornton, E.B. and R.T. Guza, Transformation of wave height distribution, J. Geophys. Res., 88(C10), 5925-5938, 1983. 


\section{Chapter 6: General Conclusions}

\subsection{Contributions}

This study has sought to further our understanding of nearshore processes by examining observations and numerical model predictions of waves, setup, and currents in the surfzone. If coastal populations continue to grow and sea level rises as predicted, understanding how the ocean interacts with and impacts the engineered and natural coastal environments will become increasingly important. The recent destruction of New

Orleans caused by Hurricane Katrina and the continual erosion of and associated property damage on many beaches are two examples of problems that may increase in frequency or severity, but whose consequences could be alleviated by a better understanding of the coastal ocean.

Specifically, this study has resulted in improved, field-evaluated models for surfzone wave transformation and wave-driven setup. Many parametric wave transformation models had previously been developed, and although these models frequently are used to drive predictions of surfzone flows and beach evolution, their relative accuracy was unknown. Here, the models are tested and calibrated with observations collected along cross-shore transects at six field sites on barred and unbarred beaches. Using default values for the free parameter $\gamma$, all the wave models predict the cross-shore distribution of the observed wave heights reasonably well (i.e., median rms errors between $10 \%$ and $20 \%$ ). However, model errors could be reduced by approximately $50 \%$ by tuning $\gamma$.The best-fit $\gamma$ are correlated with the deep-water wave height, $H_{o}$, and are well described by a hyperbolic tangent curve. Using universal curves 
to predict $\gamma$ based on $H_{o}$ from two experiments at Duck, NC (i.e., Duck94 and SandyDuck) usually reduces errors for all models at five of the six experiments relative to using the default values of $\gamma$. Use of the universal curve is especially important with the Thornton and Guza [1983] wave model, where using the default value of $\gamma=0.42$ for data records with large waves (i.e., $H_{o}>1.5 \mathrm{~m}$ ) results in significant underprediction of the wave heights in the outer surfzone.

A sensitivity analysis showed that accurate estimates of the cross-shore wave height and water-depth profiles are important for predicting setup. Thus, the wave height predictions from all wave models are compared with the observed wave heights for each data record, and the most accurate predictions are used to drive the setup models described below. The sensitivity analysis also showed that tidal water-level fluctuations, bottom stress, and wave rollers affect setup significantly.

An extended 1-D model that includes the effects of wave rollers and bottom stress is developed and is shown to predict accurately field observations of wave setup. The modeled and observed setup are correlated $\left(r^{2}\right.$ above 0.59$)$, and agree within about $30 \%$ on a barred beach off Duck, NC. Rollers typically have only a small effect on the magnitude of setup at Duck, but are important to the cross-shore setup profile and to setup on beaches with larger amplitude sandbars. Conversely, bottom stress estimated from eddy viscosity and undertow formulations and based on the surface dissipation affect setup predictions significantly. For $0.3<h<1.0 \mathrm{~m}$, excluding bottom stress increases the mean error in setup predictions by a factor of about 3 . Including rollers and bottoms stress in the model also improved predictions of setup at two near-planar beaches, suggesting the extended model is applicable at a variety of field sites.

The estimated eddy viscosities and cross-shore drag coefficients are similar to those found previously in the swash and surf zones. However, the cross-shore drag coefficients are approximately an order of magnitude larger than alongshore drag coefficients found from an alongshore momentum balance. The large cross-shore drag coefficients may be related to the assumption of a vertically constant eddy viscosity, as would be appropriate 
if breaking-wave generated turbulence penetrates to the bed, or to the presence of anisotropic bedforms.

Although the extended 1-D model was developed assuming alongshore uniformity, it predicts setup accurately on a beach with significant alongshore variations in the incoming wave field. Including the alongshore gradient of the wave forcing, $\partial S_{x y} / \partial y$, in the model changes the predicted setup by less than $10 \%$. Although the importance of $\partial S_{x y} / \partial y$ will increase with increasing alongshore gradients in incident wave height and angle, simulations suggest that $\partial S_{x y} / \partial y$ is less than $15 \%$ of $\partial S_{x x} / \partial x$ even when wave heights and angles change by $1.5 \mathrm{~m}$ and $50^{\circ}$, respectively, over $150 \mathrm{~m}$ in the alongshore.

The alongshore gradients of setup predicted with the 1-D model can be used to estimate accurately setup-driven alongshore flows. In areas onshore of nearly uniform incident wave conditions, alongshore setup variations are small, and momentum balances with or without setup gradients have similar skill predicting alongshore currents. Drag coefficients based on a least squares fit between the forcing (with or without setup gradients) and the alongshore-velocity-based bottom stress are similar to previous estimates of drag coefficients from alongshore-uniform coasts. In areas onshore of large alongshore gradients in the incident wave field, momentum balances that include setup gradients (either observed or predicted by the one-dimensional setup model) have significantly higher skill predicting alongshore currents than momentum balances that neglect setup gradients, suggesting that setup gradients are important to driving alongshore currents onshore of an inhomogeneous incoming wave field.

Therefore, this study has shown that parametric wave models can predict reasonably the distribution of wave heights across both barred and unbarred surfzones, and that a simple 1-D model based on the cross-shore momentum balance and including wave rollers and bottom stress predicts the observed setup on both alongshore uniform and inhomogeneous beaches. 


\subsection{Future Questions}

Although this study has furthered our understanding of several nearshore processes, it has also suggested a number of questions on which future research could focus, including:

- the dependence of $\gamma$ on $H_{o}$ in the wave models.

- the order of magnitude difference between the along- and cross-shore drag coefficients.

- the appropriateness of using linear theory estimates of the radiation stress in the surfzone.

\subsubsection{Determining the Free Parameter in the Wave Models}

The new parameterization of $\gamma$ based on $H_{o}$ is useful for engineering and scientific applications, as it results in better estimates of the cross-shore distribution of wave heights. These improved estimates will allow for more accurate predictions of other surfzone processes, such as currents and sediment transport. However, this study leaves unanswered the question of why $\gamma$ depends on $H_{o}$. Furthermore, this relationship [i.e., $\gamma=$ $\left.f\left(H_{o}\right)\right]$ is not dimensionally consistent, with the non-dimensional $\gamma$ estimated from the dimensional $H_{o}$.

As mentioned in Chapter 2, $\gamma$ may depend on parameters other than $H_{o}$, such as the deep-water wave length and the beach slope. For example, similar agreement (i.e., similar squared correlations and model improvement) is found at the four field experiments with one or fewer sandbars (i.e., SandyDuck, Duck94, SwashX, and NCEX) using universal $\gamma$ curves based on an inverse Iribarren number where the beach slope was averaged over the surfzone. However, the surfzone averaged beach slope is poorly defined on multibarred beaches (i.e., Egmond and Terschelling), and thus it is unclear if a parameterization based on anything but the local beach slope will be practical for engineering purposes.

Furthermore, on beaches where waves break over a large bar and then reform in the trough, $\gamma$ may depend on the reformed values of the wave height and length and the local beach slope instead of deep-water and surfzone averaged values. Several previous studies 
also have suggested that $\gamma$ varies in the cross-shore [Raubenheimer et al., 1996; Ruessink et al., 2003; Chapter 2]. Therefore, $\gamma=f\left(H_{o}\right)$ is likely missing a functional dependence on at least one local parameter. Inverse modeling (i.e., following Ruessink et al, [2003]) on a variety of different beaches could help determine $\gamma$ 's cross-shore dependence, as well as define further the role of deep-water wave characteristics.

It should be noted that $\gamma$ as described in this study is a model parameter that implicitly accounts for variations in the other free parameter $B$. Therefore, attempts to find a physical justification for $\gamma$ 's functional dependence on local or deep-water parameters may fail because the dependence is owing to variations in $B$ and not $\gamma$. One possible way to avoid this problem would be to use an observation-derived $\gamma$ [e.g., Raubenheimer et al., 1996], and then fit $B$ to the observations.

Finally, the limitations of these simple parametric models could be estimated by comparing the predictions with predictions from advanced-individual wave resolving models.

\subsubsection{Drag Coefficients}

Although the along- and cross-shore drag coefficients estimated in this study (i.e., $\approx 0.002$ and 0.022 , respectively) differ by an order of magnitude, both values fall within the range of drag coefficients previously determined in the surf and swash zones (i.e., $0.001-0.030)$. Therefore, it is unclear which value is more accurate, and/or if the order of magnitude difference is controlled by anisotropic processes, such as current-bedform interaction or the generation of turbulence.

Drag coefficients could be estimated over anisotropic bedforms, such as linear transition ripples, and across the surfzone in the laboratory and field using the techniques developed by Barrantes and Madsen [2000] or Trowbridge [1998] to determine if bedform orientation affects along- and cross-shore currents differently, if near-bed turbulence is isotropic or anisotropic, and if wave-breaking turbulence reaches the bed. If the orientation of the current is found to be important, a $c_{d}(\phi)$ could be developed, where $\phi$ is the angle between the bedforms and the current. Furthermore, the penetration of wave-breaking turbulence to the bed likely varies in the cross-shore, and the observations 
could be used to develop parameterizations for a cross-shore (or water depth) dependent eddy viscosity and drag coefficient.

\subsubsection{Linear Theory Estimates of the Radiation Stress}

The radiation stress is a dominant forcing mechanism for currents, setup, and sediment transport in the surfzone. Linear theory estimates of this term are used in many models, and thus it is important to understand the errors induced by the assumption of linearity. While local linear theory estimates of the radiation stress have been shown to be reasonably accurate in the surfzone [Guza and Thornton, 1980, 1981], many of the assumptions on which linear theory estimates are based, including slowly changing waves and small-amplitude theory, are violated. Furthermore, Raubenheimer et al., [2004] showed that using the linear theory approximation of equipartion of energy underestimates the wave energy $E_{w}$ by $50 \%$ in $0.30 \mathrm{~m}$ water depth. As linear theory estimates of the radiation stress are directly proportional to estimates of $E_{w}$, linear theory may be underestimating the radiation stress by $50 \%$ in shallow water.

A systematic comparison of estimates of the radiation stress from linear theory with estimates from the full depth integral of the measured pressure and velocity could be conducted. The errors induced by using linear theory then could be assessed by comparing model predictions of currents and setup driven with linear theory estimates with those driven with nonlinear depth-integrated estimates. If there are systematic differences between the linear and nonlinear estimates of the radiation stresses, parameterizations of the true radiation stress based on easily observed quantities (e.g., wave height, water depth, and wave period) could be developed and included in new models. 


\subsection{References}

Barrantes, A.I. and O.S. Madsen, Near-bottom flow and resistance for currents obliquely incident to two-dimensional roughness elements, J. Geophys. Res., 105 (C11), 2625326264, 2000.

Guza, R.T. and E.B. Thornton, Local and shoaled comparisons of sea surface elevations, pressures, and velocities, J. Geophys. Res., 85, 1524-1530, 1980.

Guza, R.T. and E.B. Thornton, Wave set-up on a natural beach, J. Geophys. Res., 86, 4133-4137, 1981.

Raubenheimer, B., R.T. Guza, and S. Elgar, Wave transformation across the inner surf zone, J. Geophys. Res., 101, 25589-25597, 1996.

Raubenheimer, B., S. Elgar, and R.T. Guza, Observations of swash zone velocities: A note on friction coefficients, J. Geophys. Res., 109, C01027, doi:10.1029/2003JC001877, 2004.

Ruessink, B.G., D.J.R. Walstra, and H.N. Southgate, Calibration and verification of a parametric wave model on barred beaches, Coastal Eng., 48, 139-149, 2003.

Thornton, E.B. and R.T. Guza, Transformation of wave height distribution, J. Geophys. Res., 88, 5925-5938, 1983.

Trowbridge, J.H., On a technique for measurement of turbulent shear stress in the presence of surface waves, J. Atmos. Oceanic Technol., 15, 290-298, 1998. 